\title{
Los contextos urbanos de producción artesanal en el complejo arqueológico de las huacas del Sol y de la Luna
}

Les contextes urbains de production artisanale du complexe archéologique des huacas del Sol et de la Luna

The urban context of craft production at the Huacas of the Sun and the Moon Archaeological Project

\section{Santiago Uceda Castillo}

\section{(2) OpenEdition}

\section{Journals}

Edición electrónica

URL: http://journals.openedition.org/bifea/1930

DOI: $10.4000 /$ bifea. 1930

ISSN: 2076-5827

Editor

Institut Français d'Études Andines

Edición impresa

Fecha de publicación: 1 agosto 2010

Paginación: 243-297

ISSN: 0303-7495

Referencia electrónica

Santiago Uceda Castillo, « Los contextos urbanos de producción artesanal en el complejo arqueológico de las huacas del Sol y de la Luna », Bulletin de l'Institut français d'études andines [En línea], 39 (2) | 2010, Publicado el 01 febrero 2011, consultado el 07 noviembre 2020. URL : http:// journals.openedition.org/bifea/1930; DOI : https://doi.org/10.4000/bifea.1930

\section{(2) $(0 \Theta \Theta$}

Les contenus du Bulletin de l'Institut français d'études andines sont mis à disposition selon les termes de la licence Creative Commons Attribution - Pas d'Utilisation Commerciale - Pas de Modification 4.0 International. 


\title{
Los contextos urbanos de producción artesanal en el complejo arqueológico de las huacas del Sol y de la Luna
}

\author{
Santiago Uceda Castillo*
}

\begin{abstract}
Resumen
Las excavaciones en los tres últimos pisos de ocupación del Núcleo Urbano de las huacas del Sol y de la Luna han permitido registrar por lo menos cuatro centros de producción artesanal. Cuatro líneas de evidencias permiten establecer que se trata de centros de producción especializada, a saber: (1) estos centros se ubican en espacios definidos dentro de un área residencial multifuncional; (2) las actividades productivas se repiten en más de dos pisos de ocupación; (3) el volumen de producción es muy superior a las necesidades de consumo familiar y, otros productos, por su calidad y simbología, están destinados a los miembros de la elite moche $y_{;}(4)$ se han registrado tanto instrumentos de producción como productos en diversas fases de producción.

Esta mayor especialización y su control por unidades mayores de residencia en el sitio nos permiten sostener que los especialistas estuvieron adscritos a grupos corporativos y que este nuevo sistema de organización social y productiva se produjo como consecuencia del colapso de la estructura teocrática de la sociedad moche; ello se tradujo en intentos de esta sociedad por la búsqueda de un nuevo modelo social, más civil, donde los grupos urbanos empezaron a adquirir mayor poder económico.
\end{abstract}

Palabras clave: Cultura Moche, urbanismo, talleres artesanales, estructura social, especialistas

\section{Les contextes urbains de production artisanale du complexe archéologique des huacas del Sol et de la Luna}

\section{Résumé}

La fouille des trois dernières couches d'occupation du Centre Urbain des huacas del Sol y de la Luna, a permis de mettre à jour au moins quatre centres de production artisanale. Quatre sortes

Universidad Nacional de Trujillo, Dpto. de Arqueología y Antropología. Email: santiago_uceda@ hotmail.com 
d'indices permettent d'établir qu'il s'agit de centres de production spécialisés, à savoir: (1) ces centres se localisent dans des espaces définis à l'intérieur d'une aire résidentielle multifonctionnelle; (2) les activités productives se répètent au moins dans deux couches d'occupation; (3) le volume de production excède trés nettement les besoins d'une consommation domestique et, d'autres produits, de par leur qualité et leur valeur symbolique, sont destinés aux membres de l'élite mochica, enfin; (4) plusieurs outils ainsi que divers produits, correspondant à diverses étapes de la fabrication, ont été découverts.

Cet important degré de spécialisation et son contrôle par des unités résidentielles majeures du site nous permet d'avancer l'hypothèse selon laquelle les spécialistes étaient attachés à des groupes corporatifs et que ce nouveau système d'organisation sociale et de production fut la conséquence du déclin de la structure théocratique de la société mochica. Ce phénomène a conduit cette société à chercher un nouveau modèle social, plus civil, dans lequel les groupes urbains se sont arrogés un plus grand pouvoir économique.

Mots Clés : Culture Mochica, urbanisme, ateliers artisanaux, structure sociale, spécialistes

\title{
The urban context of craft production at the Huacas of the Sun and the Moon Archaeological Project
}

\begin{abstract}
The excavations of the three last occupational floors of the Urban Nucleus at Huacas of the Sun and the Moon in the Moche Valley have allowed us to register at least four craft production centers. Four following lines of evidence allow us to establish that they are centers of specialized production: (1) these centers are placed in definite spaces within a multifunctional residential area; (2) the productive activities are repeated on more than two occupational floors; (3) the volume of production is far greater than the needs of family consumption; other products, given their quality and symbolism, were produced for members of the Moche elite, and; (4) production instruments and products from several production steps have been registered.

This greater specialization and its control through residential units at the site allow us to hold that the specialists were associated with corporate groups and that this new system of social and productive organization was produced as consequence of the collapse of the theocratic structure of Moche society; this resulted in attempts by this society to look for a new social model, one that was more civic, and in which urban groups began to acquire a greater economic power.
\end{abstract}

Key Words: Moche Culture, Urbanism, Craft Workshops, Social Structure, Specialists

\section{INTRODUCCIÓN}

Con el establecimiento de la Ciudad y del Estado aparecen los talleres de producción y los artesanos especialistas (Childe, 1954). Su estudio es indisoluble, y resulta hasta cierto modo inútil establecer cuál depende o deriva de cuál. Sin embargo, es claro que estos fenómenos sociales tienen variantes que se establecen por la naturaleza del Estado, el tipo de desarrollo urbano alcanzado y, en menor medida por los aspectos culturales de cada grupo. Es conocido que, en diversas sociedades antiguas del mundo, los talleres de producción se han desarrollado en un inicio al amparo de los templos o palacios, para luego ir surgiendo talleres de artesanos independientes 
junto a la aparición de los mercados y los comerciantes (Redman, 1990). En el área andina, la presencia de mercados ha sido muchas veces cuestionada (Rowe, 1997); sin embargo, diversos documentos, tanto de cronistas como de administrativos españoles, indican que en la Costa Norte los artesanos tenían independencia marcada y que formaron verdaderas corporaciones dirigidas por curacas. Estos especialistas vivían en barrios y no estaban obligados a tributar (Espinoza, 1975: 285; Netherly, 1978: 157; Ramírez-Horton, 1981: 290; Rostworoski, 1977b: 221 222). Esta información ha sido corroborada con los estudios arqueológicos de la Universidad de Harvard (Topic, 1990) en la década de 1970.

Las investigaciones en el sitio de huacas del Sol y la Luna han permitido conocer una amplia y compleja red urbana, donde resalta la presencia de centros de producción artesanal de vieja data. Sin embargo, la planificación urbana de la zona residencial y productiva ha variado en el tiempo y muy posiblemente ello se deba a los cambios sociopolíticos de la sociedad mochica (Uceda, 2004).

En esta ocasión quisiera discutir los contextos urbanos de producción a partir del estudio de la planificación urbana, es decir, cómo estuvo organizada, desde el punto de vista urbanístico, la producción de bienes en la ciudad, en particular en su periodo final de ocupación. Pero, al mismo tiempo, vamos a intentar discutir la(s) forma(s) de organización social de esta producción y el estatus de los especialistas, para finalmente establecer dentro de qué contexto sociopolítico moche se insertó este sistema de producción. Para este trabajo usaremos la información de los conjuntos arquitectónicos 17, 21, 27, 30 y 35. La información de los otros centros de producción estudiados en el sitio, como los reportados por Bernier (1998; 1999; 2005; 2008), Chapdelaine (2001; 2003), Uceda \& Armas (1997; 1998), no será usada aquí pues no contamos con informaciones contextuales relacionadas con la estructura urbana colindante. Finalmente, nuestro trabajo se inicia con un resumen sobre la secuencia ocupacional del sitio. Por no ser el tema central de este trabajo, no ahondaremos en los detalles sobre nuestra propuesta; para una mayor información, el lector puede consultar otros trabajos ya publicados (Uceda, $2007 ; 2010)$.

\section{ASPECTOS TEÓRICOS}

Tratar de estudiar la estructura social de los artesanos y sus talleres en época moche, nos obliga a una breve revisión de algunos conceptos básicos sobre los que se estructuraron las sociedades andinas tardías para, a partir de ellos, ensayar un modelo o interpretación de la sociedad moche.

\section{1. La organización social de la producción: las fuentes etnohistóricas}

Al tratar de estudiar la organización social y la producción de las sociedades andinas, se siguió la propuesta de Murra $(1972 ; 1975 ; 1980)$ para la organización social inca; 
esta se basaba en los principios de la reciprocidad y complementariedad ecológica vertical. Sin embargo estudios sobre fuentes documentales de la costa central y norte peruana indicaron que este modelo inca no era aplicable a sociedades de estas zonas. María Rostworowski (1970; 1977a; 1977b) documentó la presencia de mercaderes chinchanos a larga distancia. La misma autora concluyó que hubo una vasta diferencia entre las formas de organización socioeconómica de la sierra y la costa; las economías costeñas se caracterizaban por una división del trabajo altamente especializada.

Los documentos coloniales dan prueba de la existencia en la Costa Norte de parcialidades enteras ejerciendo oficios especializados, incluidos sus propios principales y señores (Espinoza, 1975: 285; Netherly, 1978: 157; RamírezHorton, 1981: 290; Rostworoski, 1977b: 221-222). Estos grupos vivían en barrios o pueblos aparte, no tenían tierras y estaban exentos de servicios de trabajo (modalidad fundamental de tributación), contribuyendo al Estado solo con sus productos especializados (Rostworowski 1977a: 177; 1977b: 244).

En cuanto a la forma de intercambio de bienes existen dos posiciones opuestas. Según Rostworowski (1977a: 181) el trueque directo entre los grupos de especialistas formaba parte del sistema económico de la costa. Por su lado, Netherly (1978: 208) y Ramírez-Horton (1981: 292-95) proponen que la economía costeña fue esencialmente redistributiva. A cambio de otorgarles sus tierras y sus servicios religiosos, los señores recibían los productos agrícolas de los campesinos y redistribuían sus productos a los artesanos especializados.

\section{2. El taller y la estructuración urbana: estudios previos}

Poco conocemos, desde la perspectiva arqueológica, sobre cómo se articulaban los talleres artesanales dentro de las redes urbanas en las sociedades tardías andinas. Para el caso inca, no conocemos dónde se ubicaban los artesanos en el Cusco y si estos formaban parte de barrios independientes o si los talleres formaron parte de un componente mayor (palacio, edificio público o grupo corporativo mayor).

Según Agurto (1987: 80) la ciudad del Cusco estaba compuesta de dos zonas: la zona urbana, que integraba el núcleo básico del sector central, el área de expansión del sector central y el cinturón de aislamiento. La segunda zona era el sector periférico compuesto por la zona suburbana y la zona rural. De este modo el núcleo básico era considerado la parte sagrada y administrativa del Cusco, donde residía la nobleza y el personal a su servicio. Tal como es descrita esta ciudad por muchos cronistas, en ella debieron existir los aclla-huasicuna, donde mujeres escogidas se dedicaban a la producción de tejidos. Los otros artesanos no son mencionados, por lo que es posible pensar que estos productores se asentaron en el sector periférico. Estos barrios periféricos, siguiendo a cronistas como Garcilazo (1943), se componían de gente venidas de todas partes del imperio y que se organizaban de acuerdo a sus propias costumbres locales.

Los datos arqueológicos más importantes de las sociedades tardías las tenemos para la sociedad chimú; aquí presentaremos la información recuperada en Chan Chan. 
Chan Chan es considerada la ciudad capital del reino del Chimor o Chimú. Su trama urbana no sigue la misma lógica que la descrita para el Cusco. Si bien existe tres tipos de arquitectura bien diferenciada en términos sociales (la arquitectura monumental, compuesta de los llamados palacios y los templos; la arquitectura intermedia, destinada a las residencias de los administradores y comerciantes; y la arquitectura popular, destinada a la clase baja urbana), estos tres tipos de arquitectura no se encuentran separados como el caso inca; los llamados barrios se ubican preferentemente en la parte sur y oeste de la ciudad.

Según John Topic (1990: 152), los especialistas en Chan Chan ocuparon tres áreas distintas: barrios, áreas de servidores y áreas para alojamiento de comerciantes (fig. 1).

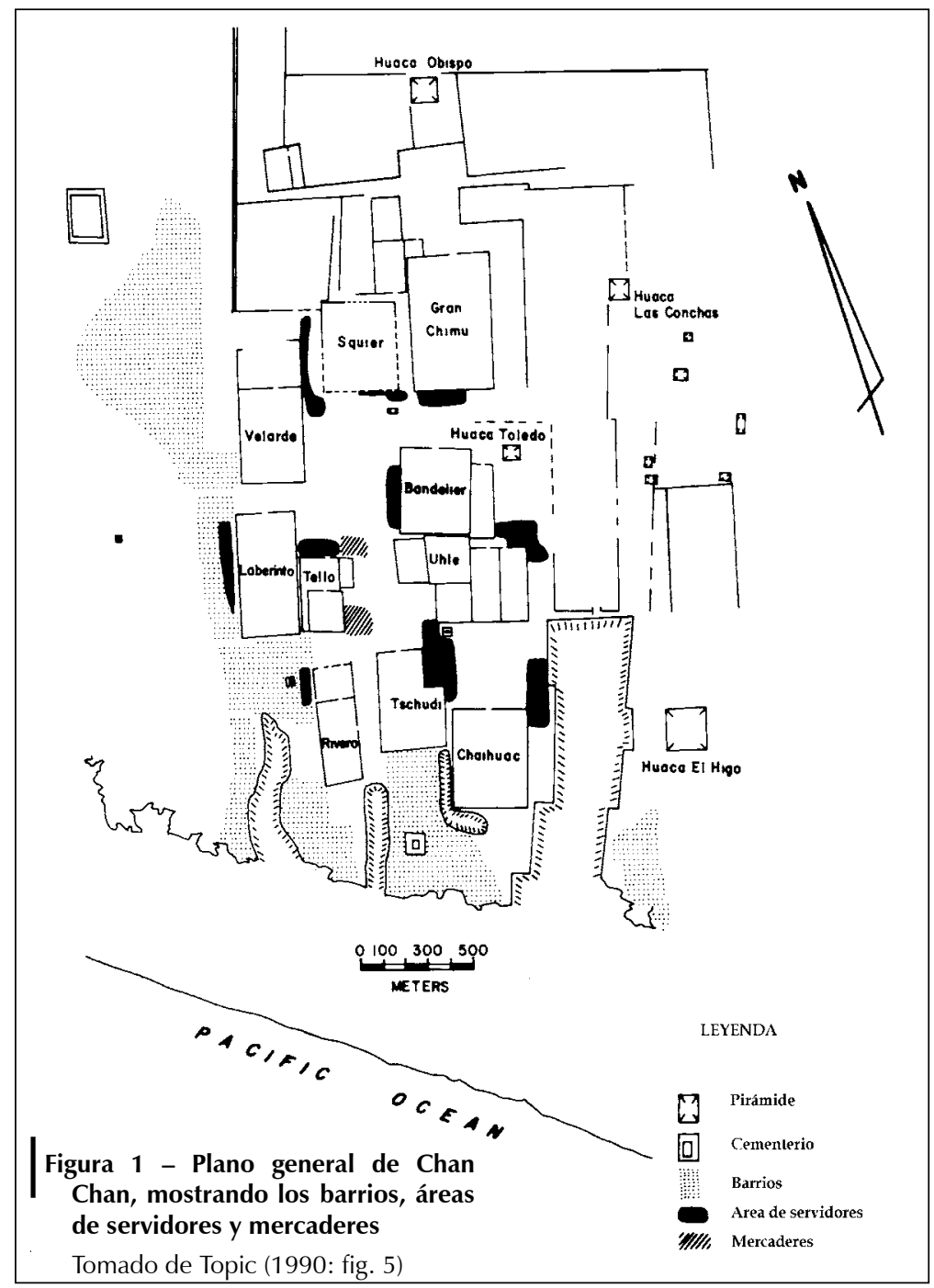


Existen cuatro barrios separados por cementerios que podrían indicar cuatro parcialidades asentadas en la ciudad. Dentro de cada barrio el artesano vivió en una unidad doméstica independiente con una cocina, área de depósitos, espacio de trabajo y animales domésticos (fig. 2). Mayormente las viviendas contienen

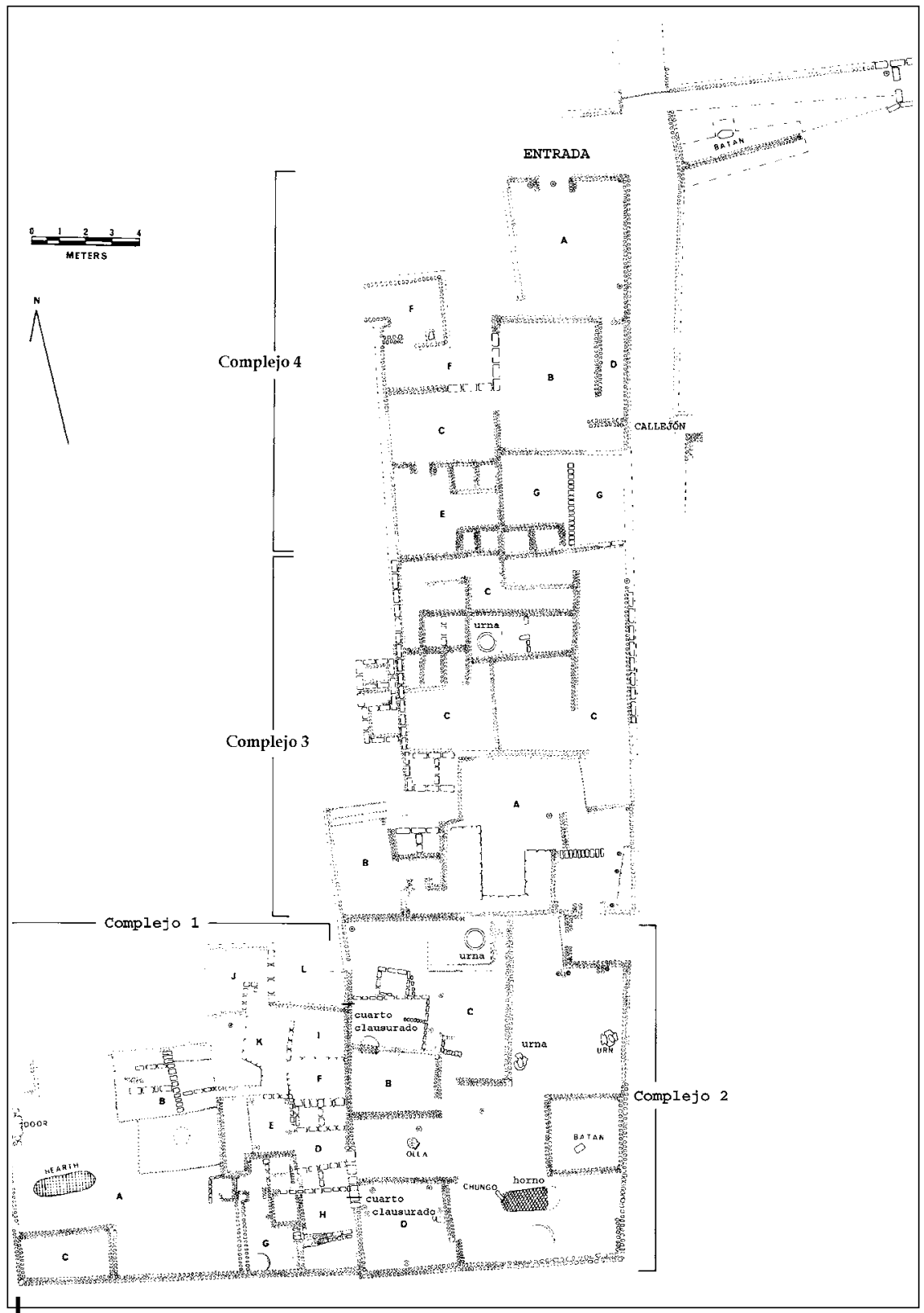

Figura 2 - Complejos arquitectónicos del barrio ubicado al sur de la ciudadela Laberinto, Chan Chan

Tomado de Topic (1990: fig. 6) 
evidencia tanto de talleres de metalurgia como de tejeduría. El hecho que todos los lingotes y los martillos de piedra fueron hallados en las viviendas de los barrios sugiere que la preocupación fundamental en sus talleres era la producción de láminas de metal. Otra información relevante en la organización del espacio urbano de estos barrios es que las viviendas se agrupaban de dos maneras distintas: algunos bloques se formaron adicionando cuartos extras a un núcleo ya existente, sugiriendo que, del mismo modo que la familia fue creciendo, ellos ampliaban y subdividían sus viviendas; en la otra forma (fig. 2), el lindero del bloque quedó estable pero el espacio fluctuó de una vivienda a otra por la remodelación de la entrada. Los espacios entre cada vivienda fueron los talleres (fig. 2, complejo 3; fig. 3) y el área administrativa (fig. 4), esta última indicada por la presencia de arcones o una estructura en forma de «U» con depósitos.

El área de servidores tiene ejemplos de algunas mixturas de actividades de tejeduría y metalurgia, pero su organización es diferente. Esta área de servidores difiere de aquella de los barrios por estar construida sobre plataformas y tener un acomodo diferente del área de la cocina. En el área de servicio adjunta al Palacio de Velarde, ella posee una amplia área de cocina que abarca al menos tres

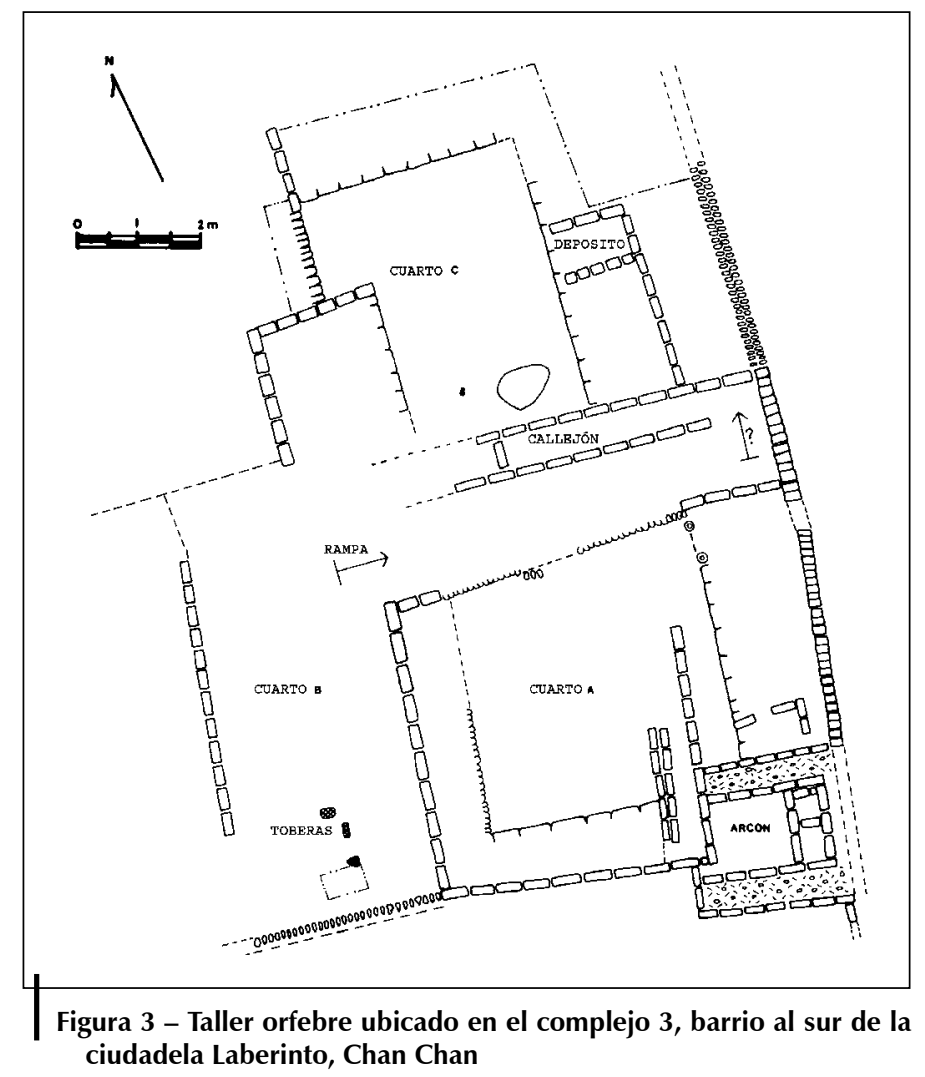

Tomado de Topic (1990: fig. 7) 


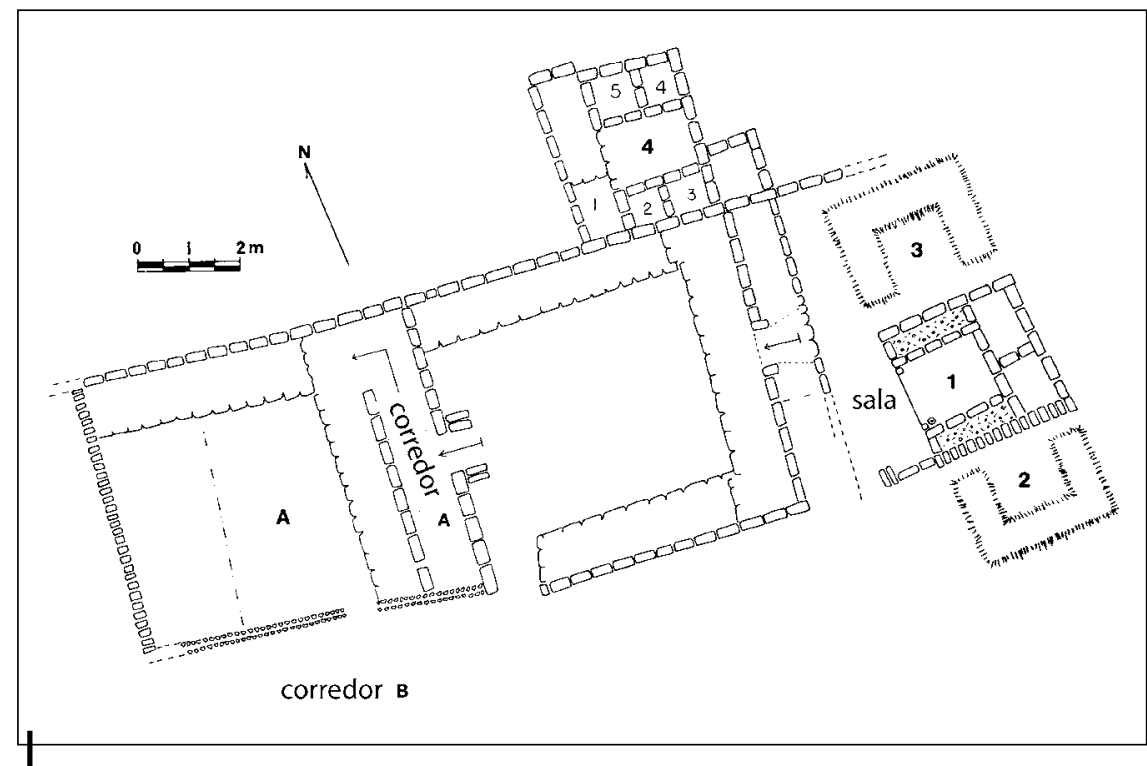

Figura 4 - Área administrativa ligada a los talleres del complejo 3, Chan Chan

Tomado de Topic (1990: fig. 8)

ambientes (fig. 5). Estas cocinas tienen dos fogones en un cuarto y otro en otro cuarto adyacente. Estos también fueron espacios para tres zonas de molienda (por la presencia de batanes) y el área de cocina incluía dos arcones; la ausencia de evidencia de producción de chicha es un indicador de arreglo social comparado a la de los barrios. Las áreas de los servidores pueden ser consideradas como viviendas particulares, al menos en términos de preparación de alimentos.

Las evidencias recuperadas en las excavaciones indican, en términos del proceso de producción, que el trabajo preliminar (tanto el laminado del metal como el hilado), fue menos importante en estas áreas, que el del acabado de los objetos. Todas estas características llevan a Topic (1990: 161) a postular que la gente que vivió en estas áreas tuvo un más alto estatus que aquellos de los barrios. Del mismo modo, la cercanía a los palacios, así como las características de las construcciones, le permite suponer que esta gente estuvo sujeta a los señores chimúes.

El tercer tipo de especialistas son los comerciantes. Las dos áreas registradas se ubican en la parte central del sitio y al final de la red de caminos. La mejor estudiada (fig. 6) poseía una cocina comunal, amplios corrales, una plataforma llena de entierros de llamas y cuartos con múltiples banquetas para dormir (fig. 7). Según los cálculos efectuados, estos fueron capaces de albergar cerca de 600 personas. La evidencia de artefactos y materiales registrados (madera exótica, lana de alpaca, lingotes de metal) sugiere el intercambio entre la costa y la sierra y otros lugares lejanos. Por ello estas áreas corresponderían a estructuras para acoger temporalmente a estos especialistas.

Los estudios de talleres artesanales para la época Moche con mayor información de contextos urbanos en conjunto, sin lugar a dudas, son aquellos realizados 


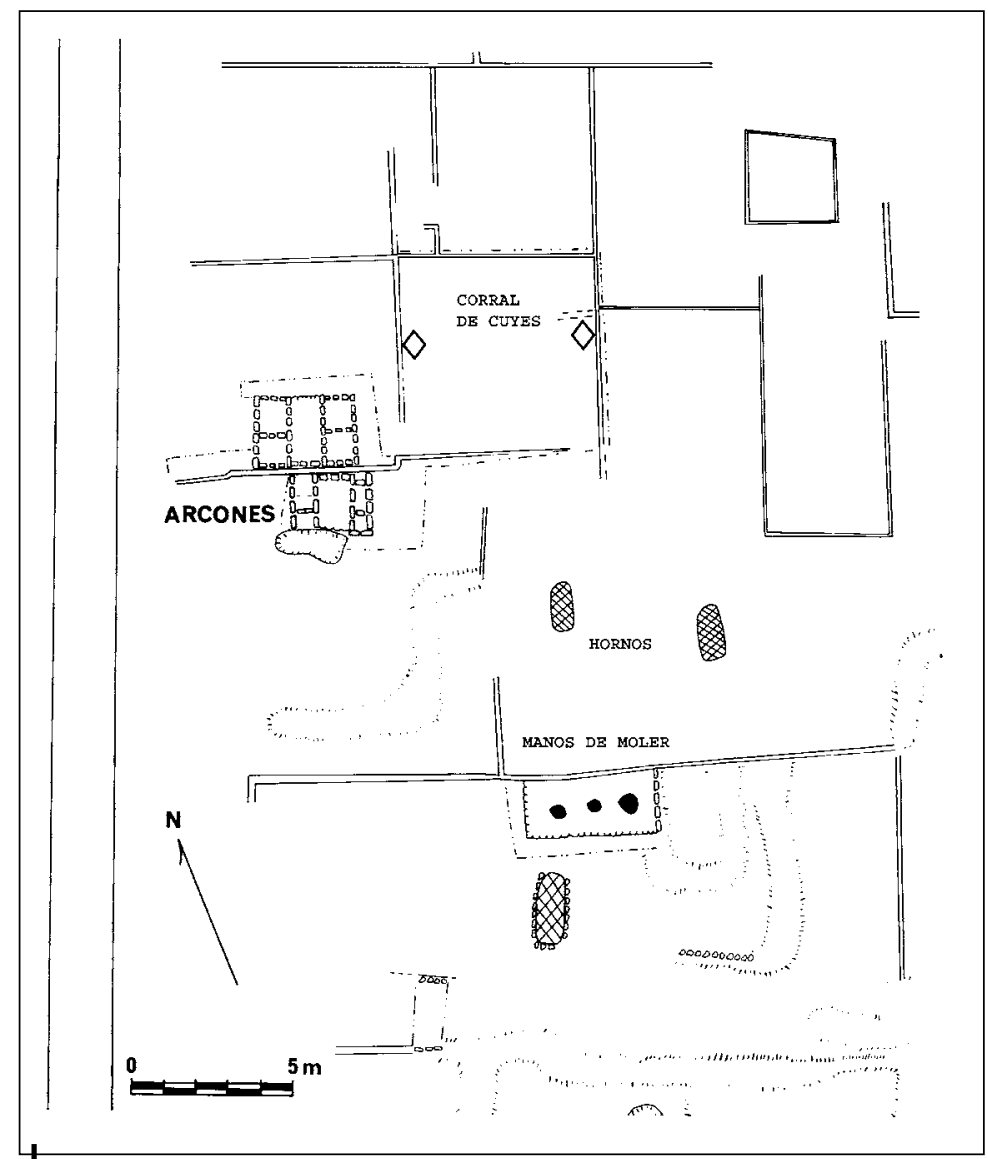

Figura 5 - Área de servidores orfebres, junto a la ciudadela Velarde, Chan Chan

Tomado de Topic (1990: fig. 11)

en Pampa Grande (Shimada, 1994), en el valle de Lambayeque. En términos generales, existen tres tipos de talleres por su ubicación y quizás, como más adelante lo discutiremos, por su relación con procesos y contextos sociales diferentes. El primer grupo es el de los talleres cercanos a las estructuras o plataformas piramidales (el mejor ejemplo es el taller de textiles de la Casa del Ciervo). El segundo tipo lo conforman aquellos ubicados en los sectores $\mathrm{H}$ y D, considerados como barrios donde se ubican viviendas, áreas administrativas de control de la producción artesanal y de bienes. El tercer tipo de talleres se ubica en zonas domésticas.

Para fines de nuestro estudio, vamos a describir con mayor detalle el taller de metalurgia, pues los contextos y excavaciones permitieron a los investigadores de Pampa Grande obtener mayor información sobre las áreas de actividad en el proceso productivo de los objetos en metal. Este taller fue ubicado en la estructura 52 del sector H (Shimada, 1994: 203-206, fig. 8.20); definitivamente 


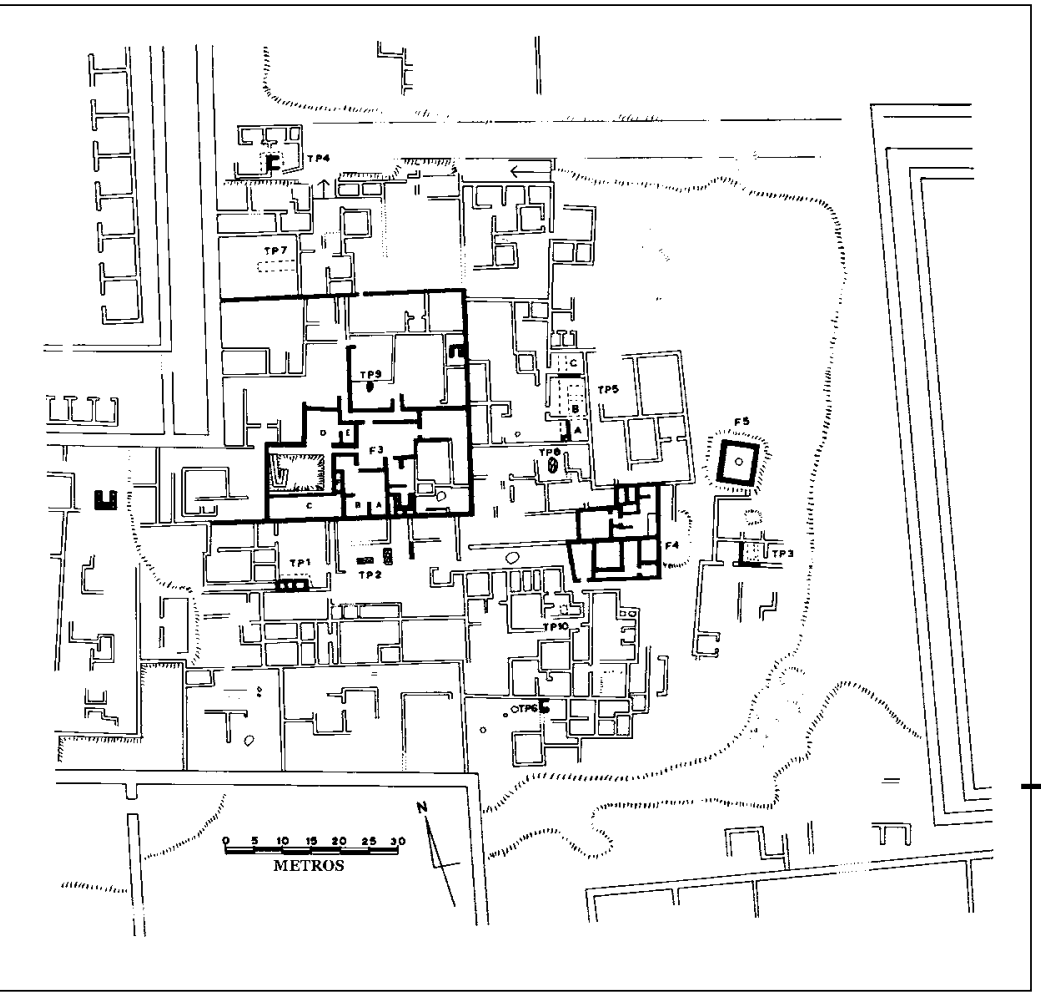

Figura 6 - Área de mercaderes, Chan Chan

Tomado de Topic, 1990 (fig. 13)

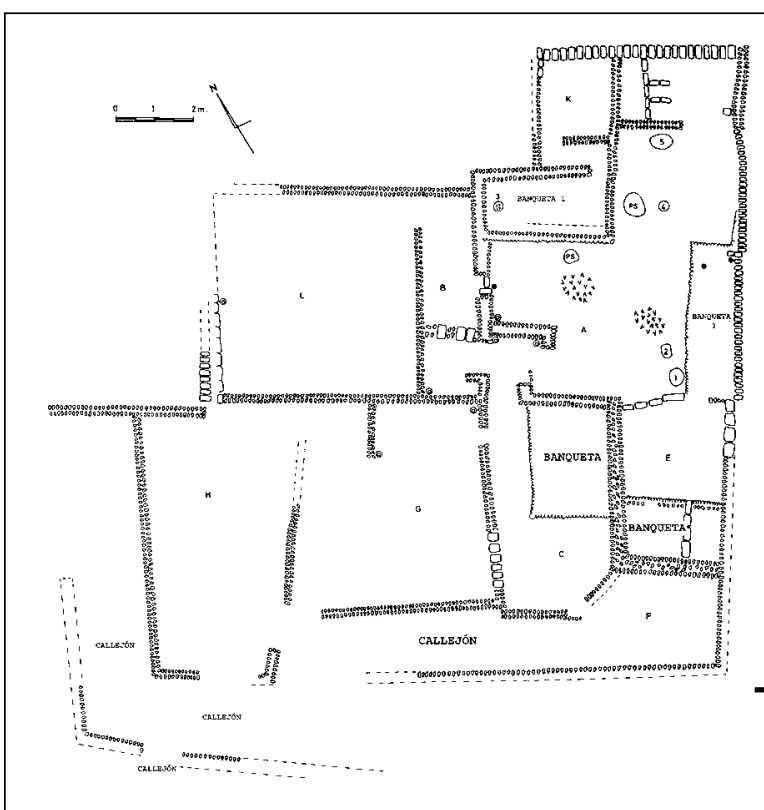

Figura 7 - Área de vivienda de los mercaderes, Chan Chan

Tomado de Topic (1990, fig. 14) 
Los contextos urbanos de producción artesanal en las huacas del Sol y de la Luna:

estaba involucrado en la forja, la elaboración o formado del metal por martillado y templado alternado.

El taller estaba situado en el extremo de una estrecha calle que también permitía el acceso a una aparente residencia en el otro extremo y a RS 65, con una espaciosa terraza jerárquica ubicada para controlar el tránsito a y desde la calle (fig. 8). El taller consistía de cuatro áreas interrelacionadas pero funcionalmente diferenciadas involucradas en (1) templado y fundición, (2) forjado, cortado y formado de láminas de metal, (3) almacenamiento y consumo de alimento y bebida, y (4) posible preparación de alimentos y disposición de desechos.

El área de fundición y templado se ubica en una zona espaciosa y amurallada cercana a la calle, donde se registraron dos fogones en forma de cubeta con fondos enlucidos de arcilla y paredes construidas con piedras en un mortero de arcilla. Sobre el piso, cerca de los fogones, había un cuenco en miniatura roto pero completo, de forma rectangular $(4 \times 6,5 \times 4 \mathrm{~cm}$ de alto, con una capacidad máxima de alrededor de 50-60 cc) con distintivas incrustaciones verdosas en la superficie interior.

El ambiente ARm 61 poseía una banqueta y dos mesas de trabajo; aquí se recuperaron dos conjuntos de artefactos en piedra que indican actividades

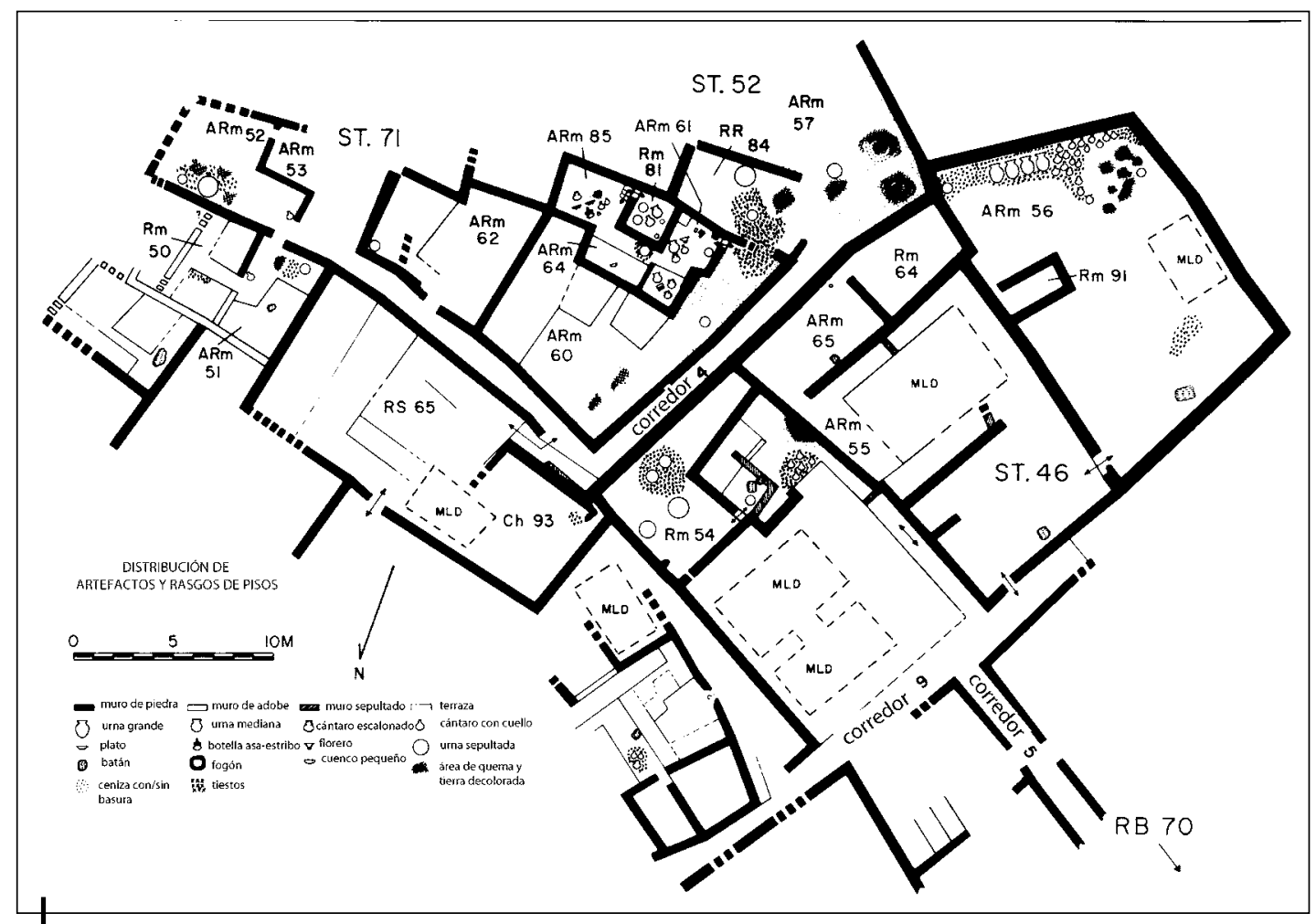

Figura 8 - Taller orfebre. Estructura 52, sector H, Pampa Grande

Tomado de Shimada (1994: fig. 8.20) 
relacionadas: un conjunto, sobre la banqueta, consistía en objetos de basalto con facetas planas pulidas; el segundo conjunto consistía en cantos pulidos con varias facetas. A estos conjuntos se deben agregar dos bloques de andesita con huellas de haber sido usadas para cortar objetos, así como un bloque de andesita que originalmente debió estar sobre una de las mesas con una cara mostrando huellas de trabajo. Este contexto ha sido interpretado como dos fases de actividades de la producción orfebre: la primera, el trabajo con los cantos de una cara amplia pulida usados como martillos, para fabricar las láminas de metal a partir de los lingotes. Las placas de andesita sirvieron para recortar las láminas y los guijarros con múltiples facetas para doblar y repujar las láminas; la cercanía de los fogones permitía el trabajo de recalentamiento del metal para el proceso de laminado.

La presencia de cerámica fina en los ambientes ARm 64 y 85 ha permitido inferir que dichos ambientes estuvieron destinados a personajes de la elite moche que tuvieron las funciones de control o administración de este taller. Se puede señalar que el acceso al taller estuvo muy controlado por el ambiente con banquetas RD 65. En el pequeño ambiente Rm 81, con umbral alto en su vano de acceso, se registraron varios cántaros firmemente incrustados en el piso para contener líquidos (posiblemente chicha).

En todos los ambientes antes descritos no se registró evidencia de actividad doméstica. La presencia de fogones con gruesas capas de ceniza y restos de alimentos en los ambientes ARm 60 y RR 84, sugieren que aquí se prepararon los alimentos.

\section{3. La producción artesanal y el estatus de los artesanos}

El tratar el tema de la especialización artesanal dentro de las esferas de la producción en sociedades antiguas implica, como ha sido señalado por diversos trabajos teóricos, la definición de cómo funcionaban y se organizaban los artesanos especialistas (véase Brumfiel, 1980; 1998; Brumfiel \& Earle, 1987; Costin \& Wright, 1998; Inomata, 2001). De este modo, por su afiliación en el contexto de producción, siguiendo a Costin \& Earle (1989) o Brumfiel \& Earle (1987), se distinguen dos tipos de especialistas: los primeros son los llamados «independientes» y los segundos los «dependientes» o «adjuntos». Los primeros son aquellos cuya producción intercambian o venden directamente a los consumidores; la presencia de mercados y comerciantes es el modelo económico mejor logrado donde se inscribirían este tipo de productores. En el segundo caso, la producción se hace bajo el patrocinio de individuos que controlan el poder económico y político. La movilización de la producción la hace la elite; en el mundo andino sirvieron para definir roles o estatus de los individuos, así como para crear lealtades entre los grupos mediante «la generosidad», mediante el mecanismo de la reciprocidad.

Dentro de un centro urbano es de esperar que sea posible identificar y diferenciar estos tipos de artesanos, pues aquellos que son independientes formarán barrios particulares y sus talleres serán una parte de su residencia; en el otro caso, los talleres deben estar integrados a los palacios o residencias de la elite que los 
auspician. Nuestro estudio estará centrado en resolver esta pregunta, así como la escala de la producción artesanal en el sitio de las huacas del Sol y de la Luna.

Por otro lado, la producción artesanal puede ser hecha a diversas escalas, pero siempre que lo producido esté destinado a consumidores fuera del núcleo de los productores, es decir que ello involucra un sistema de movilización de los bienes a través de mecanismos de mercados o mediante el intercambio auspiciado por las elites gobernantes.

La producción artesanal también involucra el concepto del espacio físico donde se realiza la producción: los talleres. Un taller no indica un espacio único; dependiendo de la complejidad del producto y de la escala de la especialización, los talleres podrían tener tantos espacios o áreas como tipos de artesanos especialistas existan en la producción, atendiendo al trabajo específico que realicen dentro de una cadena productiva determinada. El registro arqueológico nos informa directamente sobre los talleres, en un primer momento, pero esta visión que nos brinda la arqueología es parcial, en tanto corresponde a la cantidad de información que ha perdurado en el tiempo y lo que dejaron los ocupantes antes de abandonar o transformar el taller. En estos espacios, las áreas de actividad se deducen por los objetos recuperados y ciertos elementos fijos que los talleres requieren, como fogones, «mesas» de trabajo y herramientas para realizar los diversos pasos de la cadena operativa, principalmente.

\section{UN ENSAYO DE SECUENCIA GENERAL DEL SITIO}

La información que hemos recuperado en dieciocho años de investigaciones en el sitio (Uceda, 2007; 2010) nos permite considerar tres grandes momentos en la historia de ocupación del mismo (fig. 9). El primero, desde sus orígenes — que por ahora no son precisos- hasta el año 600 ó 650 d.C., es el momento de dominio de la sociedad por parte de un modelo teocrático que tuvo sus inicios en la época de Chavín o antes y que culminó con los moches. El segundo, desde los 600 ó 650 hasta los 850 ó 900 d.C., es el momento del colapso de la sociedad teocrática y la búsqueda de un nuevo modelo de organización social y política, una sociedad de poder civil, que culmina con el abandono del sitio y la desaparición de lo que ahora denominamos cultura Moche. El tercer momento, después del 900 d.C. hasta la llegada de los españoles, es aquel del abandono del sitio y su reutilización por los chimúes, tanto en algunos de sus espacios sagrados - para usarlos como lugares de culto y entierro- o en el Núcleo Urbano moche, transformándolo en campos de cultivo y sus cementerios. La correlación de estos tres sectores del complejo ha sido realizada en un trabajo colectivo (Uceda et al., 2008), donde se ha puesto en discusión las secuencias estratigráficas y constructivas, las asociaciones con material cerámico, en particular la secuencia estilística propuesta por Larco (1948) y los fechados radiocarbónicos existentes. A estas fechas debemos agregar dos últimas que fechan la secuencia del Templo Nuevo (Uceda et al., 2010), que ubican el inicio de la construcción de dicho templo hacia inicios del siglo VII, coincidiendo con las últimas fechas de ocupación del Templo Antiguo. 


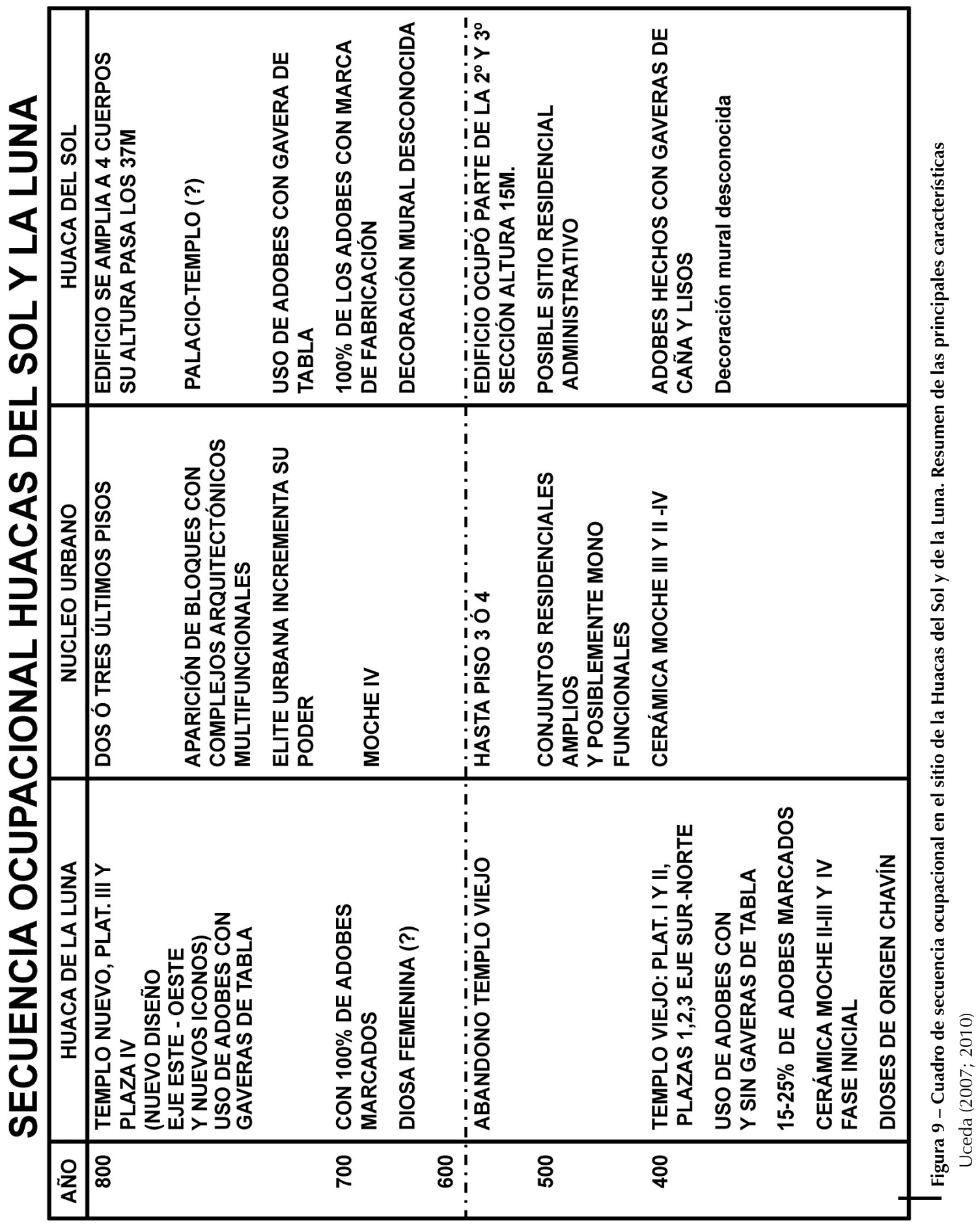




\section{1. El primer momento moche: la vieja ciudad y el rol del templo}

Los cinco edificios registrados en la huaca de la Luna corresponden a los pisos 4 al 12 registrados en el Núcleo Urbano, así como a la secuencia de las remodelaciones de las plataformas 2 y 3 de la huaca del Sol y la secuencia de pisos y remodelaciones que están por debajo de los rellenos de adobes tramados de la sección 1 de la huaca del Sol.

Durante este periodo de tiempo, 100 a 650 d.C, el componente más importante del sitio era sin duda el viejo templo de la huaca de la Luna (plataformas I y II y las plazas 1, 2 y 3). A partir de la evidencia de los contextos arqueológicos y arquitectónicos (Uceda \& Tufinio, 2003; Uceda \& Canziani, 1998; Uceda et al., 2008), se puede decir que el templo era el centro del poder político; los ceremoniales y rituales que allí se realizaban eran destinados a legitimar el poder político de la elite moche (Uceda \& Tufinio, 2003). Por ello el calificativo de teocrático en cuanto a su forma de gobierno para este momento. Es claro que el templo tuvo el control de los bienes y la mano de obra de los diversos grupos y estamentos de la sociedad; la clase urbana, siendo parte de la elite moche, no gozó del poder y la riqueza que ostentaron los grupos ligados al templo. Para comprobar lo dicho, basta observar que las tumbas más ricas recuperadas de la sociedad moche ostentan los símbolos y vestimentas que presentan los personajes representados en las escenas iconográficas de las ceremonias y rituales de aquella época (Alva, 1994).

Aunque por ahora solo tenemos una menor información de la clase urbana para esta época, podemos afirmar sin embargo, que las viviendas son simples y no tienden a formar grupos complementarios. Domina un espacio amplio (patio), raramente con banquetas formales, pocos depósitos. Estos elementos asociados a la poca diversidad de recursos con los que cuentan, nos indican claramente que esta elite urbana, si bien gozó de privilegios, estaban directamente controlados por el poder del templo. Siguiendo las ideas de Garth Bawden (1994), durante este periodo de desarrollo del Estado Moche se impulsó una ideología individualista, donde los gobernantes asumieron roles de las divinidades o las encarnaron en los principales ceremoniales y rituales, como aquél del sacrificio humano. Para ser más preciso, este modelo individualizante y la conformación del Estado territorial se pueden observar cuando el discurso iconográfico se formaliza en los diversos espacios arquitectónicos en los templos: patio con relieves, terraza del nivel alto y el frontis del Templo Antiguo. Las evidencias apuntan a que ello suceda a partir de la construcción del edificio D, pues para el edificio $E$ no se ha registrado el Recinto Esquinero ni los relieves en el patio del nivel bajo de la plataforma I.

En este sentido, es plausible suponer que los productos manufacturados en los talleres del Núcleo Urbano, aparte de estar destinados a los rituales y ceremoniales celebrados en el Templo Antiguo, como signos o emblemas de distinción social o política, también se destinaron a rituales relacionados con el mundo de los muertos o la elaboración de las identidades de los individuos en sus entierros. Desde esta perspectiva, es explicable que, para este momento de la historia del sitio, los talleres estén más localizados en ciertos espacios y que no todos los 
conjuntos residenciales posean áreas destinadas a actividades productivas, como sí es visible para los momentos finales de la ocupación moche en el sitio.

\section{2. Segundo momento moche: el abandono del Templo Antiguo y la búsqueda de nuevos modelos de organización social y política}

En el periodo del 600 al 900 d.C., se construyeron la plataforma III y la plaza 4 que, juntas, configuran el Templo Nuevo, así como la última fase constructiva en la huaca del Sol. Ambas edificaciones comparten para este momento los mismos tipos de adobes; las marcas de fabricantes fueron dominantes y se encuentran por bloques constructivos (cf. Hastings \& Moseley, 1975; García et al., 1994). Además, para este momento corresponde la vigencia de los dos o, en algunos lugares, tres últimos pisos en el Núcleo Urbano. Es el momento del colapso del sistema político teocrático moche.

En este punto de la historia, la huaca del Sol adquiere mayor importancia, si tomamos en consideración su volumen. De este hecho surge la pregunta: para este momento ¿el rol de la ideología religiosa había sufrido cambios sustantivos?, o inuevos dioses tomaron importancia frente a los viejos dioses que gobernaron el «Olimpo Moche»? Para ensayar una respuesta notamos que en el Templo Antiguo de la huaca de la Luna, las divinidades representadas en casi todas sus etapas constructivas, tuvieron una fuerte afiliación con las divinidades cupisniques. Los nuevos trabajos realizados en este edificio nos muestran que su estructura es distinta: está conformada de tres plataformas escalonadas siguiendo un eje oeste-este y su acceso se hacía a través de una rampa y escalinatas empotradas; no poseía un discurso iconográfico externo visible desde la plaza de acceso. Finalmente, hay que remarcar que dentro de los restos de individuos sacrificados se distingue un caso en particular, pues presenta evidencia de cortes a la altura del esternón destinado a separar las costillas para tener acceso al corazón; este tipo de sacrificios es muy usual en época chimú y no tiene una tradición típica moche (Uceda et al., 2010; Tufinio et al., 2010). Entre los murales descubiertos en este templo no aparecen los dioses cupisniques, en ellos destacan escenas de desfiles de guerreros, tejedoras, felinos y símbolos geométricos como aquel de la ola y la escalera. Pero el más emblemático es aquel del tema de la «Rebelión de los Artefactos», donde dominan los símbolos emblemáticos relacionados con la divinidad femenina (Makowski, 2003: 373). La aparición de nuevos dioses en el arte moche en su fases finales ha sido ya advertida por Elizabeth Benson (2003) en el arte cerámico. Estas evidencias y preguntas nos plantean la necesidad de repensar el modelo de organización política que adquirió la sociedad mochica tardía, y el rol que cumplió este sitio con relación a Galindo y Pampa Grande, por citar los otros complejos arqueológicos más conocidos.

Hemos discutido en otras ocasiones (Uceda \& Tufinio, 2003) que el abandono del Templo Antiguo debió ocurrir entre 550 ó 600 d.C., según fechas radiocarbónicas, y estuvo asociado a la presencia de fuertes lluvias (Mega Evento El Niño). Sin embargo, el abandono del templo y la presencia de El Niño no significaron el 
abandono de la ciudad, pues la ocupación moche continuó en el sitio unos siglos más. Claude Chapdelaine (2003), al revisar las fechas radiocarbónicas en el núcleo urbano coincide con nosotros al demostrar que el sitio fue ocupado hasta mediados del siglo IX y que el estilo Moche IV perduró en el sitio desde el año 400 hasta el año 880 d.C. De ello concluye que el mega Niño de 600 d.C. no fue la causa del abandono del sitio Moche. Las excavaciones de Chapdelaine no le permitieron descubrir para la época tardía de ocupación un nuevo elemento urbano que hemos denominado bloque arquitectónico, que bien puede considerarse homólogo a las manzanas de nuestras ciudades actuales.

¿Cuál es el real significado del abandono de este templo? Desde nuestra perspectiva de análisis, el Templo Antiguo encarnó un modelo político que sustentó la emergencia del Estado territorial Moche Sur, con su centro de poder o capital: la ciudad de las huacas del Sol y de la Luna. En este momento, la huaca de la Luna era el centro del poder político. Su abandono, en primer lugar, debe ser entendido como el colapso del modelo político teocrático moche y el desmembramiento del territorio estatal.

En segundo lugar, la pérdida de un poder central que acumuló la riqueza para sî debió motivar que esta riqueza se transfiriera de alguna manera a la clase urbana, con los respectivos cambios en sus patrones de vida (Uceda, 2010). Finalmente, el colapso del modelo político teocrático moche significó la búsqueda de nuevas formas de organización social, con las disputas y conflictos entre grupos menores de la misma elite moche. Vamos a revisar brevemente cada una de estas tres implicancias.

Luego del colapso político sigue un largo periodo, que debió durar más de 150 años, donde la sociedad moche buscó afanosamente un nuevo orden social donde el poder civil empezó a tener más importancia en la sociedad y en la estructura del Estado; este proceso posiblemente se produjo con flujos y reflujos. La causa interna era el modelo teocrático que no respondió a las tensiones internas, esto es a los conflictos entre las elites dominadas no moche (por ejemplo los virúes o gallinazos), así como aquellos conflictos surgidos por los intereses entre la clase urbana emergente y los dirigentes sacerdotales moches. Pero también debieron influir factores externos como la influencia de la cultura Wari o de Pachacamac, y las presiones de grupos serranos como los cajamarcas o los huamachucos. En este sentido la ocurrencia de catástrofes naturales debió acelerar estos procesos en marcha.

Uno de los primeros efectos de estas contradicciones, fue sin duda, la pérdida del control de territorios conquistados (Nepeña, Santa, Chao y quizás Virú). El Estado territorial se desintegraba, y la sociedad moche debió retroceder a un modelo organizacional tipo jefatura: en cada valle aparecen uno o más centros de poder que compiten entre sí, formando alianzas con unos y otros, sin lograr que uno de ellos se imponga en definitiva.

Un segundo efecto fue el incremento del poder político y económico de la clase urbana. El incremento del poder económico es observable por el hecho de que durante los últimos pisos ocupacionales, que corresponden a este momento 
de colapso de la sociedad moche, la clase urbana tiene un mayor acceso a diversos productos, en particular a aquellos que se generan por especialistas u otros grupos no urbanos. Antes de la década de 1990, el único indicio de la existencia de talleres productivos en el sitio huacas de Moche fue ubicado al pie de la huaca del Sol, donde se registró una concentración de turquesas bajo la forma de cuentas, preformas y fragmentos no trabajados (Topic, 1977). Con el inicio de las excavaciones en el Núcleo Urbano y en los flancos del Cerro Blanco, se fueron documentando paulatinamente sectores de producción de cerámica fina (Armas, 1999; Uceda \& Armas, 1997; 1998) y cerámica doméstica (Jara, 2000), áreas de preparación de chicha (Chapdelaine, 2001; 2003; Gamarra et al., 2004), espacios de manufactura de ornamentos corporales y trabajos en piedra (Bernier, 1999; Chapdelaine et al., 2000; Chiguala et al., 2006); sectores que posiblemente sirvieron para la fabricación y almacenamiento del material textil (Chapdelaine, 2001; 2003) y áreas relacionadas con la producción de objetos metálicos (Chapdelaine, 1998; 2003; Chapdelaine et al., 2001; Chiguala et al., 2004; Rengifo, 2005; Rengifo \& Rojas, 2005; 2008; Uceda \& Rengifo, 2006).

Los ajuares funerarios muestran un fuerte incremento en la cantidad de ofrendas, así como mayor presencia de objetos de metal, tumbas de cámara, etc. Podemos observar los cambios políticos a través del cambio de estructuras del Núcleo Urbano. La presencia de bloques arquitectónicos agrupando varios conjuntos arquitectónicos especializados, en torno a una residencia principal, nos señala un nuevo cambio de la organización social moche. Los señores de la elite urbana moche empiezan a controlar especialistas, organizar actividades ceremoniales y rituales dentro de sus residencias, como se deduce del incremento de entierros, de la producción y consumo de chicha y de la presencia de ciertos objetos rituales en las residencias como figurinas, floreros e instrumentos musicales (Uceda, 2010).

Este incremento del poder en la clase urbana es el inicio de una secularización del poder, proceso que culminará con la aparición del Estado Chimú. Esta nueva clase urbana se comportaría como un grupo corporativo y de él se desprende el poder central que debió ser frágil y quizás efímero.

Existe un inconveniente a esta línea de conjeturas, y es el de explicar cómo una sociedad en plena crisis logró edificar uno de los monumentos moches más grandes: la huaca del Sol. La primera explicación sería que se trata de un cambio social, donde el rol del poder era civil y este edificio representó el nuevo rol del poder civil. En este sentido, este edificio funcionaría como un templo palacios. Con la evidencia que tenemos es posible que estos cambios vinieran del norte.

El uso de adobes marcados tiene una tradición más antigua en el norte que en las huacas de Moche. En Sipán es notable el uso temprano de adobes marcados (Meneses \& Chero, 1994: láms: 234-235); por ello, no sería descabellado suponer que esta nueva forma de control pudiera provenir del moche norteño. A pesar de lo limitado de nuestro conocimiento sobre la forma que tuvo la huaca del Sol, una cosa es clara: no presenta el diseño del templo moche clásico. Las huacas lambayecanas presentan plataformas de lados lisos y no escalonados, el acceso se hace a través de una rampa central o lateral que llega directamente a la parte alta 
de la plataforma. En el caso de las huacas moches sureñas, estas presentan fachadas escalonadas, las rampas son laterales y en forma de «L» y frente a la plataforma existe un patio en su lado norte. Por ello, no es tampoco absurdo proponer como hipótesis de trabajo que la última edificación de esta huaca tiene un diseño más cercano a las huacas lambayecanas, cuya función de centros de residencia del poder central está bien documentada (Narváez, 1996). Así mismo, del estudio de los tres perfiles en la parte oeste (destruida) de este edificio se observa el volumen que representó la última edificación y es en este nuevo volumen donde el tipo de adobes es de paredes lisas y con marcas de fabricantes distribuidos por cada bloque constructivo (Uceda, 2010: fig. 4; Chauchat \& Herrera, 2003: encarte 6.1). En este sentido bien podemos asumir que este edificio no era un templo como huaca de la Luna sino un palacio-templo como se observa en las huacas lambayecanas tardías.

Una segunda explicación viene de otras culturas que en su ocaso iniciaron obras majestuosas como el caso de la arquitectura de Puuc, en las tierras altas mayas, a finales del periodo clásico e inicios del post clásico (Dunning, 2000). Se trata, pues, de una respuesta de la sociedad y de su elite ante la crisis. Este proyecto «faraónico» se convirtió en el símbolo de unidad para los grupos corporativos de la clase urbana, pero su ejecución en lugar de cumplir el objetivo perseguido debió empobrecer paulatinamente a la clase urbana, hasta agotar sus propios esfuerzos, y con ello motivó la desaparición de una de las sociedades más brillantes de los Andes centrales para su época.

Finalmente, debemos señalar que este proceso de cambio de una sociedad teocrática a una civil no culminó exitosamente en el sitio de las huacas del Sol y de la Luna. Otro grupo mochica de menor jerarquía que los que vivían en esta urbe, sí lograron dar el paso exitoso; me refiero a aquellos que construyeron Chan Chan, que la etnohistoria conoce como los chimúes.

\section{3. Las ocupaciones post moche: la presencia chimú}

En el periodo que va desde 900 ó 1000 d.C. hasta la época Chimú, hay evidencia que indica que el sitio fue totalmente abandonado y luego reocupado, posiblemente en forma continua, pero no como un centro urbano ceremonial. Ciertos espacios arquitectónicos del Templo Antiguo son reocupados por gente chimú para construir tumbas, altares o colocar ofrendas; ello nos indica la clara continuidad cultural entre los moches y chimúes. Estos últimos siguieron reconociendo este templo como un lugar sagrado, pues las actividades que ellos realizaron son de este carácter. No ocurre lo mismo con el Núcleo Urbano donde se destruyen las viviendas, se nivela el terreno y se le transforma en campos de cultivo y como cementerios de los ocupantes chimúes. La ciudad se abandona y sus artesanos y su elite van a ocupar Chan Chan u otros centros urbanos chimúes. 


\section{LA CIUDAD MOCHE: UNA VISIÓN GENERAL DE SU PLANIFICACIÓN Y LOS CENTROS PRODUCTIVOS}

La descripción que haremos del sitio huacas del Sol y de la Luna, es aquella que corresponde a la última ocupación moche (fig. 10). Se trata de un complejo urbano compuesto de dos grandes edificios públicos, asentados, uno al pie de las faldas oeste del Cerro Blanco (la huaca de la Luna) y otro a unos 500 metros al oeste del primero y cerca del río Moche (la huaca del Sol). Entre ellos, y en las faldas del Cerro Blanco, se desarrolló un conjunto de residencias con carácter multifuncional que hemos denominado Núcleo Urbano (Uceda, 2005).

Una gran calzada que corre de sur a norte y a unos 100 metros al oeste de la huaca de la Luna habría dividido el sitio en un área sacra y otra civil donde se desarrollaban actividades domésticas, productivas y administrativas. Por ahora desconocemos si otra calzada separaba la huaca del Sol del Núcleo Urbano.

La parte del Núcleo Urbano que se ubica entre las dos huacas presenta un diseño ortogonal (fig. 11). Un conjunto de callejones casi paralelos, separados entre sí por una distancia de 30 a 35 metros, parten de la calzada principal que separa este núcleo del área sacra de la huaca de la Luna, y penetran al interior del Núcleo Urbano. Estos callejones se conectan con espacios abiertos de unos $400 \mathrm{~m}^{2}$ que hemos denominado plazas; habrían servido como áreas de articulación entre los primeros callejones con un segundo grupo que corren de sur a norte y relacionan plazas con plazas o plazas con callejones (Chapelaine, 2003). De este modo se conforman bloques arquitectónicos a manera de manzanas urbanas modernas. Una plaza presenta evidencia de depósitos y bien puede tratarse de un área de distribución de productos como carne de camélido, pescado, entre los principales productos (Chiguala, 2004; Uceda, 2005).

El primero de los dos bloques arquitectónicos ya estudiados corresponde a los conjuntos arquitectónicos 27 y 30 que se ubican cerca de la calzada principal y en la parte central del complejo; el segundo pertenece a los conjuntos arquitectónicos 17,21 y 35 .

Esta forma de organización del espacio urbano corresponde a los dos últimos pisos. Según las excavaciones hechas en el conjunto arquitectónico 35, los pisos inferiores presentan cambios sustanciales, entre los que se destacan: (1) en los pisos tardíos existe una mayor densidad de espacios, donde hay una fuerte tendencia a la especialización, esto quiere decir, que ciertos ambientes estaban destinados a actividades domésticas (cocina), otros para reposo (dormitorios), otros para recepción, depósitos, etc.; (2) en los pisos tempranos dominan los ambientes para las recepciones, descanso y actividad doméstica; (3) a esta diferencia del diseño arquitectónico se debe agregar que, para los pisos tardíos, existe una mayor variedad de productos consumidos, así como una mayor y más diversificada presencia de productos artesanales de la época (Tello et al., 2008). Todo ello nos indica que la gente de las dos últimas ocupaciones concentró mayor poder económico a expensas de la elite religiosa, así como tendió a concentrar los rituales y ceremoniales, tal como se puede observar en la mayor uniformidad de 
Los contextos urbanos de producción artesanal en las huacas del Sol y de la Luna:

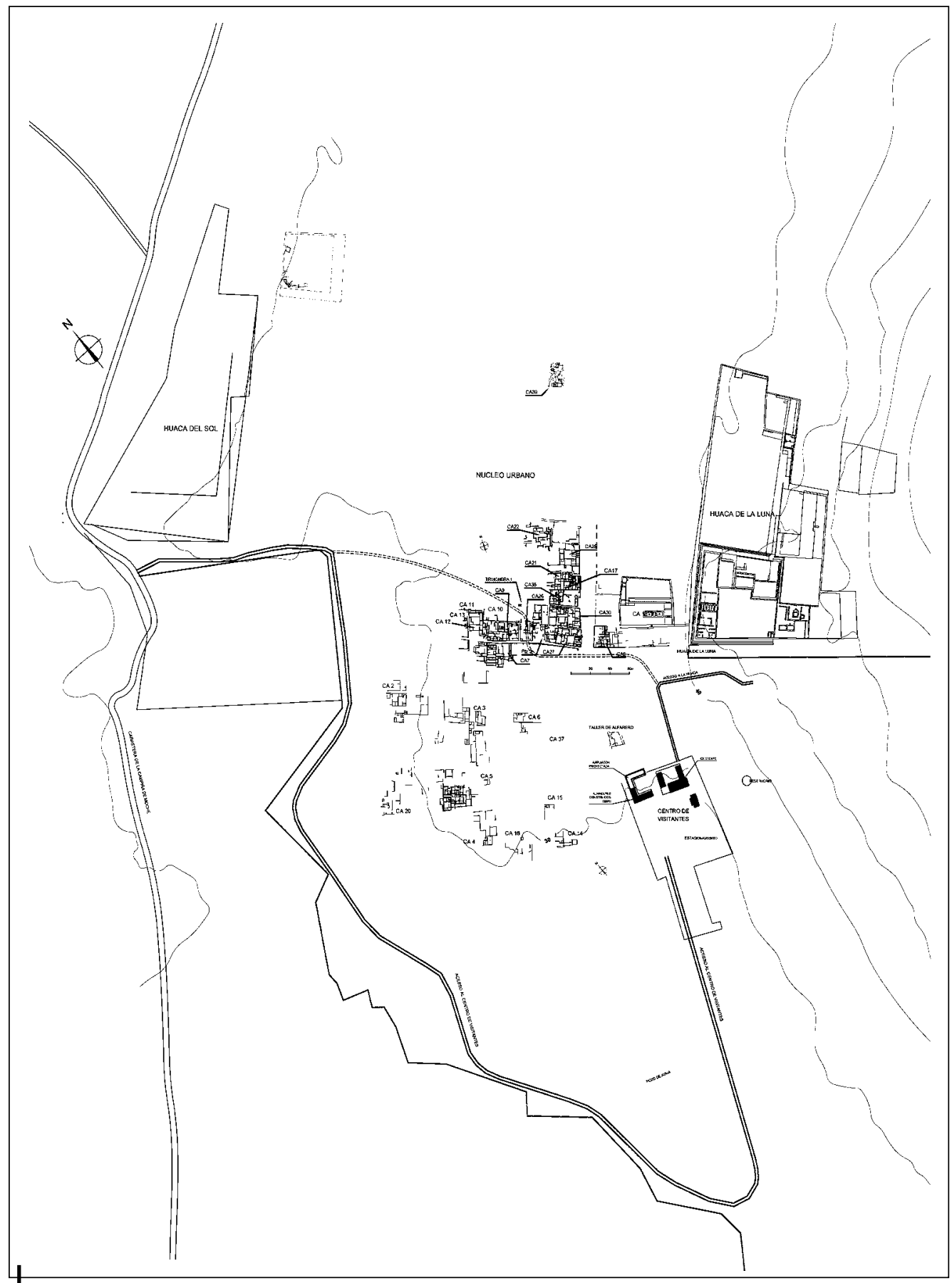

Figura 10 - Plano general del complejo arqueológico Huacas del Sol y de la Luna 


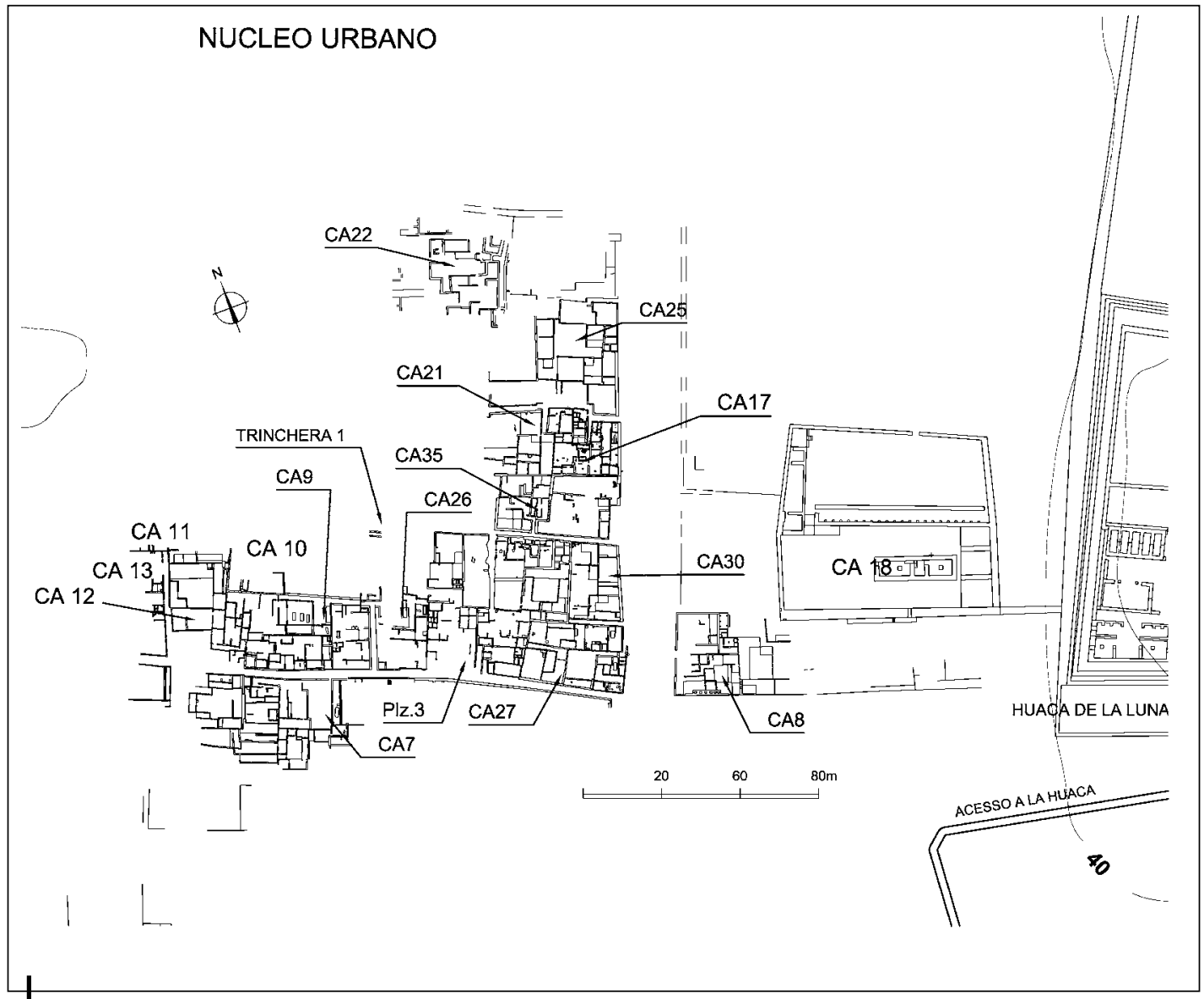

Figura 11 - Plano del sector central del Núcleo Urbano

los entierros y ofrendas que le acompañan. En definitiva, es obvio que existe un cambio en el sistema económico y quizás político entre estos dos momentos de la historia del Núcleo Urbano (Uceda, 2005; 2010).

\section{2. 1. Los bloques arquitectónicos o manzanas}

Se trata de un nuevo concepto usado para describir una forma de organización del espacio urbano en el complejo arqueológico, a partir de los trabajos realizados en la parte central del Núcleo Urbano. Previamente Claude Chapdelaine (2002; 2003) describió y definió los principales componentes de la planificación del sitio: avenidas, calles, callejones y corredores, las plazas, unidades domésticas y centros de producción. Un bloque arquitectónico o manzana se conforma a partir de la agrupación de varios subconjuntos que están delimitados básicamente por ejes de circulación como callejones, avenidas o espacios abiertos, que se han definido como plazas. 
El análisis arquitectónico nos permitió establecer una primera estratificación de los mismos. Se pudo constatar que cada subconjunto era una subentidad espacial del bloque arquitectónico o manzana. Era evidente que la presencia de patios con banquetas indicaba que este espacio era más preeminente que aquel que no las poseía. Los subconjuntos que tienen patios con banquetas poseen también espacios bien definidos como área de cocina, varios depósitos y espacios que se puede asumir cumplieron funciones de descanso (dormitorios). Hemos definido estos subconjuntos como las residencias principales de los bloques arquitectónicos o manzanas. Otros subconjuntos poseen ambientes amplios con grandes fogones y, junto a ellos, se concentran grandes tinajas. Estos espacios se han definido como áreas para la producción de chicha; los otros ambientes se pueden definir como áreas para descanso o para comer. A estos subconjuntos les hemos denominado áreas de servicios. Otros subconjuntos poseen patios centrales sin banquetas, con una presencia significativa de depósitos y ambientes para descanso, que han sido interpretadas como áreas administrativas. Finalmente, uno o dos subconjuntos tienen evidencias en uno o dos ambientes de talleres para la producción artesanal de la época a gran escala.

Vamos a describir con mayor detalle los dos bloques arquitectónicos mejor definidos a la fecha. Para su caracterización se usará tanto la arquitectura, como los contextos arqueológicos. Adicionalmente, usaremos el estudio de los restos de formas cerámicas agrupadas en categorías funcionales, para permitirnos contrastar con la información arquitectónica y contextual. Con la finalidad de intentar establecer el estatus de los ocupantes de cada subconjunto usaremos como indicador el acceso a los recursos alimenticios.

\section{- Bloque arquitectónico 1}

Se ubica en la parte central del Núcleo Urbano y adjunta a la avenida 1. Está compuesto por los conjuntos arquitectónicos 27 y 30 (fig. 12). Está delimitado al este por la avenida 1, al sur por el callejón 27-sur, al norte por el callejón 30-norte y, al oeste, por una plaza con depósitos. Fue el primer caso de bloque arquitectónico definido (Gamarra et al., 2004; Uceda, 2005), y se pudo constatar que se comportan como unidades complementarias, denominadas «áreas de actividad»: residencia principal, residencia secundaria, servicios, área administrativa y taller de orfebrería.

Área residencial y ceremonial. Se la considera así por presentar un patio con banquetas y ambientes para descanso y depósitos. Se accede a través de un corredor que parte de la avenida 1 y delimita con el subconjunto 27-2. El acceso de esta área daba a un patio amplio rodeado de banquetas a distintos niveles. Al oeste de este patio, existe un vano que comunica con la parte más amplia de esta área que permite acceder a dos ambientes que presentan fogones, lo que indica que se trata de posibles cocinas. La segunda área, ubicada en el extremo oeste, se comunica con un pequeño vestíbulo que permite comunicarse con un ambiente para descanso y a un segundo patio, rodeado de depósitos y un segundo ambiente para descanso. 


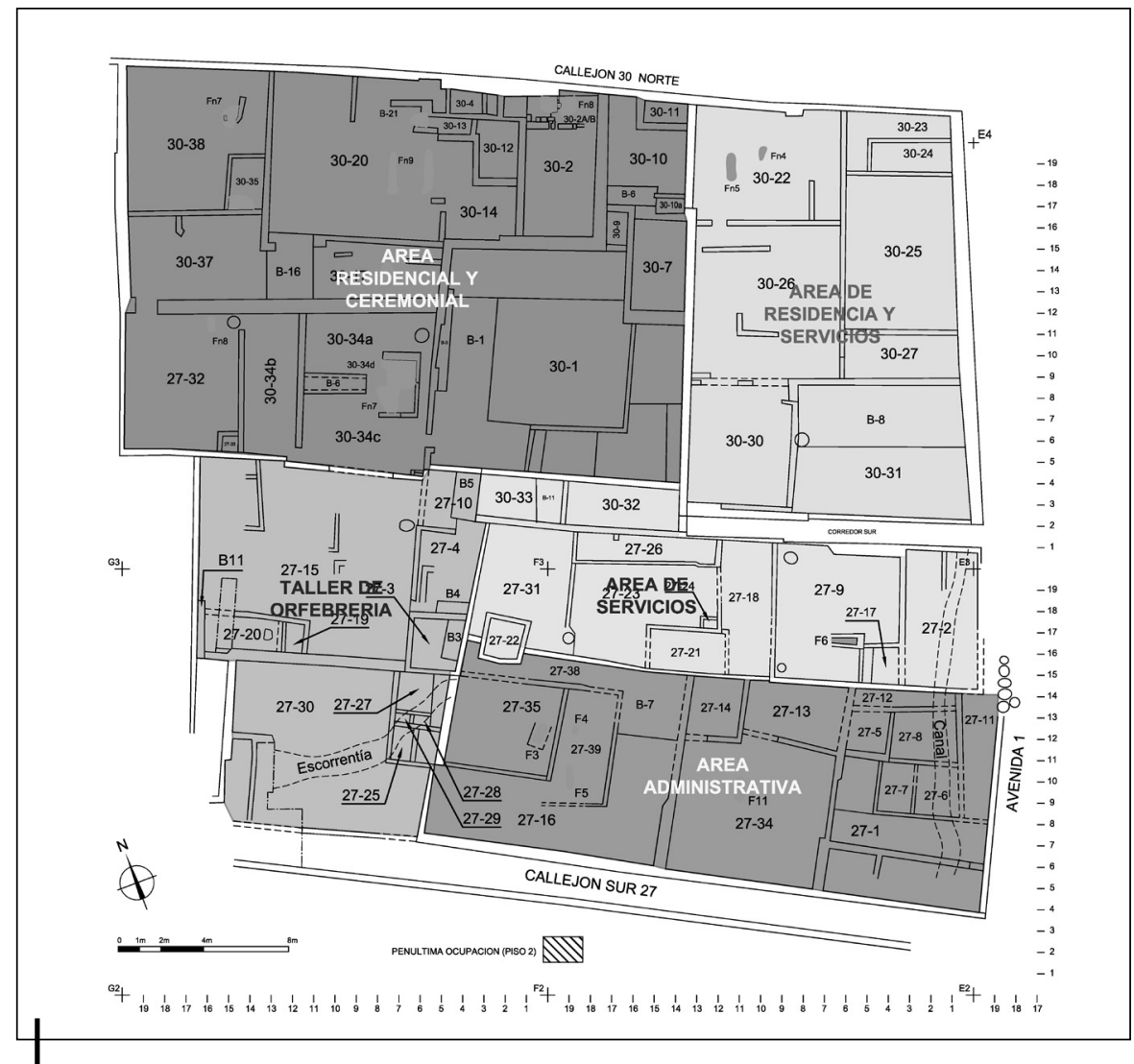

Figura 12 - Plano del bloque constructiva $n .^{\circ} 1$

El estudio de los restos cerámicos nos indica que en esta área predomina la actividad de almacenaje de enseres o de chicha, así como la actividad doméstica y ritual (fig. 13). Dentro de los recursos alimenticios registrados para esta área dominan los restos de mamíferos, en particular, los camélidos, seguidos de los moluscos (fig. 14). Si bien no se ha realizado un cálculo del volumen de carne que representan estas especies, el número de individuos camélidos representados es muy importante en la dieta. El consumo de carne (cuy y camélidos) está muy bien documentado en los festines que los señores realizaban como parte de las actividades de reciprocidad necesarias para el mantenimiento de la estructura social vigente. Estas actividades tienen íntima relación con la presencia de las banquetas en los patios, pues en ellas se debieron realizar banquetes dentro de un marco ritual de relaciones de intercambio.

Área de residencia y servicios. Se la define de este modo por la presencia de ambientes para descanso. Es un área mucho menor en extensión y está compuesta de un vestíbulo que se comunica con el corredor sur y que sirve 
Los contextos urbanos de producción artesanal en las huacas del Sol y de la Luna:

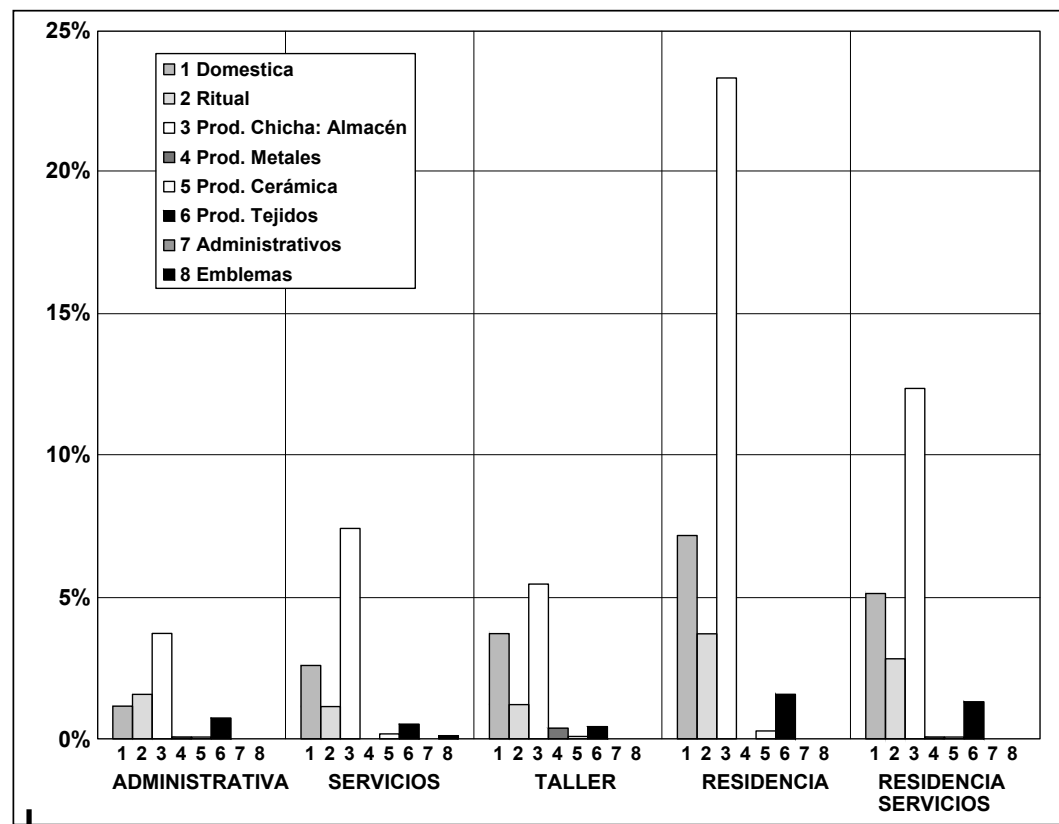

Figura 13 - Actividades según el tipo de objetos cerámicos, bloque constructivo n. ${ }^{\circ} 1$

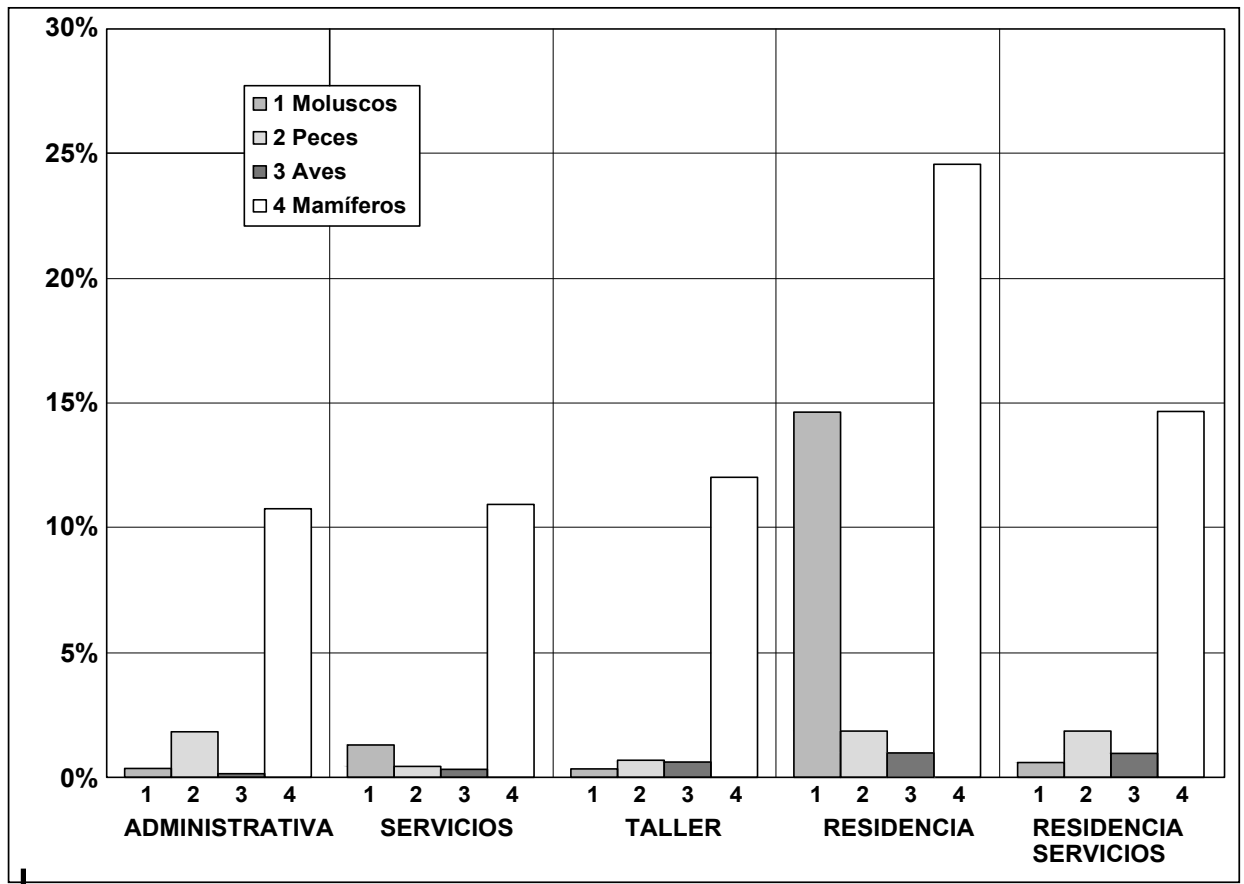

Figura 14 - Recursos alimenticios registrados en el bloque constructivo $n .^{\circ} 1$

Los porcentajes han sido calculados a partir del número de huesos analizados 
para comunicar con un ambiente con una banqueta frontal ubicado al lado este de este vestíbulo, que puede ser considerado como un ambiente para descanso. Desde el vestíbulo, hacia el norte se comunica con un patio sin banquetas. De este patio se accede a una cocina ubicada al norte donde hay dos fogones amplios; de la cocina se comunica a un ambiente con un depósito. Al lado este del patio, un vano comunica con un pequeño vestíbulo que antecede a un ambiente para descanso.

En esta residencia secundaria domina la activad de almacenaje de alimentos o de chicha, con poca actividad doméstica (fig. 13). Sin embargo, al examinar los recursos alimenticios recuperados, la presencia de restos de mamíferos es notoria, aunque no así los moluscos (fig. 14). La disminución de actividad de almacenaje y doméstica con relación al área residencial y ceremonial bien puede indicar que esta área residencial sea exclusiva para los residentes que controlaban todo el bloque arquitectónico 1.

Área de servicios. Se la denomina así por la presencia de un ambiente con un fogón largo rectangular muy similar a aquellos que se usan en la actualidad para la cocción del maíz en la preparación de chicha. Está compuesta de cinco ambientes y un vestíbulo por el que se comunica con el corredor sur. El mal estado de conservación no permite conocer detalles de algunos de ellos. Hacia el lado oeste del vestíbulo se encuentra el ambiente con un fogón central amplio y varias tinajas empotradas en el piso; formando parte de este ambiente, hacia el sur, existe un pequeño ambiente con banqueta y piso desgastado como un ambiente de descanso para varios individuos. Hacia el oeste un ambiente con banqueta frontal puede ser considerado con un espacio para descanso; no es clara la función de los otros ambientes. El análisis de los fragmentos de cerámica asociada a la ocupación de esta área nos indica que la actividad de almacenaje o producción de chicha le sigue en importancia luego de las áreas residenciales; esto podría estar ligado a su producción antes que a su consumo (fig. 13). La actividad doméstica es reducida, pero suficiente para alimentar un grupo de personas trabajando y distribuyendo la producción de chicha. El consumo de mamíferos sigue dominando, pero en menor proporción que en las áreas de residencia. Si calculamos el número de ambientes dedicados al descanso en relación al alimento consumido, éste es más reducido que aquel volumen consumido en las residencias antes descritas (fig. 14).

Área administrativa. Se la considera así por su cercanía con el área de producción de chicha y orfebrería, así como por la presencia de un grupo de depósitos. Su acceso se hacía directamente desde la avenida 1 y frente al acceso se registró un conjunto de tinajas en fila creando un acceso indirecto. Al final del corredor existe un vestíbulo o corredor que comunica con un ambiente rectangular y, al norte, con un conjunto de depósitos. Al oeste del vestíbulo hay un espacio amplio con fogón central, y dos ambientes al norte que bien pueden ser considerados como espacios para descanso. Hay un segundo espacio amplio, en cuyo lado oeste se ubican dos ambientes más con fogones en su interior. Estos ambientes nos pueden indicar que se trata de espacios destinados a 
gente foránea que es alojada en esta área; puede tratarse de gente que trae productos o los lleva desde la zona urbana. Esta hipótesis puede ser sustentada con la presencia de actividad doméstica importante y consumo de chicha y objetos para almacenaje, ligado al consumo de camélidos, con un consumo menor de moluscos, peces y aves (figs. 13 y 14).

Área taller de orfebrería. Su denominación se origina en la presencia de un espacio a manera de patio donde se registran evidencias de actividades ligadas a la elaboración de objetos de metal. Presenta dos sectores bien diferenciados y separados. Se accede al primero, ubicado al norte, por un corredor que lleva a un espacio abierto a manera de patio. Alrededor de él existe hasta cinco ambientes con banquetas que indican que se trata de ambientes para descanso, y el patio, como área común, presenta una configuración y distribución que nos hace recordar las primeras aldeas donde los ambientes de descanso unifamiliares se comunicaban a un patio central. Este sector bien puede considerarse el área de residencia de los artesanos. Es interesante notar que en este sector no se registran áreas de cocinas.

Al segundo sector se accede desde el corredor 27-Sur; el vano nos da acceso a un patio amplio en cuya esquina noreste existen un ambiente con banqueta y cuatro depósitos. En el patio se registraron tres quemas circulares alineadas de norte a sureste sobre el piso; alrededor de ellas muchos fragmentos de carbón estaban también sobre el piso.

Posteriormente este piso fue remodelado, es decir fue cubierto por un relleno y se superpuso otro piso. El relleno arrojó mucha frecuencia de fragmentos de cobre oxidado e instrumentos de piedra, así como toberas.

Esta remodelación presenta sobre el piso, hacia el lado sureste del ambiente, un yunque de piedra con adherencias de cobre oxidado a su superficie (fig. 15).

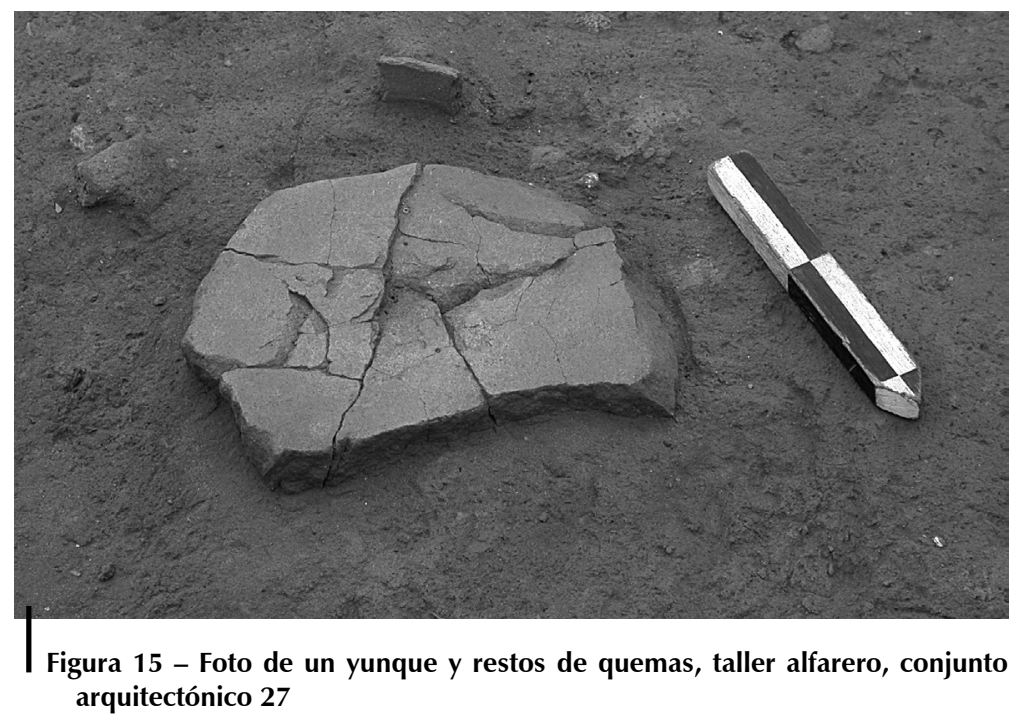


También se encontraron abundantes fragmentos circulares de cobre oxidado (prills) sobre el piso y alrededor de este yunque, así como fragmentos de cerámica con cobre adherido. Cabe resaltar que el área donde se encontraba el yunque y los fragmentos de cobre oxidado sobre el piso presentaba una tonalidad oscura, como si se hubiera realizado una quema en esa zona. Adicionalmente, en el relleno que tapaba este piso se encontró abundante escoria de cobre e instrumentos de piedra (martillo, fragmentos de crisoles con escoria de cobre, toberas, entre otros). Hacia el norte del ambiente dos manchas de color blanco humo parecían estar alineadas; muy cerca de ellas un adobe rubefactado indicaba que en ese área se realizaron fuertes quemas. Creemos que estas manchas de color blanco son cenizas producto de una fuerte combustión, producto de fundir metal o de su recalentamiento. Por los contextos recuperados, se propone que este ambiente, para la penúltima fase de ocupación, funcionó como un taller de producción de objetos pequeños de cobre y cobre dorado.

En ninguno de los sectores se registraron fogones, pero sí el consumo de alimentos y chicha (figs. 13 y 14). Ello nos indica que la gente que ocupó este taller fue abastecida de alimento y que éste es muy similar a aquel que se ha registrado para la residencia principal, aunque en mayor porcentaje.

Área de actividad asociada al taller. Tenemos poca información contextual; la primera es la presencia de las tres zonas de quemas, la segunda la presencia de un yunque, la tercera los prills y finalmente, aunque no asociados a los pisos sino a un área de escorrentía, la presencia de implementos típicos para trabajos de laminado y repujado en metal. La ausencia de materiales minerales no fundidos, así como la poca cantidad de escoria, nos indican que en este taller no se procesaron los óxidos o carbonatos en minerales a partir de la reducción y fundición. Es decir que los metales trabajados llegaron en forma de lingotes, listos para el trabajo final. La presencia de prills ha sido interpretada, por otros investigadores como producto del recalentamiento de láminas en el proceso de trabajo de martillado para su adelgazamiento. Este proceso se pudo realizar en pequeños hornos portátiles, avivados mediante el sistema de sopladores, tal como se ha descrito en diversos documentos de cronistas, así como en representaciones cerámicas. La zona donde se registró el yunque (fig. 15) es el lugar principal donde se efectuó el laminado. No conocemos, ni tenemos evidencias del lugar exacto o la manera cómo se realizaron los otros procedimientos. Esta interpretación se hace más verosímil si vemos los materiales recuperados: los metales recuperados son pocos así como los objetos terminados y muchos fragmentos de láminas o alambres (cuadro 1). Entre los materiales líticos relacionados con la metalurgia destacan los martillos para el laminado (cuadro 2, fig. 16). A esto debemos agregar la presencia de toberas (fig. 17)

- Bloque arquitectónico 2

Se encuentra ubicado adjunto y al norte del primero y está compuesto por los conjuntos arquitectónicos 17, 21 y 35. Delimita por el sur con el callejón 
Los contextos urbanos de producción artesanal en las huacas del Sol y de la Luna:

\section{Cuadro 1 - Metales, taller orfebrería, CA 27}

\begin{tabular}{|c|c|c|c|c|c|c|c|c|c|c|c|c|c|}
\hline \multirow[b]{2}{*}{ Formas } & \multirow[t]{2}{*}{ Nivel Ocupación } & \multicolumn{2}{|c|}{ Última } & \multicolumn{2}{|c|}{ Penúltima } & \multicolumn{2}{|c|}{ Antepenúltima } & \multicolumn{2}{|c|}{ Piso 4} & \multicolumn{4}{|c|}{ TOTAL } \\
\hline & & $\mathrm{n}$ & $\%$ & $\mathrm{n}$ & $\%$ & $n$ & $\%$ & $\mathrm{n}$ & $\%$ & $\mathrm{n}$ & $\%$ & $\mathrm{n}$ & $\%$ \\
\hline
\end{tabular}

\begin{tabular}{|c|c|c|c|c|c|c|c|c|c|c|c|c|c|}
\hline \multirow{3}{*}{$\begin{array}{l}\text { Objetos e } \\
\text { instrumentos }\end{array}$} & aguja & 3 & 1,15 & 5 & 1,92 & 4 & 1,54 & 0 & 0,00 & 12 & 4,62 & \multirow{3}{*}{16} & \multirow{3}{*}{6,15} \\
\hline & dardo & & 0,00 & 1 & 0,38 & 2 & 0,77 & & 0,00 & 3 & 1,15 & & \\
\hline & $\begin{array}{l}\begin{array}{l}\text { cuchillo- } \\
\text { tumi }\end{array} \\
\end{array}$ & & 0,00 & & 0,00 & 1 & 0,38 & & 0,00 & 1 & 0,38 & & \\
\hline \multirow{5}{*}{ Fragmentos } & alargados & 1 & 0,38 & 9 & 3,46 & 44 & 16,92 & & 0,00 & 54 & 20,77 & \multirow{6}{*}{244} & \multirow{6}{*}{93,85} \\
\hline & laminares & & 0,00 & 1 & 0,38 & 22 & 8,46 & & 0,00 & 23 & 8,85 & & \\
\hline & esféricos & & 0,00 & 1 & 0,38 & 3 & 1,15 & & 0,00 & 4 & 1,54 & & \\
\hline & alambres & & 0,00 & 1 & 0,38 & 2 & 0,77 & & 0,00 & 3 & 1,15 & & \\
\hline & $\begin{array}{l}\text { indetermi- } \\
\text { nados }\end{array}$ & & 0,00 & 4 & 1,54 & 55 & 21,15 & 1 & 0,38 & 60 & 23,08 & & \\
\hline \multicolumn{2}{|c|}{ Prills } & 1 & 0,38 & 54 & 20,77 & 45 & 17,31 & & 0,00 & 100 & 38,46 & & \\
\hline \multicolumn{2}{|c|}{ TOTAL } & 5 & 1,92 & 76 & 29,23 & 178 & 68,46 & 1 & 0,38 & 260 & 100,00 & 260 & 100,00 \\
\hline
\end{tabular}

\section{Cuadro 2 - Instrumentos para trabajos en orfebrería, CA 27}

\begin{tabular}{|c|c|c|c|c|c|c|c|c|c|c|c|c|}
\hline \multirow[t]{2}{*}{ Nivel Ocupación } & \multicolumn{2}{|c|}{ Última } & \multicolumn{2}{|c|}{ Penúltima } & \multicolumn{2}{|c|}{ Antepenúltima } & \multicolumn{2}{|c|}{ Piso 4} & \multicolumn{4}{|c|}{ TOTAL } \\
\hline & $\mathrm{n}$ & $\%$ & $\mathrm{n}$ & $\%$ & $\mathrm{n}$ & $\%$ & $\mathrm{n}$ & $\%$ & $\mathrm{n}$ & $\%$ & I & $\%$ \\
\hline
\end{tabular}

\begin{tabular}{|c|c|c|c|c|c|c|c|c|c|c|c|c|}
\hline \multirow{5}{*}{ Instrumentos } & Percutor & 1 & 1,16 & 6 & 6,98 & 15 & 17,44 & 1 & 1,16 & 23 & 26,74 & \multirow{5}{*}{48} \\
\hline & Pulidor sobre guijarro & & 0,00 & & 0,00 & 3 & 3,49 & & 0,00 & 3 & 3,49 & \\
\hline & Martillo & & 0,00 & 2 & 2,33 & 6 & 6,98 & & 0,00 & 8 & 9,30 & \\
\hline & Pulidor trabajado & & 0,00 & & 0,00 & 5 & 5,81 & 1 & 1,16 & 6 & 6,98 & \\
\hline & Yunque & & 0,00 & 4 & 4,65 & 4 & 4,65 & & 0,00 & 8 & 9,30 & \\
\hline \multirow{9}{*}{$\begin{array}{l}\text { Objtetos } \\
\text { pulidos }\end{array}$} & Abalorio & & 0,00 & 2 & 2,33 & & 0,00 & & 0,00 & 2 & 2,33 & \multirow{9}{*}{38} \\
\hline & Colgante & & 0,00 & 2 & 2,33 & 4 & 4,65 & & 0,00 & 6 & 6,98 & \\
\hline & Elemento pulido & 2 & 2,33 & 3 & 3,49 & & 0,00 & & 0,00 & 5 & 5,81 & \\
\hline & $\begin{array}{l}\text { Elemento pul. en } \\
\text { proceso }\end{array}$ & & 0,00 & 1 & 1,16 & 11 & 12,79 & 2 & 2,33 & 14 & 16,28 & \\
\hline & Pesa & & 0,00 & & 0,00 & 2 & 2,33 & & 0,00 & 2 & 2,33 & \\
\hline & pesa en proceso & & 0,00 & & 0,00 & 3 & 3,49 & & 0,00 & 3 & 3,49 & \\
\hline & Piruro & & 0,00 & 1 & 1,16 & 4 & 4,65 & & 0,00 & 5 & 5,81 & \\
\hline & Porra & & 0,00 & 1 & 1,16 & & 0,00 & & 0,00 & 1 & 1.16 & \\
\hline & Cuenta & & 0,00 & & 0,00 & & 0,00 & & 0,00 & 0 & 0,00 & \\
\hline & TOTAL & 3 & 3,49 & 22 & 25,58 & 57 & 66,28 & 4 & 4,65 & 86 & 100,00 & 86 \\
\hline
\end{tabular}

30-norte, por el este con la avenida 1, por el norte con el callejón 17-21 y por el oeste con la plaza 4 (fig. 18). Este bloque arquitectónico posee seis áreas complementarias, como se vera más adelante, las cuales no son exactamente semejantes a aquellas descritas para el bloque arquitectónico 1. En principio existen dos áreas de taller, un área residencial y administrativa, un área de residencia principal y un área de servicios.

Área de residencial principal. Corresponde al subconjunto 35-1. Su ingreso se efectúa por el callejón 30-norte. Desde el callejón un corredor corto permite 


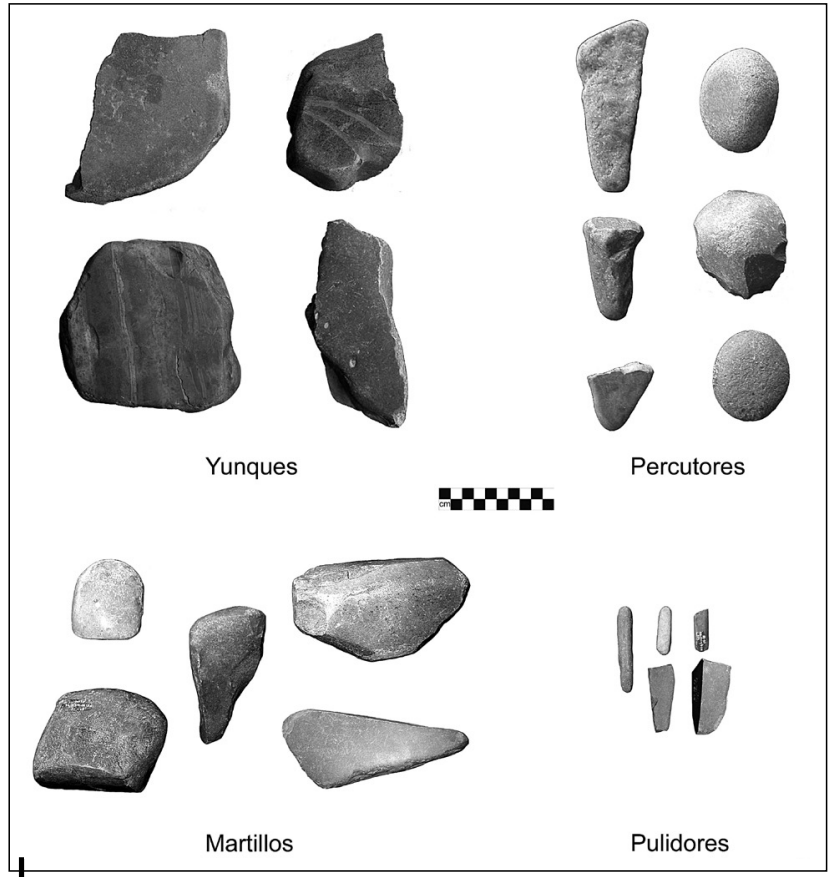

Figura 16 - Instrumentos de piedra para trabajos de orfebrería, taller de orfebres, CA 27

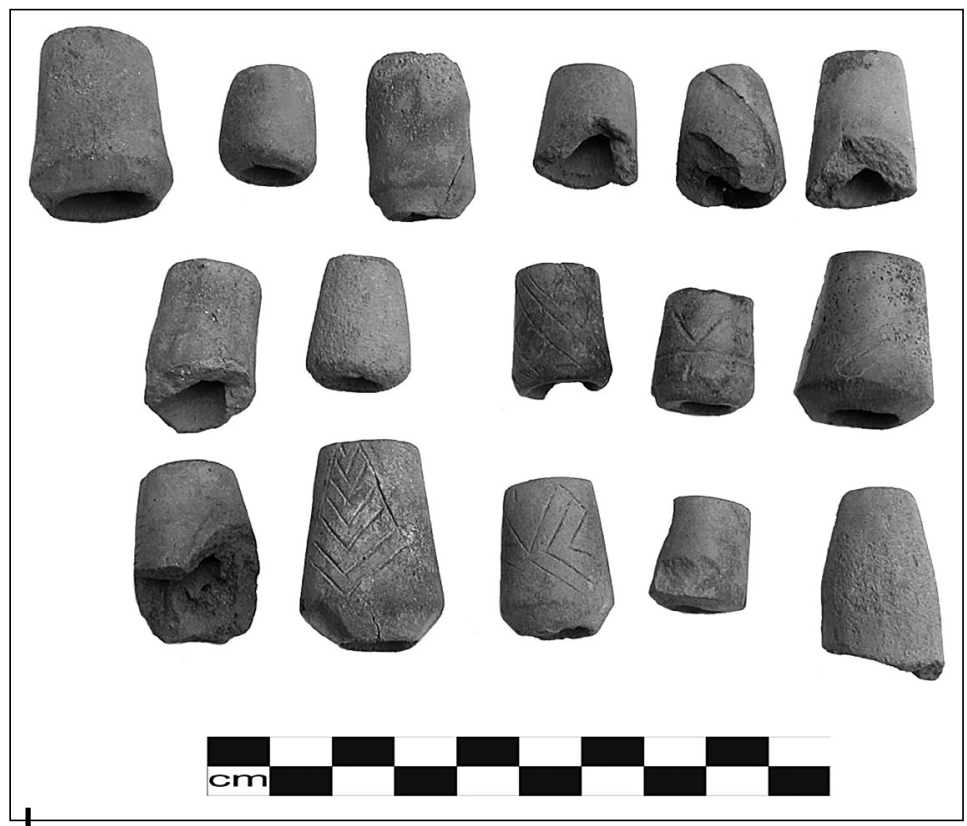

Figura 17 - Toberas del taller de orfebres, CA 27 


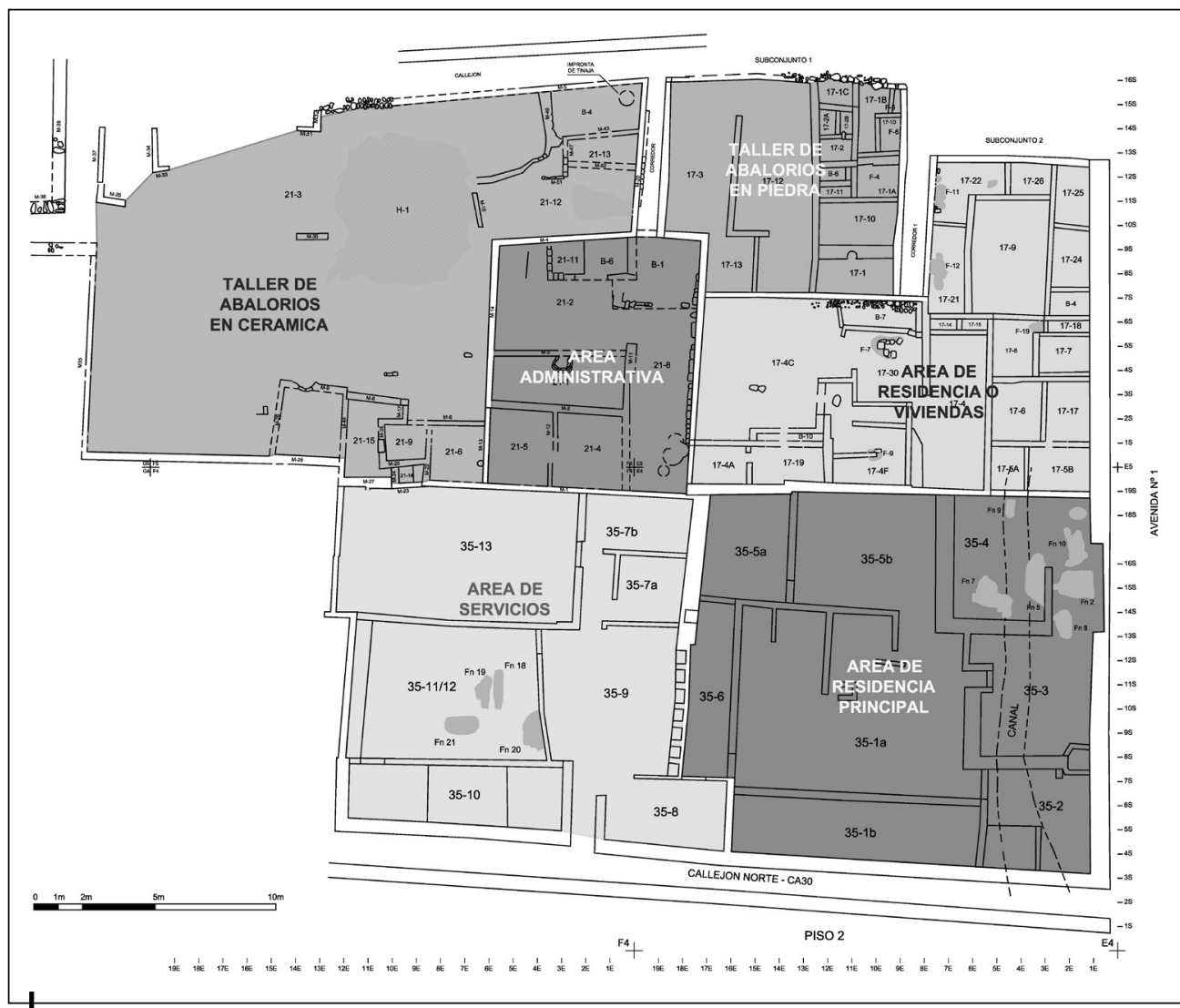

Figura 18 - Plano del bloque constructivo . $^{\circ} 2$

llegar a un vestíbulo, antesala a esta área. Del vestíbulo, un vano ubicado en su extremo noreste permite acceder a un amplio patio flanqueado por dos banquetas en sus lados sur y oeste. Posee un espacio formal de cocina donde se registró in situ varios fogones y un batán con su mano de moler. A esta cocina se accede a partir de un ambiente que se comunica con el patio y puede ser considerado como un espacio privado para el servicio o como comedor. Tres ambientes, dos en el extremo norte y uno en la esquina sureste, podrían ser espacios para descanso. Si la comparamos con la residencia del bloque arquitectónico anterior, esta sería más pequeña y menos compleja. Es importante remarcar que en los ambientes al norte del patio se han recuperado más de 14 tumbas en los 9 primeros pisos.

Del estudio de la cerámica por actividades, las actividades domésticas, de almacenaje y rituales son las dominantes frente a las otras propuestas en la lista general (fig. 19). La distorsión producida por la alta concentración en el taller de cerámica hace que los porcentajes de estos ítems en esta área se vean en la gráfica poco significativos; esto mismo se debe deducir de la poca 


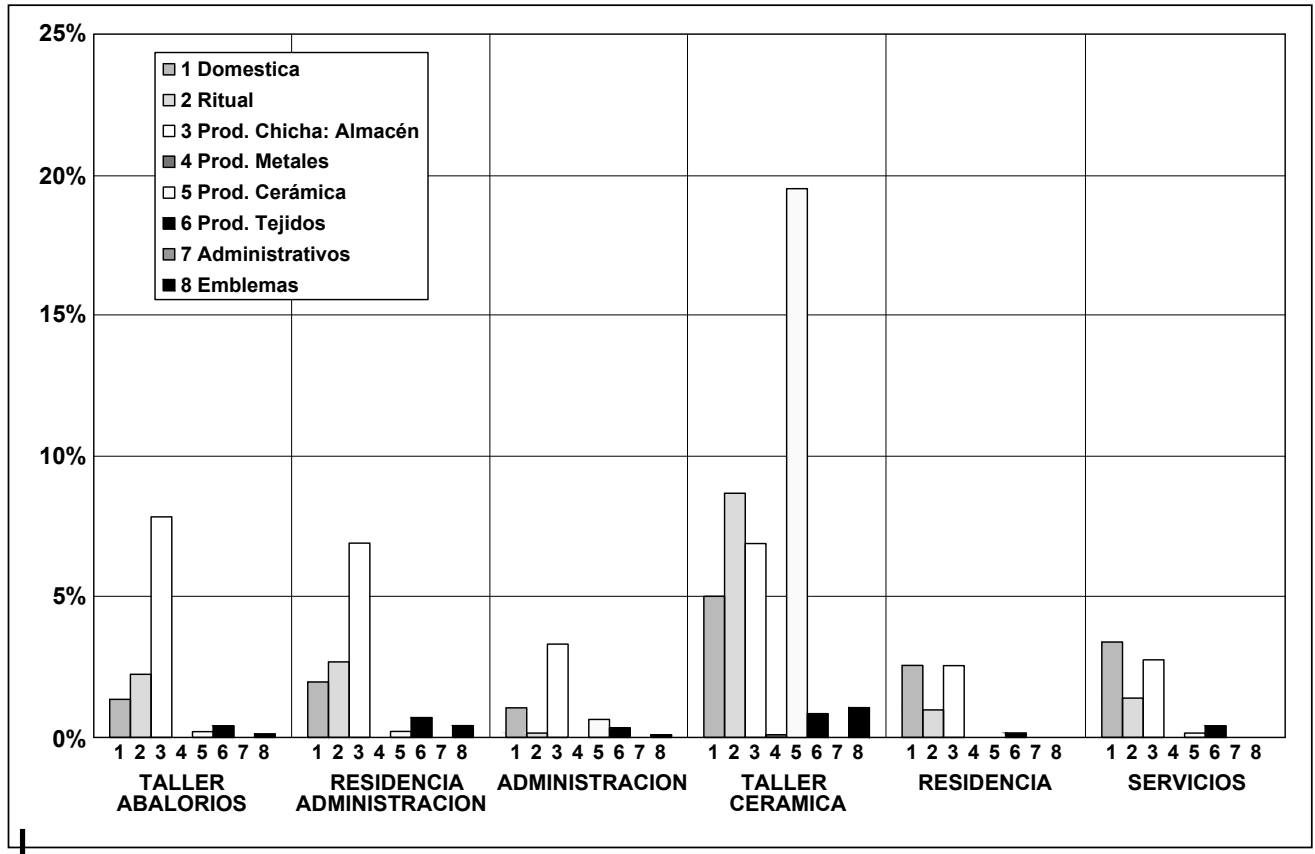

Figura 19 - Actividades según el tipo de objetos cerámicos, bloque constructivo n. 2

frecuencia en la dieta de carne de mamíferos (fig. 20). Por ahora no tenemos una explicación a este hecho, aunque la presencia de una capa muy compacta debido al uso en época Chimú del núcleo urbano moche como campos de cultivo, haya sido la causa del deterioro de los restos óseos o su fragmentación y no recojo durante la excavación. A estas condiciones del sitio hay que señalar que este conjunto arquitectónico fue uno de los primeros en excavarse en este sector y las precauciones tomadas para la recuperación de los restos óseos no fue la más óptima.

Área de Servicios. Como se indica para el bloque arquitectónico anterior, su denominación se hace por el hecho de registrarse fogones y áreas para producir y distribuir chicha. Desde el callejón y a través del pequeño corredor se ingresa a un ambiente amplio con un muro con hornacinas al pie del cual se registra un conjunto de tinajas en fila. Al oeste existe un ambiente con cuatro fogones, que bien puede tratarse de una cocina común al aire libre o con ligeras cubiertas. Al norte de esta área se registran tres ambientes, dos de ellos pequeños y que se comunican con el patio, y un tercero más amplio al que se accede a partir del segundo de los pequeños ambientes. En la parte sur del ambiente con fogones hay un ambiente amplio a tres desniveles, que estamos proponiendo como ambiente para el descanso.

Las formas cerámicas agrupadas por actividades nos indican que en esta área domina las actividades de almacenaje o producción de chicha; los contextos arquitectónicos nos llevarían a hablar de un lugar de preparación de chicha, 


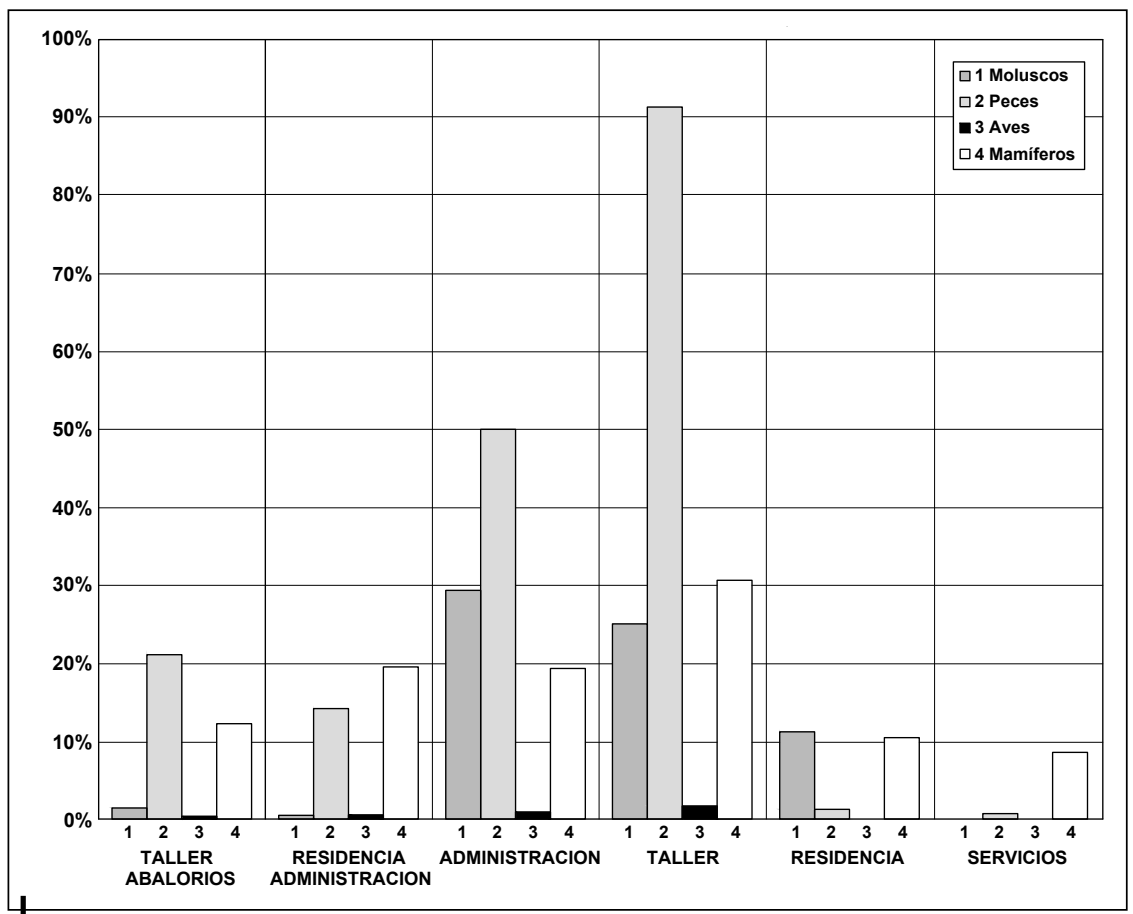

Figura 20 - Recursos alimenticios registrados en el bloque constructivo . $^{\circ} 2$

Los porcentajes han sido calculados a partir del número de huesos analizados

actividad doméstica y ritual (fig. 19). Los restos orgánicos animales usados en la alimentación son los mamíferos y un bajo porcentaje de peces (fig. 20).

Área de residencia o viviendas. Se trata de un conjunto de posibles viviendas en torno a tres patios. Se ingresa por un corredor desde el callejón 21-17-norte. Desde el corredor se accede a través de una banqueta a un patio amplio que presenta, cerca de la banqueta, un fogón hecho con dos hileras de adobes. En la parte sur del patio existen dos conjuntos de ambientes formando dos pequeñas viviendas compuestas de dos ambientes cada una. Un segundo patio ubicado al este del primero articula siete ambientes, cuya circulación y funcionamiento es difícil definir. Uno de ellos (ambiente 17-8) pudo funcionar como una antesala al tercer patio. Alrededor de este tercer patio se distribuyen cinco ambientes en forma de «U»; los ambientes del lado oeste y noroeste poseen fogones y su uso como cocinas es evidente. Los otros ambientes pudieron ser espacios para descanso y uno de ellos posee una banqueta.

La forma de distribución de estos ambientes alrededor de patios nos hace recordar las primeras viviendas aglutinadas en torno a espacios abiertos de las primeras aldeas. La presencia en esta área de materiales terminados de cuentas en piedras, son un buen indicio para postular que estas viviendas estén relacionadas con la gente que trabaja o administra el taller de abalorios en piedra que se ubica al costado de esta área. 
La distribución de cerámica por actividades nos indica una dominancia de vasijas para el almacenaje o consumo de chicha, actividad ritual y, lo que concuerda con los contextos arquitectónicos antes descritos. A esto deben sumarse otras actividades en menor medida (fig. 19). El consumo de carne de camélidos y peces son los más representativos (fig. 20).

Taller de abalorios en piedra. Corresponde a un área donde se han registrado dos espacios abiertos con evidencia de producción de abalorios en piedra. Estos espacios a manera de patios rectangulares compartieron posiblemente un solo acceso desde el callejón 17-21-norte. En su lado oeste se registra una serie de pequeños ambientes de una posible vivienda con una o dos cocinas y dos ambientes para descanso y dos pequeños depósitos. No es claro el acceso a esta pequeña vivienda, pero es posible que se hiciera a través de un vestíbulo que se comunicaba con uno de los patios o talleres.

En los espacios donde se has registrado materia prima, material en proceso de fabricación y objetos culminados, no es posible establecer los contextos de actividades de producción. Solo podemos establecer que el material llegó bajo la forma de bloques o plaquetas, las cuales mediante talla y corte fueron transformadas en tabletas del grosor deseado. Posteriormente, mediante cinceles y abrasión se lograron elaborar los objetos deseados, que básicamente son cuentas, preformas de pendientes, pendientes de diversas formas, e instrumentos para elaborar estos objetos.

La distribución de la cerámica por actividades nos indica el predominio del almacenaje, producción o consumo de chicha que concuerda con la existencia de ambientes con funciones domésticas, almacenaje y patios con tinajas incrustadas en el piso, típico de espacios para recepción. En este mismo sentido, se puede explicar presencia de actividad ritual en segundo lugar y luego la actividad doméstica (fig. 19). Aunque no es el momento de discutirlo, hay que precisar que este taller es sui generis al otro antes descrito, donde la actividad doméstica está poco representada en la cerámica, y en donde hay ausencia de espacios de carácter doméstico en la arquitectura.

Los recursos alimenticios recuperados nos indican un predominio de las aves y mamíferos en su dieta (fig. 20).

Los ornamentos corporales en piedra resultan de una cadena operativa compleja, la cual consta en una serie de etapas rigurosas y bien ordenadas (Bernier, 1998). En lo que respecta el taller de adornos corporales de este conjunto, se han registrado elementos que demuestran que en esta área se realizaron cuatro etapas de manufactura.

La primera etapa estaría dada por la reducción del núcleo a varios fragmentos de pequeño tamaño y de forma más o menos cuadrangular; esto se pudo evidenciar con la presencia de fragmentos de núcleo y núcleos con huellas de corte. Las herramientas empleadas eran los alisadores y cortadores, colocando el núcleo en soportes sobre los que se realizaban los cortes. Cuando la finalidad era obtener colgantes, los fragmentos de núcleos eran reducidos a plaquetas, los que posteriormente fueron pulidos hasta obtener unas piezas de regular tamaño, de forma cuadrangular y de superficies lisas. 
La segunda etapa estuvo dada con la elaboración de las preformas; estas son el resultado del desgaste de los núcleos reducidos o de las plaquetas, dándole la apariencia deseada para obtener las formas aún toscas de las cuentas y colgantes respectivamente; asimismo se da el pulimento preliminar para darle la forma inicial a estos adornos.

La siguiente etapa, consistió en la perforación del adorno; esta se realizaba en el caso de los colgantes, mayormente por un solo lado. En el caso de las cuentas, la perforación se daba por ambos extremos, lo que podemos evidenciar por las estrías presentes en los orificios de las cuentas y colgantes registradas en este conjunto.

Finalmente, la cuarta etapa consistió en el pulimento final del ornamento; este se realizó luego de que la pieza estuviera perforada completamente y después de haber seguido los procedimientos antes mencionados. Cabe mencionar que, en algunos casos, se han registrado cuentas y colgantes que han sido pulidos completamente, pero no contaban con perforación alguna, por lo que se puede asumir que, en ocasiones, no se respetaron las últimas dos etapas de elaboración.

En este taller se han registrado para esta ocupación materiales y objetos descritos para el proceso productivo de estos materiales de adorno corporal. En el cuadro 3 se presentan los efectivos y porcentajes de estos materiales líticos para las tres ocupaciones estudiadas en el conjunto arquitectónico 17.

Las herramientas están conformadas por los percutores, cortadores, soportes para corte, alisadores y pulidores; estos elementos fueron elaborados en piedras de forma alargada y de color gris oscuro. Asimismo, algunas de estas herramientas desempeñaron doble función, ya que en algunos casos los alisadores funcionaban como cortadores

Los núcleos están conformados por los núcleos y fragmentos de núcleo. Estos elementos presentan regular tamaño, formas irregulares y colores diversos, predominando los colores rojo, gris claro, gris oscuro y en menor cantidad los colores beige y crema (fig. 21).

Los objetos en proceso están conformados por las plaquetas, fragmentos de plaquetas, así como las preformas de cuentas y colgantes (figs. 22 y 23). En cuanto a los fragmentos de plaqueta, los colores predominantes son el gris claro, gris oscuro, rojo y beige. Las preformas de cuenta son más abundantes que las de colgante; predominan las de tipo cilíndrico, cónico, discoidal y elipsoidal. Son preferentemente de color gris claro, rojo, gris oscuro y beige y la mayoría de ellas no presentan perforación; así también tenemos las que tienen perforación por un solo lado y por ambos lados que no ha sido concluida porque, al parecer, en ese momento se produjo la fractura. Finalmente las menos comunes son las que culminaron la perforación pero aún les falta el pulido final. En lo que respecta a las preformas de colgante, predominan las de tipo fitomorfos, zoomorfos y geométricos; preferentemente también son de color gris claro, rojo, gris oscuro y beige. En su mayoría, estas no presentan 


\begin{tabular}{|c|c|c|c|c|c|c|c|c|c|c|c|c|c|c|c|c|c|c|c|}
\hline$\therefore$ & $\mid$ & 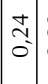 & $\begin{array}{lll} & \\
0 & & \end{array}$ & $\begin{array}{lll}\hat{N} & b \\
-\infty\end{array}$ & 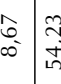 & $\begin{array}{lll}0 & 0 \\
\vdots & 0 & 0\end{array}$ & $\mid \begin{array}{l}\tilde{a} \\
0 \\
0\end{array}$ & $\begin{array}{lll}0 & 1 \\
0 & 0 & 0\end{array}$ & \begin{tabular}{l|l}
$\hat{0}$ & \multirow{2}{*}{0} \\
0 &
\end{tabular} & $\stackrel{\cong}{=} \stackrel{m}{=}$ & : & $\frac{\infty}{0}$ & \begin{tabular}{l|l} 
& $=$ \\
0 & 0
\end{tabular} & $=0$ & $\mid \begin{array}{l}0 \\
8 \\
0 \\
0\end{array}$ & $\begin{array}{l}\hat{0} \\
0 \\
\infty^{\circ}\end{array}$ & $\begin{array}{l}7 \\
\vdots \\
0\end{array}$ & \begin{tabular}{l|l}
0 & 0 \\
$\mathfrak{c}^{\circ}$ & 0
\end{tabular} & $\frac{g}{g}$ \\
\hline \# & $\therefore$ & $=$ & $-r$ & 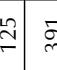 & 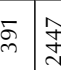 & $\wedge$ & - & -10 & $m s$ & $8:$ & $=0$ & $\infty$ & \begin{tabular}{l|ll}
$\sim$ & $\sim n$
\end{tabular} & t & $\stackrel{0}{m}$ & $\begin{array}{l}\vec{d} \\
\text { D }\end{array}$ & $\stackrel{\sim}{2}$ & 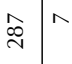 & 奋 \\
\hline$\therefore$ & & & & \begin{tabular}{l|l}
$\bar{\sigma}$ & \multicolumn{1}{c}{}
\end{tabular} & $\begin{array}{lll}0 \\
\stackrel{N}{N} & \infty \\
\end{array}$ & $\frac{n}{0}$ & $\mid \begin{array}{l}\stackrel{n}{0} \\
0 \\
0\end{array}$ & & & $\begin{array}{lll}0 & 0 \\
0 & 0 & 0\end{array}$ & & & \begin{tabular}{l|l}
$\stackrel{2}{2}$ & \multicolumn{2}{c}{} \\
0 & 0 \\
0 & 0
\end{tabular} & $\frac{0}{0}$ & 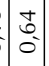 & $\begin{array}{l}\stackrel{0}{h} \\
\end{array}$ & $\mid$ & 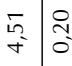 & 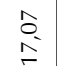 \\
\hline \# & & & & $\stackrel{m}{ }$ & \begin{tabular}{l|l}
$f$ & $\infty$ \\
& $\infty$
\end{tabular} & $m$ & - & & & \begin{tabular}{l|l}
$\square$ & $\nabla$
\end{tabular} & & & $-T^{-}-$ & $-v$ & $m$ & $\stackrel{\mathscr{m}}{\sim}$ & - & สิ + & $\stackrel{\infty}{m}$ \\
\hline 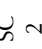 & & & & - & & & & & & & & & & & & & & - & - \\
\hline $\bar{u}$ & & & & 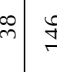 & 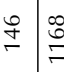 & $=m$ & - & & & 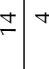 & & & $-T^{-}-$ & $-\alpha$ & $m$ & $\stackrel{\Re}{\sim}$ & - & б & 点 \\
\hline$\therefore$ & $\mid \begin{array}{l}0 \\
\infty \\
0 \\
0 \\
0\end{array}$ & $\mid \begin{array}{l}J \\
⿱ \\
0\end{array}$ & & \begin{tabular}{l|l}
$\stackrel{\sigma}{\circ}$ & \multirow{7}{*}{} \\
$\mathrm{i}$ &
\end{tabular} & 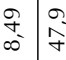 & กิ & & & 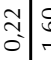 & \begin{tabular}{l|l}
0 \\
\hdashline \\
\hdashline & 0
\end{tabular} & $\begin{array}{l}0 \\
0 \\
0\end{array}$ & \begin{tabular}{|l|}
2 \\
0 \\
0
\end{tabular} & స̃ & $\begin{array}{l}0 \\
0 \\
0\end{array}$ & $\mid \begin{array}{l}1 \\
0 \\
0 \\
0\end{array}$ & $\begin{array}{l}\infty \\
\stackrel{2}{2} \\
\sigma\end{array}$ & $\begin{array}{l}8 \\
0 \\
=\end{array}$ & $\bar{o}$ & $\begin{array}{l}0 \\
\stackrel{1}{\simeq}\end{array}$ \\
\hline \# & $=$ & 6 & & q & $\cong:$ & $\begin{array}{l}m \\
0\end{array}$ & & & $m \curvearrowright$ & 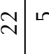 & $n-$ & $\sim \mid$ & $m$ & $\mid-$ & $\approx$ & $\tilde{\check{m}}$ & $\stackrel{\llcorner}{\sim}$ & 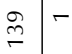 & $\stackrel{\Re}{\unrhd}$ \\
\hline N & a & $m$ & & $\stackrel{9}{-}$ & $\stackrel{m}{\stackrel{J}{\sim}}$ & 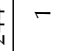 & & & $m \div$ & $\stackrel{2}{\Rightarrow}$ & $n-1$ & $\sim \mid$ & $\sim$ & & $\infty$ & $\therefore$ & $\nabla$ & 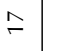 & $\stackrel{\sim}{~}$ \\
\hline $\bar{u}$ & $\sim$ & $m$ & & $\bar{v}$ & \begin{tabular}{l|l}
$\stackrel{\sigma}{巳}$ & $\stackrel{f}{~}$
\end{tabular} & $\sim$ & & & & $m$ & & & - & $-1-$ & + & $\stackrel{\stackrel{n}{2}}{=}$ & $=$ & $\underset{\mathbb{N}}{\stackrel{-}{-}}$ & $\stackrel{n}{n}$ \\
\hline$\therefore$ & fo & $\left|\begin{array}{l}g \\
g \\
0\end{array}\right|$ & $\begin{array}{ll}\cong & \\
\circ & \end{array}$ & 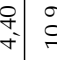 & 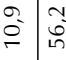 & $\stackrel{1}{2}$ & & $\begin{array}{l}1 \\
0 \\
0\end{array}$ & & 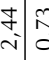 & $\begin{array}{c}c \\
\vdots\end{array}$ & $\left|\begin{array}{l}n \\
0 \\
0\end{array}\right|$ & $\stackrel{1}{0}$ & & $\left|\begin{array}{l}m \\
\hat{0}\end{array}\right|$ & $\stackrel{m}{\sim}$ & $\begin{array}{c}1 \\
0 \\
0\end{array}$ & 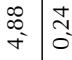 & 㱏 \\
\hline * & $\nabla$ & + & - & 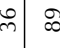 & \begin{tabular}{l|l}
$\infty$ \\
\end{tabular} & - & & - & & จ & $0 \infty$ & 0 & - & & 0 & 8 & $m$ & \& & ชิ \\
\hline$u \sim$ & $\nabla$ & $\sim$ & $-?$ & $\simeq \frown$ & $\therefore \overbrace{\tilde{N}}$ & $\begin{array}{ll}- \\
y^{2}\end{array}$ & & - & & $m m$ & $m m$ & - & - & & $m$ & $n$ & $\sim$ & 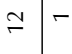 & $\simeq$ \\
\hline$\dot{n}-$ & & $\sim$ & & $\dot{\sim} \approx$ & 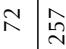 & & & & & $\wedge \pi$ & $n$ & 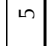 & & & $m$ & $\tilde{n}$ & - & 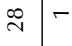 & in \\
\hline ú & - & & & $-\quad-$ & $-F$ & & & & & & & & - & & - & - & & & in \\
\hline$\dot{\sim}$ & - & - & & $-\quad-$ & $-\stackrel{\stackrel{n}{\prime}}{-}$ & & & & & - & & & & & $\nabla$ & & & & \\
\hline$\underset{s}{s}$ & & & & $\infty \stackrel{\wedge}{m}$ & \begin{tabular}{c|c}
$\stackrel{m}{m}$ & $\stackrel{m}{m}$
\end{tabular} & & & & & $m$ & & & & - & & $\stackrel{m}{\sim}$ & - & $\underset{I}{ \pm}$ & $\wedge$ \\
\hline 完 & & & & & $m$ & & & & & & & & & & & in & & $N$ & \\
\hline & 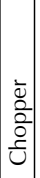 & 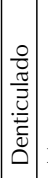 & 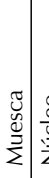 & 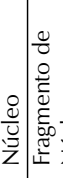 & 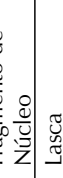 & 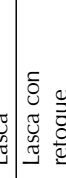 & 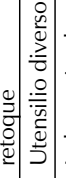 & 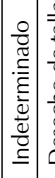 & 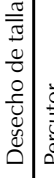 & 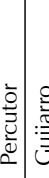 & 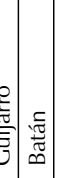 & 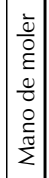 & 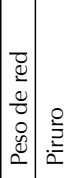 & 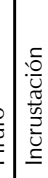 & : & 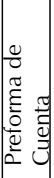 & 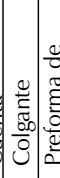 & 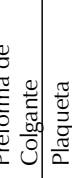 & 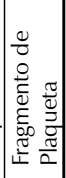 \\
\hline $\begin{array}{l}\text { o } \\
\text { o } \\
\text { 岁 } \\
\frac{J}{J}\end{array}$ & & & & & $\begin{array}{l}n \\
0 \\
\frac{1}{3} \\
\frac{1}{5}\end{array}$ & & & & & & 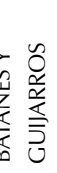 & & 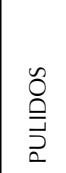 & & & & 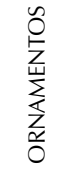 & & \\
\hline
\end{tabular}


Los contextos urbanos de producción artesanal en las huacas del Sol y de la Luna:
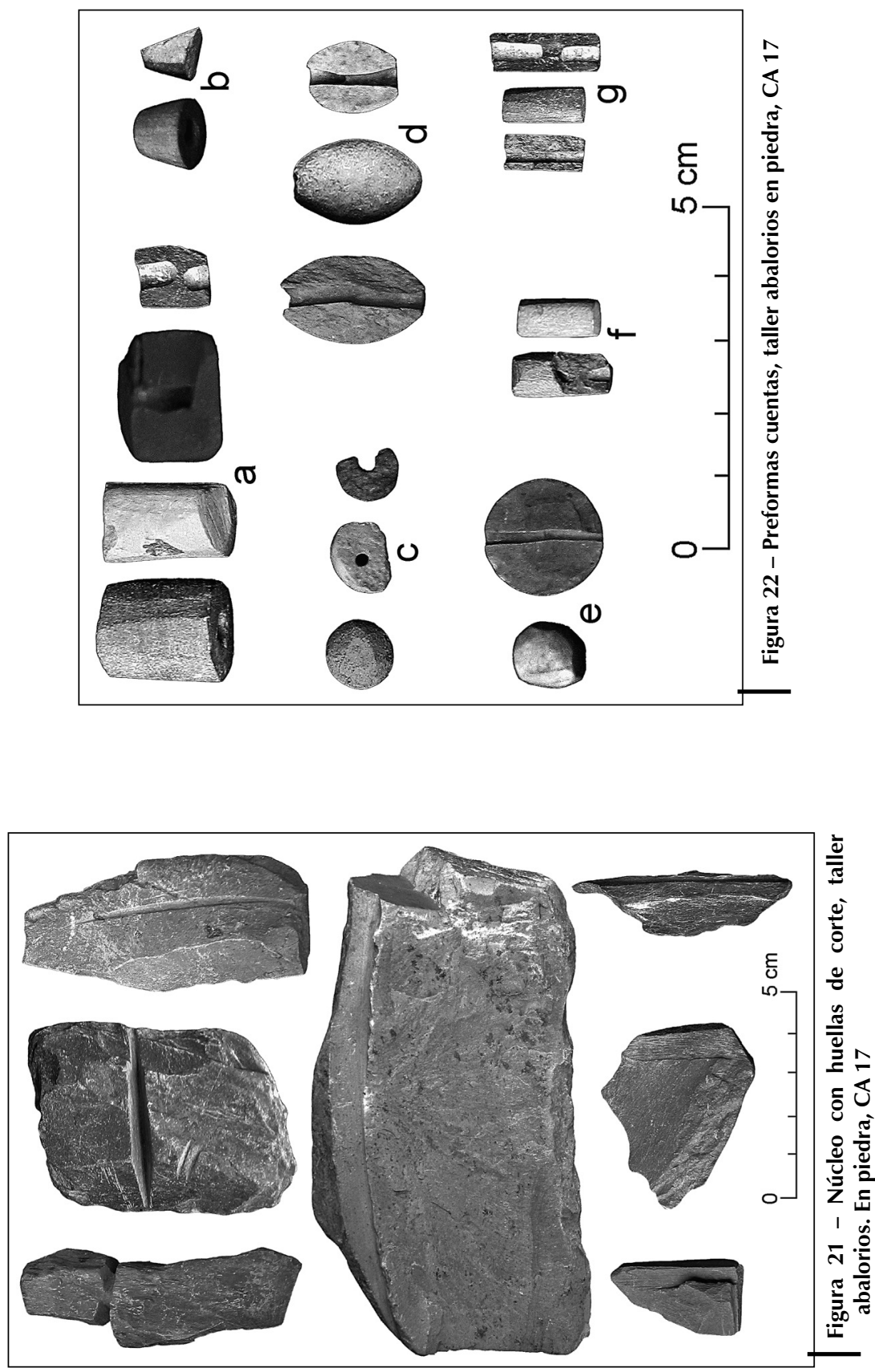


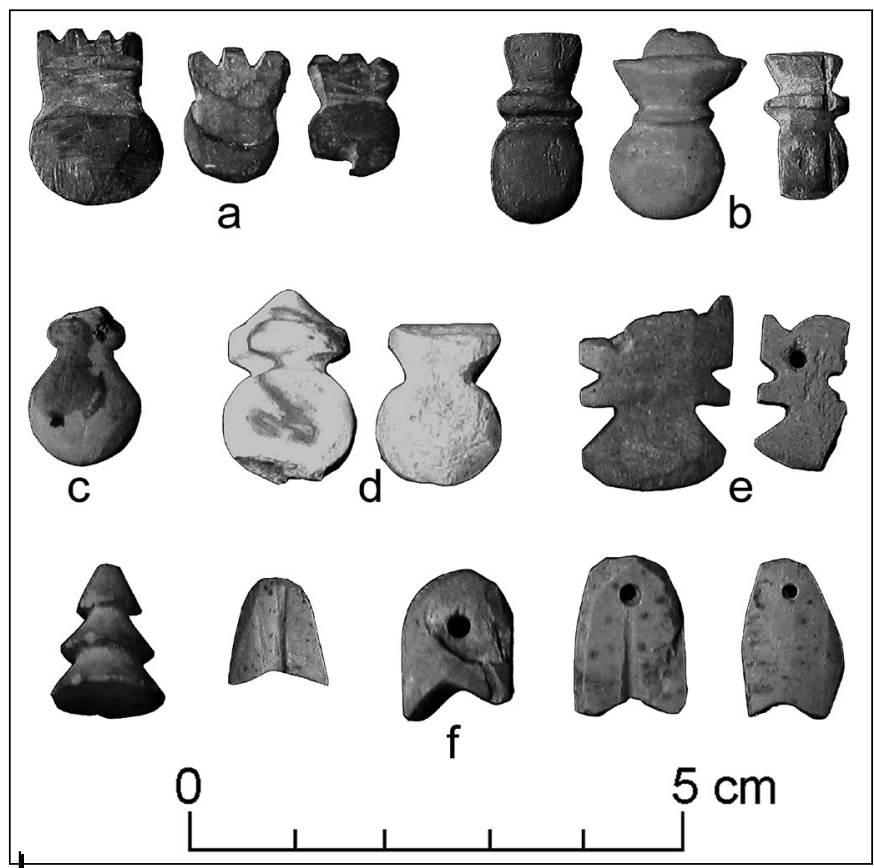

Figura 23 - Preformas colgantes, taller abalorios en piedra, CA 17

perforación; también contamos con las de perforación concluida que aún no presentan el pulido final y algunas se han fracturado durante este proceso. Cabe mencionar que en el caso de los colgantes la perforación se realiza en su mayoría por un solo lado.

Los objetos terminados están conformados por las cuentas y los colgantes (fig. 24). Las cuentas presentan mayormente color gris oscuro, gris claro, rojo y beige; asimismo son del tipo cilíndrico, cónico, discoidal y elipsoidal. En cuanto a los colgantes, los colores predominantes son el gris claro, gris oscuro y beige; de igual manera predominan las representaciones fitomorfas, principalmente las formas de grano, pallar y ulluchu.

Los desechos de talla están conformados por las lascas, las cuales son abundantes en este conjunto arquitectónico; estas se encuentran en muchos casos cortadas por uno o ambos lados, presentan huellas de corte en su superficie y son esencialmente de colores gris claro, gris oscuro, rojo o beige.

La cantidad y variedad de material recuperado nos indican que la producción se hizo a gran escala y que en ella se empleó una mano de obra especializada, aunque algunos errores técnicos en algunos objetos señalan la presencia de aprendices dentro del taller.

Área administrativa. Colinda por su lado oeste con las dos áreas antes descritas. Se ha considerado como un área administrativa por la ausencia de actividad doméstica de cocina y por la presencia de un patio con banquetas a desnivel 


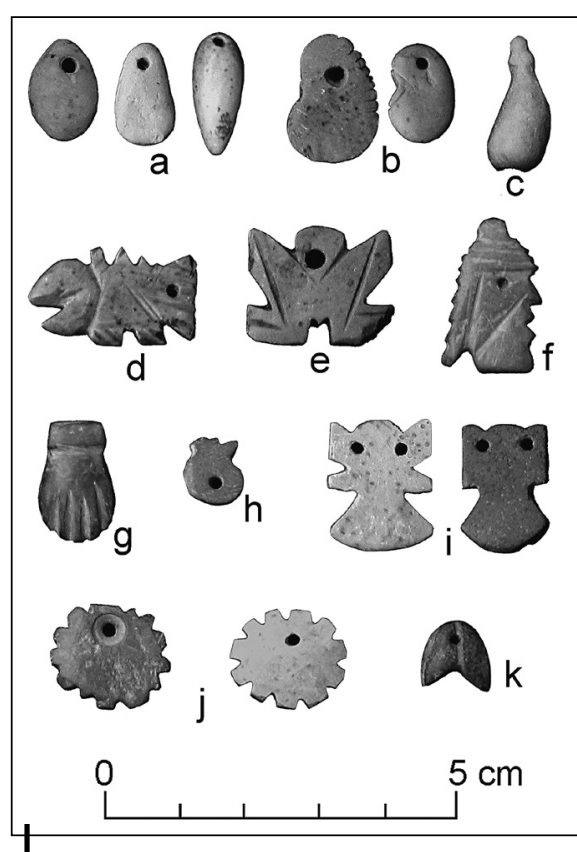

Figura 24 - Pendientes terminado, taller abalorios en piedra, CA 17

a la entrada de otro espacio en forma de «L». En la parte sur de este patio se registraron tres grandes tinajas empotradas en el piso que sirvieron como contenedores de líquido, probablemente chicha, para ser usada en actos rituales relacionados con el personal ligado a los talleres o al intercambio de productos. Completa esta área la presencia de tres ambientes que pueden ser considerados como ambientes para el descanso.

La distribución de cerámica por actividades presenta valores bajos en general, pero de ellos destaca la actividad de almacenaje de chicha, seguido por la actividad doméstica y en mejor medida la ritual, producción de cerámica y tejidos (fig. 19). Se debería esperar un mayor porcentaje en almacenaje y actividad ritual. Pero, al examinar los recursos alimenticios de origen animal recuperados, vemos que la diversidad de ellos, así como la presencia en buen porcentaje de restos de mamíferos (fig. 20) nos indican que la gente que ocupó este espacio tenía acceso a ellos y, por lo tanto, poseía un estatus elevado.

Taller de cerámica. Se ubica en la parte noroeste del bloque arquitectónico o manzana. Ocupa un área extensa, pero que ha sufrido muchas alteraciones por acción de las excavaciones clandestinas y escorrentía antiguas. Estas alteraciones no han permitido definir los muros en la esquina noroeste y no es claro si el acceso a esta área se realizaba por su lado oeste - con ello tendría directa comunicación con la plaza 4- o por el lado norte, desde el callejón. Al igual que en los otros talleres no se ha encontrado espacios destinados a la preparación de alimentos. Este taller está compuesto de un amplio espacio abierto que ocupa una quinta parte de la superficie de esta área y dos concentraciones de estructuras ubicadas en la esquina noreste y la sureste.

La primera consiste en dos ambientes, uno con una comunicación directa con el patio y el otro en relación con el primer ambiente y presentando una banqueta amplia en donde se registró una tinaja empotrada en el piso de la banqueta. Si bien es cierto no se ha registrado evidencia de objetos en cerámica cruda o arcilla, o pasta en proceso de preparación, la morfología de estos espacios comparada con aquellos estudiados etnográficamente en Morrope (Shimada, 1994: fig. 10) nos permite postular que estos espacios, y en particular la banqueta, se usaron para preparar la masa de arcilla y dejarla madurar antes de elaborar los objetos. Estos ambientes debieron estar 
techados, muy posiblemente a manera de una ramada. Los ambientes de la esquina sureste, más aglutinados y concentrados, pudieron ser usados como depósitos, en particular aquellos más pequeños.

Dos manchas de quemas, una ubicada en el patio principal y ocupando la parte central norte $y$, la segunda, en el ambiente abierto de la esquina noreste, serían huellas dejadas por hornos abiertos de alfarería, como se atestigua por la presencia de cerámica recocida registrada in situ.

De los materiales registrados se desprende la información del cuadro 4; este taller estuvo dedicado a la fabricación de ornamentos personales, tales como cuentas, colgajos, pendientes, figurinas y miniaturas. La presencia de moldes no es abundante si las comparamos con aquellas encontradas en el taller alfarero registrado en 1994 (Uceda \& Armas, 1997). Es interesante ver en este cuadro que la mayor concentración de moldes, cuentas, así como matriz, plato y disco de alfarero se registran en el ambiente 3 del subcojunto 21-2; es decir, lo que nosotros estamos denominando el área de taller de alfarero. Una segunda concentración de estos materiales se registra en los ambientes 21-12 y 21-13, aquel sector de estructuras que estamos proponiendo como área para el reposo de la pasta y la elaboración. A esta primera evidencia debe sumarse que, para sectores del taller (patio y zona trabajo), también se registraron objetos de hueso y piedra (cuadros 5, 6) como alisadores, punzones, perforadores, etc., que conforman los instrumentos típicos en los talleres de alfareros (Shimada, 1994).

El proceso productivo, a partir de los espacios arquitectónicos descritos así como los materiales e instrumentos asociados, nos indica que aquí se debió preparar la masa para la cerámica, dejarla descansar, para luego, usando moldes (figs. 25, 26) o modelando la arcilla, confeccionar los diversos objetos deseados (figs. 27, 28). La cocción no requirió de la construcción de hornos sofisticados; una simple cubeta, poco profunda, fue suficiente para ser usada como horno para quemar la cerámica. La mancha de ceniza en el patio de este taller, por sus dimensiones, bien pudo servir para quemar cerámica de grandes dimensiones como tinajas. Por los restos de carbones recuperados, se sabe que se usó madera de algarrobo como combustible. Los productos fueron almacenados y luego distribuidos o puestos a intercambio.

Al examinar la distribución de la cerámica por actividades, es impresionante el porcentaje de cerámica destinada a las actividades productivas de cerámica rituales, de almacenaje y domésticas (fig. 19). Tratándose de un taller, la diversidad de cerámica en diversas formas no debe ser indicador de actividades diversas, sino de producción de formas diversas. Sin embargo, es interesante resaltar que en la dieta de esta área del bloque arquitectónico, dominan ampliamente los peces, mamíferos y moluscos (fig. 20). 


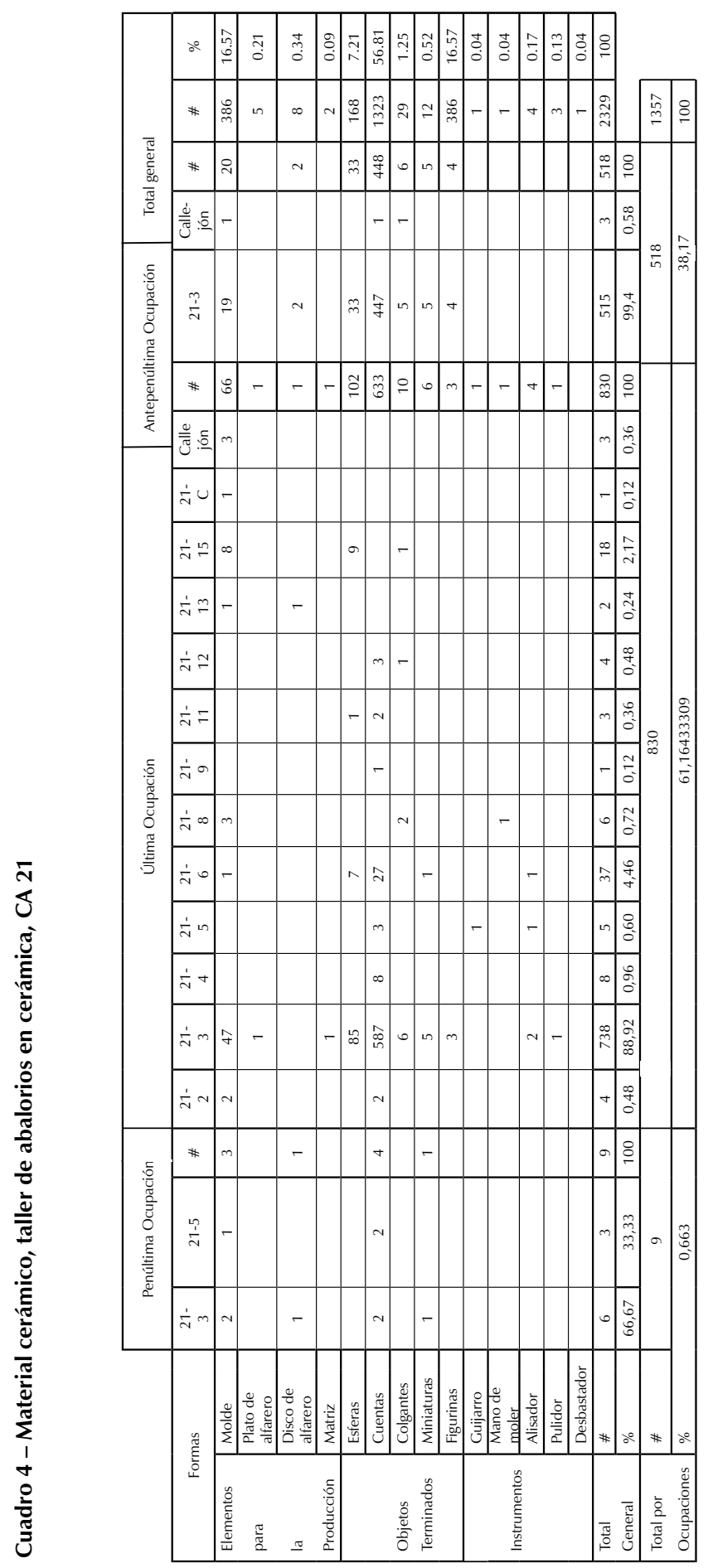


Santiago Uceda Castillo

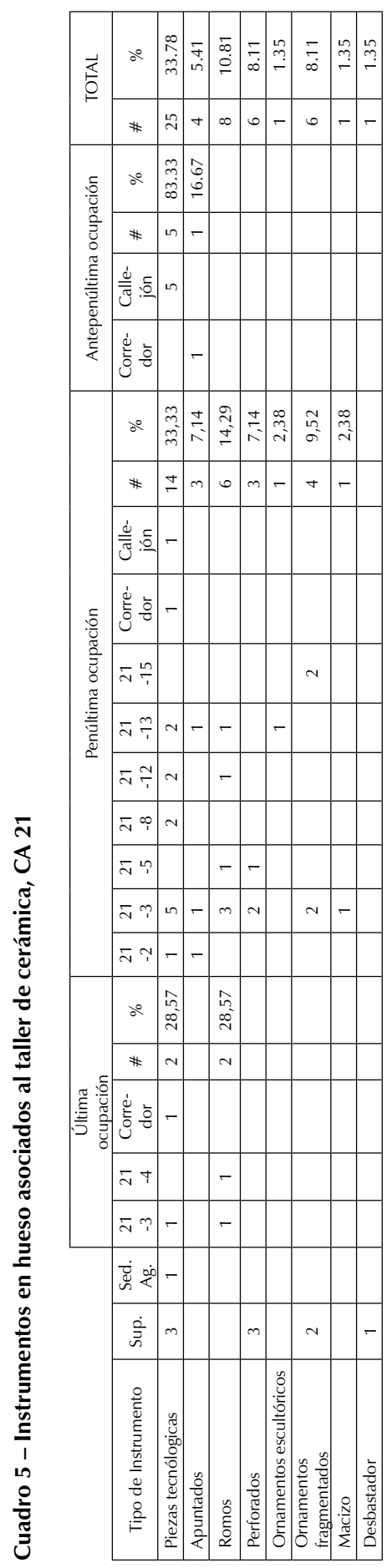

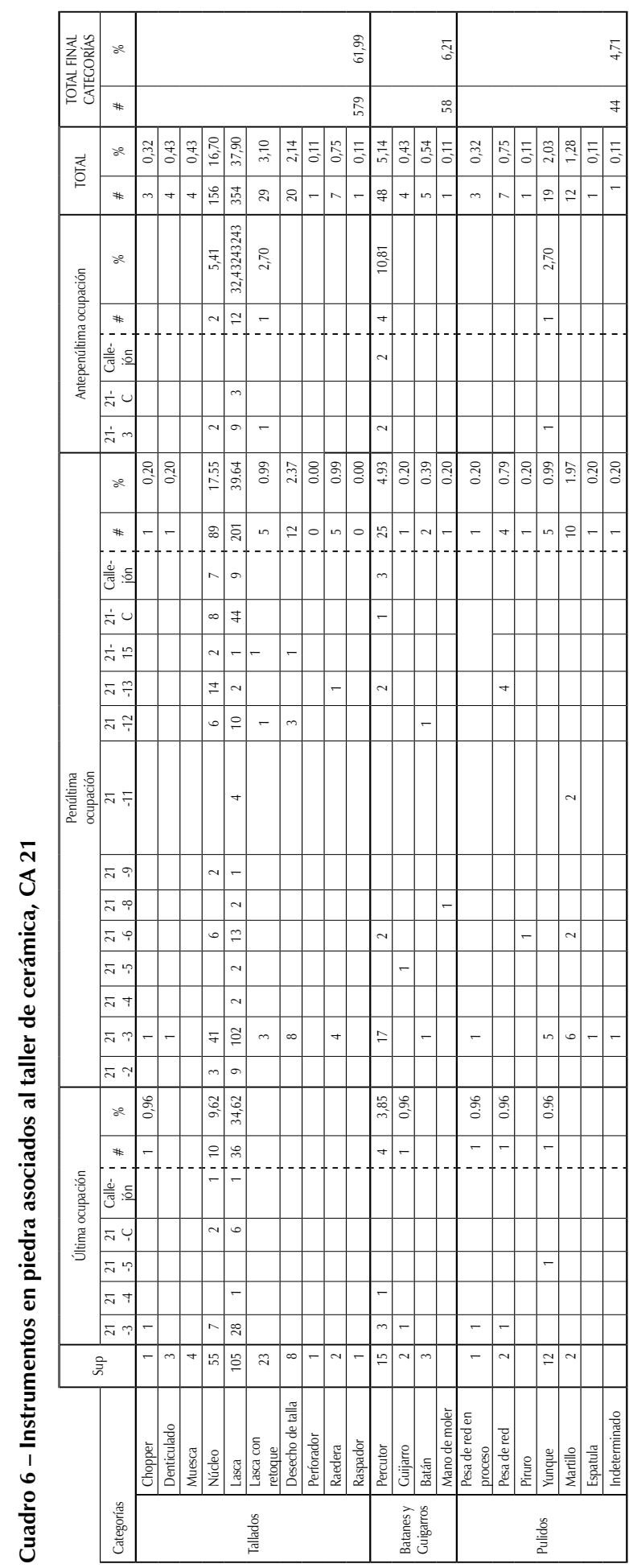


Los contextos urbanos de producción artesanal en las huacas del Sol y de la Luna:

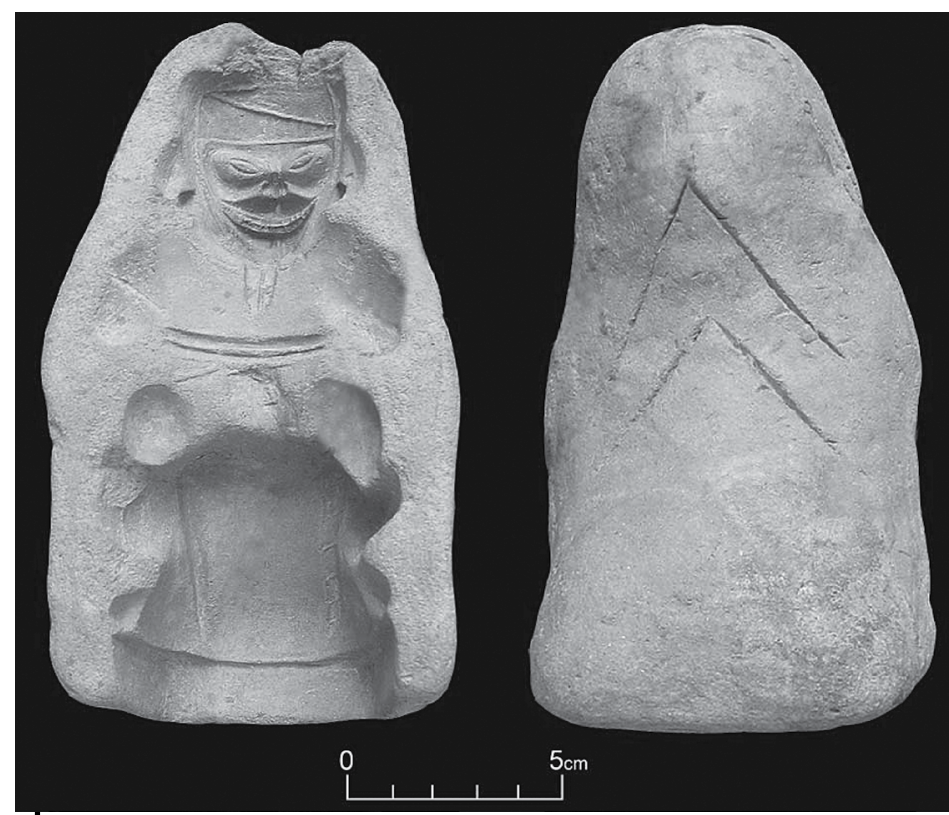

Figura 25 - Molde bivalvo figurina, taller abalorio en cerámica, CA 21

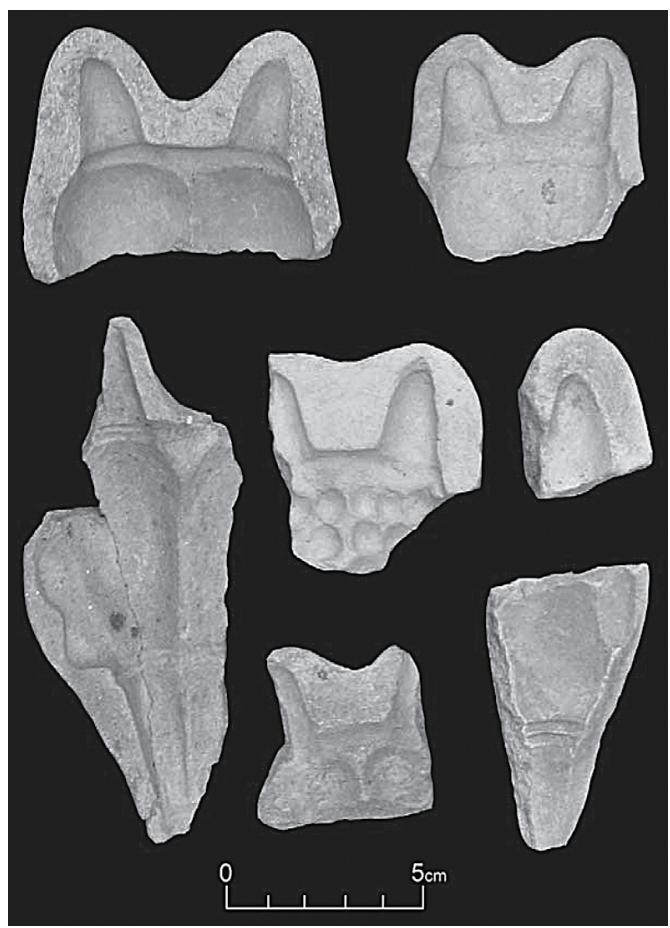

Figura 26 - Moldes diversos, taller abalorio en cerámica, CA 21 


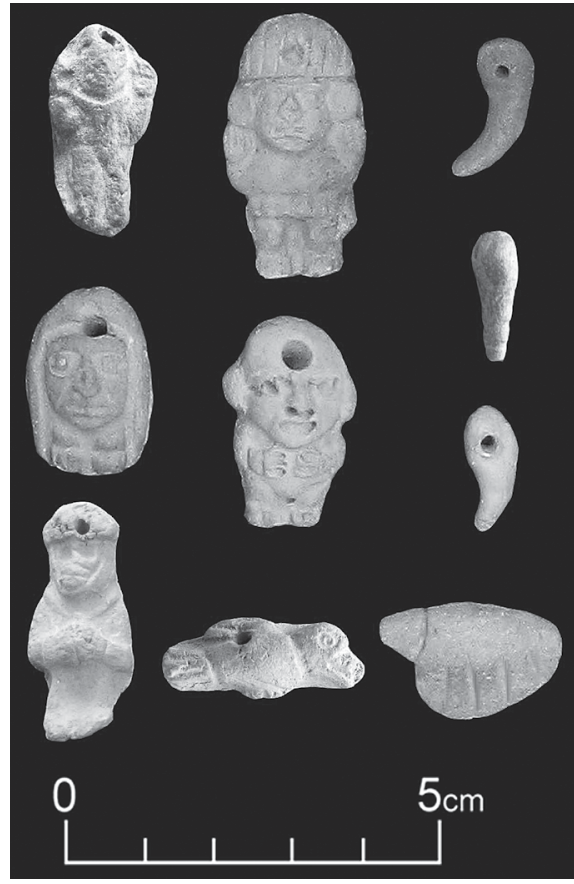

Figura 27 - Pendientes, taller abalorio en cerámica, CA 21

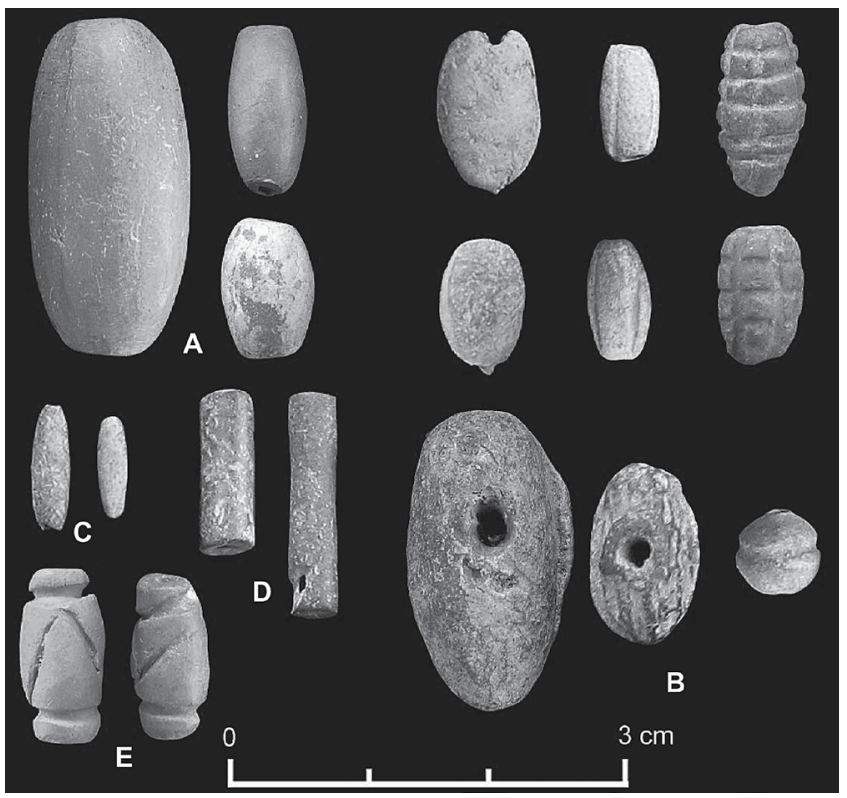

Figura 28 - Cuentas, taller abalorio en cerámica, CA 21 


\section{DISCUSIÓN}

Nuestro estudio pretende poner en perspectiva social la información recuperada en los contextos del Núcleo Urbano del complejo arqueológico de las huacas del Sol y de la Luna. Para ello vamos a examinar esta información desde tres puntos de vista: el primero es la forma de planificación urbana tardía en este complejo y sus implicancias sociales; luego veremos los talleres artesanales dentro del contexto urbano, para discutir la estructura social de ellos en la sociedad tardía moche; finalmente, veremos las implicancias sociopolíticas que se pueden extraer de la presencia de los bloques arquitectónicos o manzanas del Núcleo Urbano como una forma especial de organización urbana.

\section{1. La planificación urbana y organización social}

La forma de organizar el espacio urbano, al igual se organiza una edificación, responde a las necesidades y tradiciones culturales de los pueblos. Hemos visto que la sociedad moche, a partir del año 600 de nuestra era, introduce una serie de cambios en la forma de organizar el espacio urbano en la ciudad de las huacas del Sol y de la Luna. Claramente aparecen bloques de edificaciones cada una con funciones bien específicas y a todas luces complementándose entre sí. Los dos casos estudiados, y que hemos denominado con fines de estudio bloques arquitectónicos 1 y 2, presentan características comunes como diferencias que los singularizan.

La presencia dentro de cada bloque arquitectónico de una residencia principal con un patio con banquetas, otorga a este espacio un estatuto elevado. No es ilógico pensar que este espacio estuvo destinado a reuniones donde el señor de esta vivienda atendía a invitados o realizaba un sin número de festines y ceremoniales, a través de los cuales le permitían el control y sustento de su poder político en el seno de la sociedad moche. Es conocido en la literatura arqueológica el rol de los ceremoniales y festines que los curacas organizaban para establecer lazos de lealtad y reciprocidad (Millones \& Onuki, 1994). Los otros espacios con presencia de grandes fogones para la preparación de chicha o alimentos, depósitos y talleres de producción, indican que estuvieron bajo control del señor de la residencia principal. ¿Cómo debemos entender esta forma de organización del espacio urbano tardío en este sitio? ¿Este cambio de organización reflejaría cambios en la organización social moche?

En otra ocasión, cuando presentábamos la estructura del primer bloque arquitectónico identificado (Uceda, 2005), propusimos la hipótesis que se trata de un espacio urbano relacionado con la presencia de un grupo corporativo. El concepto abarcó una gran variedad de formas y naturaleza de estos grupos; en sociedades del pasado se pueden restringir a grupos ligados al templo, al palacio o linajes familiares. El hecho que, justo por ese tiempo, el templo de la huaca de la Luna sea abandonado y se construya la huaca del Sol, como símbolo del poder del palacio, nos lleva a descartar que estos grupos estén ligados al templo. Los grupos 
corporativos ligados al templo o palacio en el Medio Oriente, por lo general están dentro del templo o el palacio en áreas específicas, pues ellos dependen de los intereses de quienes tienen el manejo del templo o del palacio. En nuestro caso, los bloques arquitectónicos se presentan como unidades urbanas que pueden estar ligadas a estructuras sociales menores en la jerarquía social moche. ¿Quiénes serían estos señores que los controlaban, de quiénes dependían y cuál sería la relación entre los artesanos y los señores que controlaban los bloques?

La presencia de tumbas ricas en ajuares funerarios en una de estas residencias (bloque arquitectónico 2, subconjunto 1 del CA35) indica que estos individuos eran de un nivel social alto, en quienes se unían poderes económicos, políticos y religiosos. La presencia de tumbas tan estandarizadas como las encontradas en la huaca de la Luna, figurinas e instrumentos musicales indican que en estas residencias se desarrollaron ceremoniales y quizás rituales emulando aquellos que se hicieron en el templo, cuando este estuvo vigente. Tal como sostuviéramos anteriormente (Uceda, 2005), la caída del templo y su viejo sistema político hizo que muchas de las ceremonias que antes presidían los sacerdotes del Templo Antiguo las realicen en este momento los señores residentes en el Núcleo Urbano. No podemos descartar que estos nuevos señores hayan estado previamente relacionados o formando parte de la élite religiosa. Pero, tal como hemos mostrado anteriormente, las evidencias documentadas en los dos bloques arquitectónicos nos llevan a pensar que los artesanos que estaban inmersos en estos espacios urbanos tenían acceso a igual tipo de alimentos y menajes que los encontrados en la residencia principal. Es pues viable sostener que se trata de individuos ligados directamente a la elite con altos privilegios, sino es que formaron parte de ella. En el caso de los artesanos que producen los abalorios en piedra, se puede pensar que tuvieron un nivel menor, pues poseían viviendas familiares, mientras que en los otros casos no. La ausencia de áreas de cocina directamente ligadas a los talleres corresponde exactamente a lo observado por Shimada en Pampa Grande en la Estructura 52 del sector $\mathrm{H}$, para un taller de orfebrería. Esta información nos indica que quienes trabajaban aquí dependían para su subsistencia de una estructura social y política por encima de ellos; se trata de artesanos dependientes. Volveremos sobre este tema en el siguiente acápite.

\section{2. Los talleres artesanales y su estructura social}

La presencia de talleres artesanales en el sitio de las huacas del Sol y de la Luna, no solo se pone de manifiesto por el volumen de material que se producía en ellos, sino por una serie de evidencias, como la especialización de las áreas productivas, la presencia de estos talleres en varios pisos de ocupación dentro del mismo bloque arquitectónico. El carácter y naturaleza de estos artesanos especialistas no son muy claros, pues la evidencia que conocemos es muy fragmentada. ¿A qué nivel de especialidad Ilegaron los artesanos moches? La respuesta a esta interrogante puede ser dada parcialmente tomando como referencia los pocos contextos de producción registrada. Si tomamos en consideración las cadenas operativas, el 
primer elemento a tomar en cuenta es de dónde y quién les provee la materia prima. Con respecto al «de donde», no existen estudios exhaustivos sobre el tema; sabemos que, por ejemplo, el caolín no se encuentra en la costa y que esta materia prima viene de la sierra. Del mismo modo, no conocemos cerca al valle bajo yacimientos de cobre, pero sí una mina de oro cerca de Salaverry. Es pues de suponer que para estos materiales hayan existido grupos de especialistas para su extracción, y la distribución se hacía a través de los señores que controlaban los bloques arquitectónicos. Salvo en el caso del taller de metalurgia, que estaría asociado sólo a las fases finales de producción de objetos en metal, la cadena productiva para cada una de las otras parcialidades artesanales aquí descritas se realizó completamente dentro de un solo taller.

La variedad de productos y calidad registrada en estos talleres nos permiten sostener que no solo permitían el aprendizaje de los oficios sino que en ellos hubo una escala de «saber hacer las cosas», donde no se puede descartar especialistas en una o dos partes del proceso, como por ejemplo, los acabados de los objetos, que requieren de técnicas más complejas y el uso de artefactos más especializados. En este mismo sentido podemos incluir aquellos artesanos que formaron parte de la elite y que tenían el control de los mensajes a transmitir y que serían plasmados en algunos de estos productos, me refiero en particular a las escenas iconográficas representadas en la cerámica.

Por otro lado, sabemos que los artesanos especialistas se dividen en dos grandes tipos, considerando su forma de producir a nivel social: por un lado, están los artesanos libres o independientes, quienes producen sus bienes para un mercado que ellos no controlan, pero participan a fin de conseguir, a cambio de sus productos, o dinero o bienes de consumo para su propia manutención. En el Medio Oriente, la ciudad de Ur paleo babilónica es el único caso donde se tiene evidencia de barrios de especialistas. Para épocas posteriores y en otras ciudades se han registrado un conjunto de talleres con una administración única (Postgate, 1999). En Chan Chan, Topic (1990) nos documenta sobre un grupo de artesanos que vivió en barrios separados de los centros de poder político y religioso dentro de la ciudad. Este no es el caso que hemos descrito para la ciudad de las huacas del Sol y de la Luna. Recordemos que, para Chan Chan, los artesanos ubicados en barrios poseían cada uno una vivienda familiar, y un señor controlaba al grupo de artesanos de un barrio. Es pues fácil de pensar, como lo señalan las crónicas, que estos artesanos no eran típicamente independientes, pues dependieron de un cacique quien administraba los bienes y productos; los artesanos no dependían de los templos ni tributaban directamente al palacio. Se trataría de grupos incrustados (Ames, 1995), relacionados por vínculos de parentesco. En el caso de los artesanos dependientes, siguiendo la información de Topic (1990), correspondería a lo que este investigador llama los servidores (reteiners). En este caso, los artesanos llamados independientes no deben considerarse como aquellos del viejo mundo, pues su producción estuvo controlada por jefes de parcialidades.

Para poder caracterizar a qué tipo correspondían los artesanos de los talleres tardíos del Núcleo Urbano de las huacas del Sol y de la Luna, podemos usar, 
en primer nivel, el contexto arqueológico. Estos talleres se encuentran dentro de complejos urbanos dominados por una vivienda de elite; en este sentido, es plausible considerar que se trata de una forma de organización del tipo adjunta y adscrita, tal como lo ha propuesto Gayoso (2008). En ninguno de los tres talleres aquí descritos se ha registrado actividad doméstica, pero sí la de consumo de alimentos, es decir que su alimentación les era proveída por terceros. En los bloques estudiados las cocinas están relacionadas con la residencia de elite y en otros casos a cocinas comunes. A este nivel de nuestro conocimiento no podemos responder a qué tipo de adscripción correspondió el estatus de los artesanos moche en la época tardía en el sitio Moche. Es posible que algunos individuos con ciertas habilidades artesanales hayan sido reclutados de sus parcialidades por los señores Moche que residían en los bloques arquitectónicos. No debemos olvidar que en este momento el estado Moche sureño había colapsado y los territorios conquistados dejaron de ser controlados; es probable que estos artesanos provenían de estos territorios, así como los señores que los controlaban. Se trata de meras especulaciones que deberán ser confirmadas con futuras investigaciones. Por otro lado, si consideramos las diversas cadenas operacionales y los símbolos que en algunos productos se transmitían, en particular aquellos que contienen ideas religiosas o de cosmovisión, bien podemos suponer que estos elementos fueron confeccionado por especialistas que manejaron la ideología moche, es decir, miembros de la elite moche. Todo este panorama nos indica que en un taller moche pudo haber varios tipos de artesanos con estatutos diferentes. En este sentido, los artesanos moche, considerando su forma de organización social, deben considerarse como una fase intermedia entre los artesanos dependientes del templo y una forma independiente de los barrios chimúes de Chan Chan.

\section{3. Implicancias sociopolíticas de los bloques arquitectónicos o manzanas en el Núcleo Urbano}

Es evidente que la presencia de este tipo de organización urbana tiene relación directa con los cambios mayores que pasó la sociedad moche entre el 600 y 850 d.C. La forma de organización sociopolítica de la sociedad moche temprana, como un Estado teocrático centralizado y expansivo, implica que el Estado se organizara a través de los ceremoniales y rituales que se realizaban en los templos para legitimizar el poder político de la elite dominante. El estatuto de los individuos se definía por el rol que ocupaban en las ceremonias religiosas; cada rol se diferenciaba tanto por la parafernalia que poseían como por el tipo de atuendos y adornos que portaban durante estas ceremonias. De aquí que la producción de estos elementos de prestigio debía estar controlada por la elite religiosa o también podía ser que los artesanos formaran parte de la elite moche.

En las sociedades civiles, donde el poder político está separado del religioso, aunque mantengan una íntima relación, la producción de bienes suntuarios se adscribió al palacio y los bienes que no lo eran fueron producidos por artesanos libres. Solo en sociedades que desarrollaron los mercados como centros de 
distribución e intercambio se puede observar la presencia de artesanos libres que intercambian sus productos a través de otros especialistas, los mercaderes y los mercados.

En una sociedad en tránsito de una forma de organización a otra, es de esperar que la evidencia material que documenta la arqueología, nos muestre de cierta manera formas intermedias entre los modelos extremos. Esto parece ser el caso que ahora discutimos. En los bloques arquitectónicos, los artesanos formaban parte de un grupo de linaje dominado por un señor que controlaba tanto los bienes suntuarios como de consumo cotidiano. Estos señores pudieron ser los intermediarios de la producción de los talleres tanto en la distribución al interior de la misma ciudad como fuera de ella.

Cuando presentamos por primera vez la existencia de estos bloques arquitectónicos, también se indicó la presencia de plazas articulando o asociadas a estos bloques arquitectónicos y propusimos (Uceda, 2005) que podrían corresponder a áreas dedicadas a la distribución de los bienes producidos en los talleres. Con las nuevas evidencias disponibles, podemos decir que estas áreas solo se pudieron utilizar para la distribución de bienes de consumo cotidiano. Los bienes suntuarios formaron parte de la red de intercambio recíproco de las elites urbanas, como una manera de distinción y rango.

Es evidente que nuestra percepción de la organización social y política moche es aún fragmentaria, si usamos la evidencia contextual arqueológica que la apoye. Las nuevas investigaciones, no dudamos, irán ampliando nuestro conocimiento y perfeccionándolo.

\section{CONCLUSIONES}

Las investigaciones actuales realizadas en el sitio de las huacas del Sol y de la Luna nos han permitido hacer algunas modificaciones a nuestro conocimiento que se tenía de este sitio.

Sabemos que existen dos grandes momentos en su historia social y política en este sitio de la sociedad moche: un primer momento de desarrollo de estado teocrático y una final de tránsito a un sistema social político civil.

Creemos que la reorganización de la planificación urbana en el sitio refleja este momento de cambios y búsqueda de nuevas formas de organización social, donde el poder del templo se traslada a los residentes de la zona urbana, quienes no solo asumen roles de producción de bienes de consumo suntuario y cotidiano, sino roles en ceremoniales y distribución de dichos bienes.

Los artesanos se adscribieron a grupos de linajes de la elite urbana, manteniendo un rol y estatus social elevado, considerando que ellos tenían acceso a los mismos productos alimenticios que los señores que vivían en las residencias principales de cada bloque arquitectónico. 


\section{Referencias citadas}

ALVA, W., 1994 - Sipán, 331 pp.; Lima: Cervecería Backus \& Johnston S. A. J. A. de Lavalle, editor. Colección Cultura y Artes del Perú.

AMES, K. M., 1995 - Chiefly Power and Household Production on the Northwest Coast. In: Foundation of Social Inequatily (T. Douglas \& G. M. Feinman, eds.): 155-187; New York: Plenum Press.

ARMAS, J., 1999 - Talleres Alfareros Moche: secuencia y estructura espacial, Complejo Arqueológico Huacas del Sol y de la Luna. Proyecto de investigación para optar por el título de Licenciado en Arqueología; Trujillo: Universidad Nacional de Trujillo, Facultad de Ciencias Sociales, Escuela de arqueología.

AGURTO, S., 1987 - Estudio acerca de la construcción, arquitectura y planeamiento Incas, 295 pp.; Lima: Cámara peruana de la construcción.

BAWDEN, G.,1994 - La paradoja estructural: la cultura Moche como ideología política. In: Moche: propuestas y perspectivas (S. Uceda \& E. Mujica, eds.): 389-412; Lima: Universidad de La Libertad-Trujillo, Instituto Francés de Estudios Andinos, Asociación Peruana para el Fomento de las Ciencias Sociales. Actas del Primer Coloquio sobre la Cultura Moche (Trujillo, 12 al 16 de abril de 1993).

BENSON, E., 2003 - Cambios de temas y motivos en la cerámica moche. In: Moche: hacia el final del milenio (S. Uceda \& E. Mujica, eds.): 477-495, tomo I; Lima: Universidad Nacional de Trujillo, Pontificia Universidad Católica del Perú. Actas del Segundo Coloquio sobre la Cultura Moche (Trujillo, 1 al 7 de agosto de 1999).

BERNIER, H., 1998 - L'usage de la parure corporelle dans la culture Moche du Pérou précolombien et le cas du site Moche, capitale urbaine; Montreal: Universidad de Montreal, Departamento de Antropología. Tesis de maestría.

BERNIER, H., 1999 - Cuentas geométricas: características morfológicas y tecnológicas en el sitio Moche. Revista Arqueológica Sian, 8: 24-27; Trujillo.

BERNIER, H., 2005 - Étude Archéologique de la production artisanale au site Huacas de Moche, côte nord du Pérou; Montreal: Universidad de Montreal, Facultad de Estudios Superiores. Tesis Doctoral.

BERNIER, H., 2008 - Especialización artesanal en el sitio Huacas de Moche: contextos de producción y función sociopolítica. In: Arqueología Mochica: nuevos enfoques (L. J. Castillo, H. Bernier, G. Lockard \& J. Rucabado Yong, eds.): 33-51; Lima: Fondo Editorial de la Pontificia Universidad Católica del Perú, Instituto Francés de Estudios Andinos. Actas del Primer Congreso Internacional de Jóvenes Investigadores de la Cultura Mochica (Lima, 4 y 5 de agosto de 2004).

BRUMFIEL, E. M., 1980 - Specialization, market exchange, and the Aztec state: a view from Huexotla. Current Anthropology, vol. 21 (4): 459-467.

BRUMFIEL, E. M., 1998 - The multiple identities of aztec craft specialists. In: Craft and social identity (C. L. Costin \& R. P. Wright, eds.): 145- 152; Arlington: Archaeological papers of the American Anthropological Association n. ${ }^{\circ} 8$.

BRUMFIEL, E. \& EARLE, T., 1987 - Specialization, market exchange, and complex societies: an introduction. In: Specialization, exchange and complex societies: 1-9; Cambridge: Cambridge University Press.

CHAPDELAINE, C., 1998 - Excavaciones en la Zona Urbana de Moche durante 1996. In: Investigaciones en la Huaca de la Luna 1996 (S. Uceda, E. Mujica \& R. Morales, eds.): 85-115; Trujillo: Facultad de Ciencias Sociales de la Universidad Nacional de La Libertad-Trujillo. 
Los contextos urbanos de producción artesanal en las huacas del Sol y de la Luna:

CHAPDELAINE, C., 2001 - The Growing Power of a Moche Urban Class. In: Moche Art and Archaeology in Ancient Peru (J. Pillsbury, ed.): 69-87; Washington, D.C.: Center for Advanced Study in the Visual Arts, Symposium Papers XL, National Galery of Art. Studies in the History of Art 63.

CHAPDELAINE, C., 2002 - Out of the streets of Moche: Urbanism and sociopolitical organization at a Moche IV urban center. In: Andean Archaeology I: Variations in Sociopolitical Organization (William H. Isbell \& Helaine Silverman, eds.): 53-88; New York-Londres: Kluwer Academic, Plenium Publishers.

CHAPDELAINE, C., 2003 - La ciudad de Moche: urbanismo y estado. In: Moche: hacia el final del milenio (S. Uceda \& E. Mujica, eds.): 247-285, tomo II; Lima: Universidad Nacional de Trujillo, Pontificia Universidad Católica del Perú. Actas del Segundo Coloquio sobre la Cultura Moche (Trujillo, 1 al 7 de agosto de 1999).

CHAPDELAINE, C., BERNIER, H. \& PIMENTEL, V., 2000 - Investigaciones en el área urbana Moche. In: Investigaciones en la Huaca de la Luna 1998-1999 (S. Uceda \& R. Morales, eds.): 85-142; Trujillo: Facultad de Ciencias Sociales de la Universidad Nacional de Trujillo.

CHAPDELAINE, C., KENNEDY, G. \& UCEDA, S., 2001 - Neutron Activation Analysis of Metal Artifacts from the Moche Site, North Coast of Peru. Archaeometry, 43 (3): 373-391.

CHAUCHAT, C. \& HERRERA, B., 2003 - La presencia moche temprano en la sección 1 de la Huaca del Sol, valle de Moche. In: Moche: hacia el final del milenio (S. Uceda \& E. Mujica, eds.): 189-216, tomo I; Lima: Universidad Nacional de Trujillo, Pontificia Universidad Católica del Perú. Actas del Segundo Coloquio sobre la Cultura Moche (Trujillo, 1 al 7 de agosto de 1999).

CHIGUALA, J., 2004 - La Plaza 3. In: Proyecto Arqueológico Huaca de la Luna, Informe Técnico 2003 (S. Uceda \& R. Morales, eds.): 153-173; Trujillo: Facultad de Ciencias Sociales de la Universidad Nacional de La Libertad-Trujillo.

CHIGUALA, J., ALMONACID, C., ORBEGOSO, M., ROJAS, D. \& SANDOVAL, M. C., 2006 - La integración funcional de los Conjuntos Arquitectónicos 17 y 35 como parte de un Bloque Arquitectónico en el Núcleo Urbano. In: Proyecto Arqueológico Huaca de la Luna. Informe Técnico 2005 (S. Uceda \& R. Morales, eds.): 138-206; Trujillo: Facultad de Ciencias Sociales de la Universidad Nacional de Trujillo.

CHIGUAlA, J., GAMARRA, N., GAYOSO, H., PRIETO, G., RENGIFO, C., \& ROJAS, C., 2004 - Dinámica ocupacional del Conjunto Arquitectónico 27-Núcleo Urbano del Complejo Arqueológico Huacas del Sol y de la Luna. In: Proyecto Arqueológico Huaca de la Luna, Informe Técnico 2003 (S. Uceda \& R. Morales, eds.): 83-152; Trujillo: Facultad de Ciencias Sociales, Universidad Nacional de Trujillo.

CHILDE, V. G., 1954 - Los orígenes de la civilización, 291 pp.; México: Fondo de Cultura económica.

COSTIN, C. L. \& EARLE, T., 1989 - Status Distinction and Legitimation of Power as Reflected in Changing Patterns of Consumption in Late Prehispanic Peru. American Antiquity, 54 (4): 691-714.

COSTIN, C. L. \& WRIGHT, R. P. (eds.) 1998 - Craft and social identity. Archaeological papers of the American Anthropological Association, n. ${ }^{\circ}$ 8: 173 pp.; Arlington.

DUNNING, N., 2000 - ¿Lento declive o nuevo comienzo? El cambio de la civilización Maya clásica en la región de Puuc. In: Los Mayas: Una civilización milenaria. (N. Grube, ed.): 323-337; Colonia: Könemann Verlagsgellschaft mbH. 
ESPINOZA, W., 1975 - El valle de Jayanca y el reino de los Mochica, siglos XV y XVI. Bulletin de l'Institut Français d'Études Andines, 4 (3-4): 243-74; Lima.

GAMARRA, N., GAYOSO, H., PRIETO, G., RENGIFO, C. \& ROJAS, C., 2004 - Dinámica ocupacional del Conjunto Arquitectónico 27-Núcleo Urbano del Complejo Arqueológico Huacas del Sol y de la Luna; Trujillo: Universidad Nacional de Trujillo, Facultad de Ciencias Sociales, Escuela de arqueología. Informe de Prácticas Pre Profesionales.

GARCÍA, E., MARINO, W. \& TUFINIO, M., 1994 - Secuencia constructiva de la Plataforma III de Huaca de la Luna; Trujillo: Universidad Nacional de Trujillo, Facultad de Ciencias Sociales, Escuela de arqueología. Informe de Prácticas Pre Profesionales (Tesina).

GARCILASO DE LA VEGA, Inca, 1943 [1609] - Comentarios Reales de los Incas. Buenos Aires: Emecé Editorial.

GAYOSO, H., 2008 - Tejiendo el poder: los especialistas textiles de huacas del Sol y de la Luna. Revista del Museo de Arqueología, Antropología e Historia, 10: 47-86; Trujillo: Universidad Nacional de Trujillo, Facultad de Ciencias Sociales.

HASTINGS, C. M. \& MOSELEY, M., 1975 - The adobes of Huaca del Sol and Huaca de la Luna. American Antiquity, 40 (2): 196-203; Washington, D.C.: Society for American Archaeology.

INOMATA, T., 2001 - The power and ideology of artistic creation. Elite craft specialists in Classic Maya society. Current Anthropology, vol. 42 (3): 321-333.

JARA, G., 2000 - Producción de vasijas domésticas en un taller alfarero Moche: en la falda Noreste de Cerro Blanco-Valle de Moche; Trujillo: Universidad Nacional de Trujillo, Facultad de Ciencias Sociales, Escuela de arqueología. Proyecto de investigación para optar el título de Licenciado en Arqueología.

LARCO, R. 1948 - Cronología arqueológica del norte del Perú; Buenos Aires: Sociedad Geográfica Americana. Biblioteca del Museo de Arqueología Rafael Larco Herrera, Hacienda Chiclín. [Reimpreso en: Arqueológicas 25. Lima, 2001].

MAKOWSKI, C., 2003 - La deidad suprema en la iconografía mochica: ¿Cómo definirla? In: Moche: hacia el final del milenio (S. Uceda \& E. Mujica, eds.): 343-381, tomo I; Lima: Universidad Nacional de Trujillo, Pontificia Universidad Católica del Perú. Actas del Segundo Coloquio sobre la Cultura Moche (Trujillo, 1 al 7 de agosto de 1999).

MENESES, S. \& CHERO, L., 1994 - La arquitectura. In: Sipán (W. Alva): 248-257; Lima: Cervecería Backus \& Johnston S. A. J. A. de Lavalle, editor. Colección Cultura y Artes del Perú.

MILLONES, L. \& ONUKI, O. (eds.), 1994 - El mundo ceremonial andino, 299 pp.; Lima: Editorial Horizonte. Serie: Etnología y Antropología 8.

MURRA, J., 1972 - El 'control vertical' de un máximo de pisos ecológicos en la economía de las sociedades andinas. In: Visita de la provincia de León de Huánuco, Iñigo Ortiz de Zúñiga, visitador (J. Murra, ed.): 429-476, vol 2; Huánuco: Universidad Nacional Hermilio Valdizán.

MURRA, J., 1975 - Formaciones económicas y políticas del mundo andino, 339 pp.; Lima: Instituto de Estudios Peruanos.

MURRA, J., 1980 - The economic organization of the Inca State; Greenwich, CT: JAT Press. Supplement 1 to Research in Economic Anthropology. 
Los contextos urbanos de producción artesanal en las huacas del Sol y de la Luna:

NARVÁEZ, A., 1996 - Las Pirámides de Túcume: Sector monumental. In: Túcume: 83-151; Lima: Banco de Crédito del Perú. Colección Arte y tesoros del Perú.

NETHERLY, P. 1978 - Local Level lord son the Coast of Peru; An Arbor: University Microfilms. Universidad de Cornell, Departamento de Antropología. Disertación doctoral.

POSTGATE, J. N., 1999 - La Mesopotamia arcaica. Sociedad y economía en el amanecer de la historia, 412 pp.; Madrid: ediciones Akal S.A. Traducción del inglés por Carlos Pérez Suárez.

RAMÍREZ-HORTON, S., 1981 - La organización económica de la costa norte: un análisis preliminar del periodo prehispánico tardío. In: Etnohistoria y Antropología Andina (A. Castelli, M. Koth de Paredes \& M. Mould de Pease, eds.): 281-297; Lima: Instituto de Estudios Peruanos. Segunda Jornada del Museo Nacional de Historia.

REDMAN, C., 1990 - Los orígenes de la civilización: Desde los primeros agricultores hasta la sociedad urbana en el Próximo Oriente, 443 pp.; Barcelona: Editorial Crítica. Serie Crítica/Arqueología. Traducido al español por Marina Picazo.

RENGIFO, C., 2005 - Talleres orfebres Mochicas en el Complejo Arqueológico Huacas de Moche: secuencia y estructura espacial. Proyecto de investigación para optar el título de Licenciado en Arqueología; Trujillo: Universidad Nacional de Trujillo, Facultad de Ciencias Sociales, Escuela de Arqueología.

RENGIFO, C. \& ROJAS, C., 2005 - Especialistas y centros de producción en el complejo arqueológico Huacas de Moche: evidencias de un taller orfebre. In: Proyecto Arqueológico Huaca de la Luna. Informe Técnico 2004 (S. Uceda \& R. Morales, eds.): 377-390; Trujillo: Facultad de Ciencias Sociales de la Universidad Nacional de Trujillo.

RENGIFO, C. \& ROJAS, C., 2008 - Talleres especializados en el Complejo Arqueológico Huacas de Moche: el carácter de los especialistas y de su producción. In: Arqueología Mochica: nuevos enfoques (L. J. Castillo, H. Bernier, G. Lockard \& J. Rucabado, eds.): 325-339; Lima: Fondo Editorial de la Pontificia Universidad Católica del Perú, Instituto Francés de Estudios Andinos. Actas del Primer Congreso Internacional de Jóvenes Investigadores de la Cultura Mochica (Lima, 4 y 5 de agosto de 2004).

ROWE, J., 1997 - ¿Existieron el tributo y los mercados en los andes antes de la invasión americana? In: Arqueología, Antropología e Historia en los Andes. Homenaje a María Rostwrowski (R. Varón \& J. Flores, eds.): 737-748; Lima: IEP, BCRP. Serie, Historia Andina 21.

ROSTWOROWSKI de DIEZ CANCECO, M., 1970 - Mercaderes del valle de Chincha en la época prehispánica: un documento y unos comentarios. Revista Española de Antropología Americana, 5: 135-178.

ROSTWOROWSKI de DIEZ CANCECO, M., 1977a - Coastal fishermen, merchants, and artisan in pre-Hispanic Peru. In: The sea in the pre-Columbian world (E. Benson, ed.): 167-186; Washington, D.C.: Dumbarton Oasks Reserch Library and Collection.

ROSTWOROWSKI de DIEZ CANCECO, M., 1977b - Etnía y sociedad. Costa peruana prehispánica, 293 pp.; Lima: Instituto de Estudios Peruanos.

SHIMADA, I., 1994 - Pampa Grande and the Mochica Culture, 323 pp.; Austin: University of Texas Press.

TELLO, R., SEOANE, S., SMITH, K., MENESES, J., BARRIGA, A. \& PALOMINO, J. 2008 El Conjunto Arquitectónico 35 de las Huacas del Sol y de la Luna: cambios en la arquitectura y función. In: Investigaciones en la Huaca de la Luna 2002 (S. Uceda, E. Mujica \& R. Morales, eds.): 93-142; Trujillo: Facultad de Ciencias Sociales de la Universidad Nacional de Trujillo, Patronato Huacas del Valle de Moche. 
TOPIC, T., 1977 - Excavations at Moche; Cambrigde: Harvard University, Departament of Anthropology. Tesis de doctorado

TOPIC, J., 1990 - Craf production in the Kingdom of Chimor. In: The Northern Dynasties: Kingship and Statecraft in Chimor (M. E. Moseley \& A. Cordy-Collins, eds.): 145-176; Washington, D.C.: Dumbarton Oaks Research Library and Collection.

TUFINIO, M., ORBEGOSO, M., VEGA, R. \& ROJAS, C. 2010 - Excavaciones en la Plataforma III de huaca de la Luna. In: Proyecto Arqueológico Huaca de la Luna, Informe Técnico 2009 (S. Uceda, E. Mujica \& R. Morales, eds.): Universidad Nacional de Trujillo, Facultad de Ciencias Sociales.

UCEDA, S. 2004 - Nivel de planificación urbana y del estado Moche: el caso del sitio de las Huacas del Sol y de la Luna. Arkinka, 9 (100): 108-115; Lima: Arkinka S.A.

UCEDA, S., 2005 - Los de Arriba y los de Abajo: Relaciones sociales, políticas y económicas entre el templo y los habitantes en el centro urbano de las Huacas de Moche. In: Proyecto Arqueológico Huaca de la Luna, Informe Técnico 2004 (S. Uceda \& R. Morales, eds.): 283-317; Trujillo: Universidad Nacional de Trujillo, Facultad de Ciencias Sociales.

UCEDA, S., 2007 - Huacas del Sol y de la Luna: Cien años después de los trabajos de Max Uhle. In: Proyecto Arqueológico Huaca de la Luna, Informe Técnico 2006 (S. Uceda \& R. Morales, eds.): 265-289; Trujillo: Universidad Nacional de Trujillo, Facultad de Ciencias Sociales.

UCEDA, S., 2010 - Theocracy and secularism: relationships between the Temple and urban Nucleus and Political Change at the Huacas de Moche. In: New Perspectives on Moche Political Organization (J. Quilter \& L. J. Castillo eds.): 132-158; Washington: Dumbarton Oaks.

UCEDA, S. \& ARMAS, J., 1997 - Los talleres alfareros en el Centro Urbano Moche. In: Investigaciones en la Huaca de la Luna 1995 (S. Uceda, E. Mujica \& R. Morales, eds.): 93-104; Trujillo: Universidad Nacional de Trujillo, Facultad de Ciencias Sociales.

UCEDA, S. \& ARMAS, J., 1998 - An urban pottery workshop at the site of Moche, North Coast of Peru. MASCA Research Papers in Science and Archaeology, supplement to Vo1 15: 91-110; Philadelphia: University of Pennsylvania, Museum of Archaeology and Anthropology.

UCEDA, S. \& CANZIANI, J., 1998 - Análisis de la secuencia arquitectónica y nuevas perspectivas de investigación en la Huaca de la Luna. In: Investigaciones en la Huaca de la Luna 1996 (S. Uceda, E. Mujica \& R. Morales, eds.): 139-158; Trujillo: Universidad Nacional de La Libertad-Trujillo, Facultad de Ciencias Sociales.

UCEDA, S., CHAPDELAINE, C. \& VERANO, J., 2008 - Fechas radiocarbónicas para el complejo arqueológico Huacas del Sol y de la Luna: una primera cronología del sitio. In: Investigaciones en la Huaca de la Luna 2001 (S. Uceda, E. Mujica \& R. Morales, eds.): 213-223; Trujillo: Universidad Nacional de Trujillo, Facultad de Ciencias Sociales, Patronato Huacas del Valle de Moche.

UCEDA, S., GAYOSO, H. \& TELLO, R., 2010 - Parte I: Las Investigaciones Arqueológicas. In: Moche: pasado y presente (S. Uceda \& R. Morales eds.): 23-107; Trujillo: Patronato Huacas del Valle de Moche, Fondo Contravalor Perú-Francia, Universidad Nacional de Trujillo.

UCEDA, S. \& RENGIFO, C., 2006 - "La especialización del trabajo: teoría y arqueología. El caso de los orfebres Mochicas. Bulletin de I'Institut Français d'Études Andines, 35 (2): 149-185; Lima. 
Los contextos urbanos de producción artesanal en las huacas del Sol y de la Luna:

UCEDA, S. \& TUFINIO, M., 2003 - El complejo arquitectónico religioso Moche de Huaca de la Luna: una aproximación a su dinámica ocupacional. In: Moche: hacia el final del milenio (S. Uceda \& E. Mujica, eds.): 179-228, tomo II; Lima: Universidad Nacional de Trujillo y Pontificia Universidad Católica del Perú. Actas del Segundo Coloquio sobre la Cultura Moche (Trujillo, 1 al 7 de agosto de 1999). 